UNIVERSIDADE DE SÃO PAULO

ESCOLA DE ENGENHARIA DE SÃO CARLOS

MARCOS JOSÉ MARIA

Modelagem e análise de uma asa piezoaeroelástica para geração de energia 
MARCOS JOSÉ MARIA

\section{Modelagem e análise de uma asa piezoaeroelástica para geração de energia}

Dissertação apresentada à Escola de Engenharia de São Carlos da Universidade de São Paulo, como parte dos requisitos para obtenção do título de Mestre em Engenharia Mecânica

Área de concentração: Engenharia Aeronáutica

Orientador: Prof. Dr. Carlos de Marqui Júnior

São Carlos 
AUTORIZO A REPRODUÇÃO E DIVULGAÇÃO TOTAL OU PARCIAL DESTE TRABALHO, POR QUALQUER MEIO CONVENCIONAL OU ELETRÔNICO, PARA FINS DE ESTUDO E PESQUISA, DESDE QUE CITADA A FONTE.

Ficha catalográfica preparada pela Seção de Tratamento da Informação do Serviço de Biblioteca - EESC/USP

J83m

\section{José Maria, Marcos}

Modelagem e análise de uma asa piezoaeroelástica

para geração de energia / Marcos José Maria ; orientador Carlos de Marqui Júnior. -- São Carlos, 2010.

Dissertação (Mestrado-Programa de Pós-Graduação em Engenharia Mecânica e Área de Concentração em Aeronaves) -- Escola de Engenharia de São Carlos da Universidade de São Paulo, 2010.

1. Piezeletricidade. 2. Aeroelasticidade.

3. Piezoaeroelasticidade. 4. Geração de energia.

5. Rajadas discretas. I. Título. 
Candidato(a): Bacharel MARCOS JOSÉ MARIA.

Dissertação defendida e julgada em 17.12.2010 perante a Comissão Julgadora:
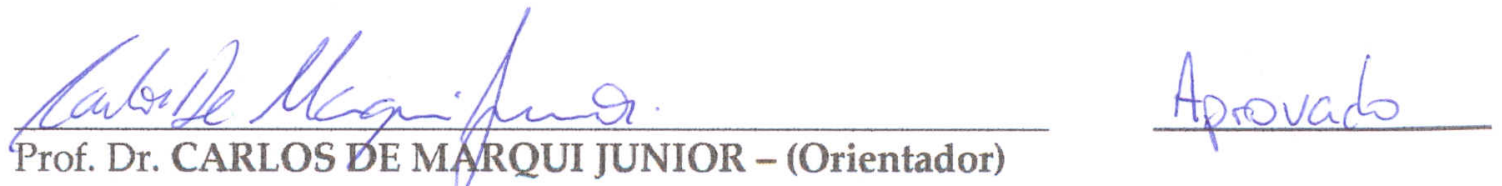

(Escola de Engenharia de São Carlos/USP)

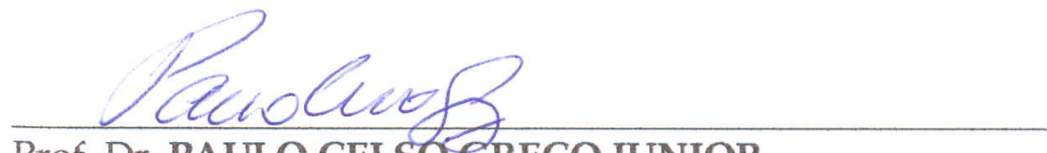

A PROVADO

Prof. Dr. PAULO CELSO GRECO JUNIOR

(Escola de Engenharia de São Carlos/USP)

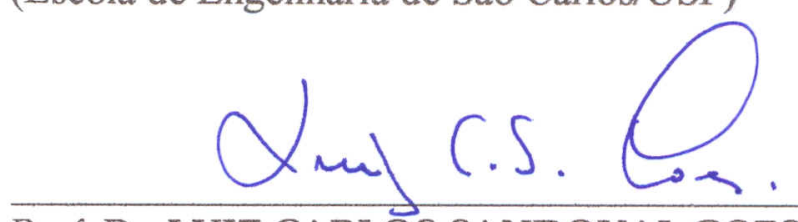

Prof. Dr. LUIZ CARLOS SANDOVAL GOES

(Instituto Tecnológico de Aeronáutica/ITA)

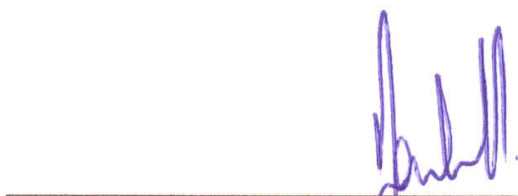

Prof. Associado JONAS DE CARVALHO

Coordenador do Programa de Pós-Graduação em

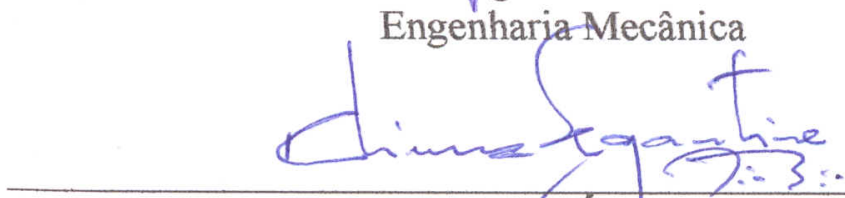

Prof. Associado PAULO CÉSAR LIMA SEGANTINE

Presidente da Comissăo de Pфs-Graduação da EESC 
Aos meus pais, Carlos e Rosalina, à minha amada esposa Sílvia pela sua compreensão e apoio e ao meu querido filho Gabriel 


\section{AGRADECIMENTOS}

Ao Prof. Dr. Carlos de Marqui Júnior, meu orientador, pelo auxílio, seriedade e orientação segura durante todo o desenvolvimento deste trabalho e também pela amizade desenvolvida.

À minha esposa, Sílvia, pelo incansável apoio, incentivo, paciência, compreensão e por acreditar que eu conseguiria atingir meu objetivo. 


\section{RESUMO}

JOSÉ MARIA, M. (2010). Modelagem e análise de uma asa piezoaeroelástica para geração de energia. São Carlos. 85p. Dissertação (Mestrado) - Escola de Engenharia de São Carlos, Universidade de São Paulo, 2010.

A redução do consumo de energia dos sistemas eletrônicos, fez com que a pesquisa de novas fontes de energia para alimentar estes dispositivos tivesse enorme importância na última década. Algumas destas fontes são provenientes da conversão de energia de vibrações mecânicas em energia elétrica. Veículos aéreos não tripulados (UAVs) e micro veículos aéreos (MAVs) constituem uma aplicação importante para utilização de geradores de energia baseados em vibrações. Este trabalho tem seu foco na conversão de oscilações aeroelásticas em eletricidade utilizando o efeito piezelétrico direto. Um modelo numérico piezoaeroelasticamente acoplado, proveniente da associação de um modelo por elementos finitos eletromecânico e um modelo aerodinâmico não estacionário é apresentado. Uma asa geradora de energia composta por uma subestrutura metálica e piezocerâmicas embutidas é modelada. Apresentam-se como resultados, saídas elétricas (tensão, corrente e potência elétrica) e mecânicas no domínio do tempo. Uma carga resistiva é assumida no domínio elétrico do problema. Uma rajada discreta do tipo '1-cos' é assumida para várias velocidades do escoamento e valores de resistências elétricas, utilizando eletrodos contínuos e segmentados. Aponta que os melhores resultados foram obtidos com a utilização de eletrodos segmentados e que em razão do melhor acoplamento eletromecânico, obtêm-se um maior efeito shunt damping, um aumento na velocidade de flutter $(1 \mathrm{~m} / \mathrm{s}$ neste trabalho) e uma maior geração de potência.

Palavras-chave: piezeletricidade. aeroelasticidade. piezoaeroelasticidade.

geração de energia. rajadas discretas. 


\begin{abstract}
JOSÉ MARIA, M. (2010). Modeling and analysis of a piezoaeroelastic wing for power generation. 85p. Dissertation (M. Sc.) - Engineering School of São Carlos, University of São Paulo, São Carlos, 2010.

Reducing the power consumption of electronic systems, has led the research for new sources of energy to power these devices have great importance in the last decade. Some of these sources are from the conversion of energy from mechanical vibrations into electrical energy. Unmanned aerial vehicles (UAVs) and Micro Air Vehicles (MAVs) are an important application for use of vibration energy harvesting. This work focuses on conversion of aeroelastic oscillations into electricity using piezoelectric direct effect. A numerical model coupled piezoaeroelastically derived from the combination of an electro-mechanical finite element model and an unsteady aerodynamic model is presented. A power generator wing consists of a metal substructure and embedded piezoceramic is modeled. They appear as results, electrical outputs (voltage, current and electric power) and mechanical time domain. A resistive load is assumed in the electric domain of the problem. A discrete gust of shape '1cos' is taken for various flow velocities and values of electrical resistances, using continuous and segmented electrodes. Indicates that the best results were obtained with the use of segmented electrodes and because of better electromechanical coupling, we obtain a higher shunt damping effect, an increase flutter speed $(1 \mathrm{~m} / \mathrm{s}$ in this work) and greater power generation.
\end{abstract}

Keywords: piezoelectricity. aeroelasticity. piezoaeroelasticity. power generation. discrete gusts. 


\section{LISTA DE ILUSTRAÇÕES}

Figura 1 - Configurações de geradores piezelétricos com excitação da base:

(a) unimorph, (b) bimorph (ligação em série) e (c) bimorph (ligação em paralelo)

Figura 2 - Aplicações do efeito piezelétrico

Figura 3 - Gerador de energia piezelétrico unimorph

Figura 4 - Elemento finito de um piezo-elétrico com 12 graus de liberdade mecânicos e 1 grau de liberdade elétrico

Figura 5 - Método de malha de vórtices para uma asa engastada .....

Figura 6 - Aeronave encontrando uma área de turbulência

Figura 7 - Uma rajada discreta modelada utilizando a forma (1-cos) dentro de uma grande região de turbulência contínua

Figura 8 - Asa geradora de energia sob excitação do escoamento em corte da região com piezocerâmicas para e eletrodos contínuos (a) e segmentados (b)

Figura 9 - Modos de vibrar e frequiências naturais da asa obtidas com o modelo por EF para a condição de curto-circuito

Figura 10 - Voltagem para 5 diferentes valores de resistência elétrica utilizando eletrodos contínuos e velocidade do escoamento $10 \mathrm{~m} / \mathrm{s}$

Figura 11 - Potência gerada para 5 diferentes valores de resistência elétrica utilizando eletrodos contínuos e velocidade do escoamento $10 \mathrm{~m} / \mathrm{s}$

Figura 12 - Deslocamento na ponta da asa para 5 diferentes valores de resistência elétrica utilizando eletrodos contínuos e velocidade do escoamento $10 \mathrm{~m} / \mathrm{s}$.....

Figura 13 - Deslocamento na ponta da asa - variação da frequência das respostas entre as condições de curto circuito $\left(R_{l}=10^{2} \Omega\right)$ e circuito aberto $\left(R_{l}=10^{6} \Omega\right)$

Figura 14 -Voltagem para 5 diferentes valores de resistência elétrica utilizando eletrodos contínuos e velocidade do escoamento $20 \mathrm{~m} / \mathrm{s}$

Figura 15 - Potência gerada para 5 diferentes valores de resistência elétrica utilizando eletrodos contínuos e velocidade do escoamento $20 \mathrm{~m} / \mathrm{s}$

Figura 16 - Deslocamento na ponta da asa para 5 diferentes valores de resistência elétrica utilizando eletrodos contínuos e velocidade do escoamento $20 \mathrm{~m} / \mathrm{s}$.....

Figura 17 - Voltagem para 5 diferentes valores de resistência elétrica utilizando eletrodos contínuos e velocidade do escoamento $35 \mathrm{~m} / \mathrm{s}$

Figura 18 - Potência gerada para 5 diferentes valores de resistência elétrica utilizando eletrodos contínuos e velocidade do escoamento $35 \mathrm{~m} / \mathrm{s}$

Figura 19 - Deslocamento na ponta da asa para 5 diferentes valores de resistência Elétrica utilizando eletrodos contínuos e velocidade do escoamento $35 \mathrm{~m} / \mathrm{s}$....

Figura 20 - Voltagem para 5 diferentes valores de resistência elétrica utilizando eletrodos contínuos e velocidade do escoamento $40 \mathrm{~m} / \mathrm{s}$

Figura 21 - Potência gerada para 5 diferentes valores de resistência elétrica utilizando eletrodos contínuos e velocidade do escoamento $40 \mathrm{~m} / \mathrm{s}$

Figura 22 - Deslocamento na ponta da asa para 5 diferentes valores de resistência elétrica utilizando eletrodos contínuos e velocidade do escoamento $40 \mathrm{~m} / \mathrm{s}$.....

Figura 23 - Condição de flutter: acoplamento do segundo modo de flexão e primeiro modo de torção 
Figura 24 - Voltagem para 5 diferentes valores de resistência elétrica utilizando eletrodos segmentados e velocidade do escoamento $20 \mathrm{~m} / \mathrm{s}$

Figura 25 - Voltagem para 5 diferentes valores de resistência elétrica utilizando eletrodos segmentados e velocidade do escoamento $40 \mathrm{~m} / \mathrm{s}$

Figura 26 - Potência gerada para 5 diferentes valores de resistência elétrica utilizando eletrodos segmentados e velocidade do escoamento $40 \mathrm{~m} / \mathrm{s}$

Figura 27 - Deslocamento na ponta da asa para 5 diferentes valores de resistência elétrica utilizando eletrodos segmentados e velocidade do escoamento $40 \mathrm{~m} / \mathrm{s}$

Figura 28 - Voltagem para 5 diferentes valores de resistência elétrica utilizando eletrodos segmentados e velocidade do escoamento $41 \mathrm{~m} / \mathrm{s}$. (velocidade de flutter)

Figura 29 - Potência gerada para 5 diferentes valores de resistência elétrica utilizando eletrodos segmentados e velocidade do escoamento $41 \mathrm{~m} / \mathrm{s}$. (velocidade de flutter)

Figura 30 - Deslocamento na ponta da asa para 5 diferentes valores de resistência elétrica utilizando eletrodos segmentados e velocidade do escoamento $41 \mathrm{~m} / \mathrm{s}$. (velocidade de flutter) 


\section{LISTA DE TABELAS}

Tabela 1 - Resumo das densidades de energia máxima de três tipos de transdutores .....

Tabela 2 - Geometria e propriedades materiais da asa de alumínio com piezocerâmicas incorporadas

Tabela 3 - Propriedades materiais e eletromecânicas do PZT-5A 


\section{LISTA DE ABREVIATURAS E SIGLAS}

AM Amplitude Modulada

CBM Plano de Manutenção (Condition Based Maintenance)

CS Certification Security (Agência Européia para a Segurança da Aviação)

EF Elementos Finitos

ETL Erro de truncamento local

FAR Federal Aviation Regulation

HVAC Aquecimento, ventilação, ar condicionado (Heating, Ventilation, Air Conditioning)

HUMS Sistema de monitoramento da integridade estrutural (Health Usage Monitoring Systems)

$\mathrm{Hz} \quad$ Hertz

Ah Àmpere hora

MAV Micro veículos aéreos (Micro Air Vehicles)

MEMS Sistemas micro-eletromecânicos (MicroElectroMechanical Systems)

$\mathrm{N} \quad$ Newton

PZT Cerâmica piezelétrica

UAV Veículos aéreos não-tripulados (Unmanned aerial vehicles)

V Volt

W Watt 


\section{LISTA DE SÍMBOLOS}

\begin{tabular}{|c|c|}
\hline$a_{K L}$ & Coeficiente de influência \\
\hline$A$ & Área de um painel \\
\hline$B_{\eta}, B_{\kappa}$ & Funções de interpolação \\
\hline c & Matriz de rigidez elástica \\
\hline $\mathbf{c}_{\mathbf{p}}$ & Capacitância \\
\hline $\mathbf{c}_{\mathrm{s}}$ & Matriz de rigidez elástica (2-D) \\
\hline $\mathbf{C}$ & Matriz global de amortecimento mecânico \\
\hline$\overline{\mathbf{C}}$ & Matriz diagonal de amortecimento modal \\
\hline $\mathbf{e}$ & Matriz de constantes piezelétricas \\
\hline $\mathbf{E}$ & Vetor de campo elétrico \\
\hline f & Conjunto de forças mecânicas discretas \\
\hline f & Vetor de forças mecânicas \\
\hline $\mathbf{F}$ & Vetor global de forças mecânicas $\left(n_{m} \times 1\right)$ \\
\hline $\boldsymbol{F}$ & Cargas aerodinâmicas na malha estrutural (nós) \\
\hline $\boldsymbol{F}_{a}$ & Cargas aerodinâmicas nos pontos de controle \\
\hline $\mathbf{G}$ & Matriz de transformação \\
\hline $\mathbf{k}$ & Matriz de rigidez \\
\hline $\mathbf{K}$ & Matriz de rigidez global $\left(\mathrm{n}_{\mathrm{m}} \times \mathrm{n}_{\mathrm{m}}\right)$ \\
\hline$\overline{\mathbf{K}}$ & Matriz diagonal de rigidez \\
\hline
\end{tabular}

\footnotetext{
${ }^{1}$ Alguns símbolos possuem mais de um significado, dependendo do contexto em que estão inseridos.
} 
Matriz de massa global $\left(\mathrm{n}_{\mathrm{m}} \times \mathrm{n}_{\mathrm{m}}\right)$

Direção da normal da superfície da asa para os pontos de controle

$\mathbf{n}$

Número de graus de liberdade - elétrico

$\mathrm{n}_{\mathrm{e}}$

Número de elementos finitos utilizados na malha de piezocerâmica

nf Número de forças mecânicas discretas

$\mathbf{n}_{\mathbf{m}} \quad$ Número de graus de liberdade - mecânico

$n q \quad$ Número de pares de eletrodos

$p$

Camadas piezocerâmicas

$p$

$\mathbf{q}$

Pressão estática

\section{Q}

Conjunto discreto de saídas de cargas elétricas

$R$

$U$

$\mathbf{v}$

$\boldsymbol{v}_{\text {esteira }}$

Deslocamentos na direção x, y e z

Vetor de deslocamentos mecânicos

Vetor global de cargas elétricas $\left(\mathrm{n}_{\mathrm{e}} \mathrm{x} 1\right)$

Número de painéis ao longo da corda

Representa a camada metálica (chamada de subestrutura)

Número de painéis ao longo da envergadura

Vetor de deformações mecânicas

Tempo

Energia cinética total

Vetor de tensões mecânicas

Energia potencial total

Vetor global de tensões de saída $\left(\mathrm{n}_{\mathrm{e}} \mathrm{x} 1\right)$

Velocidade induzida pela esteira nos pontos de controle 


$\begin{array}{ll}\boldsymbol{v}_{\text {movimento }} & \text { Velocidade em razão do movimento da asa } \\ v_{p} & \text { Diferença de potencial } \\ \mathrm{v}_{\mathrm{s}} & \text { Função de Poisson } \\ \mathbf{V} & \text { Volume } \\ V_{\infty} & \text { Velocidade do fluxo livre } \\ \mathbf{W} & \text { Deformação transversal da superfície de referência } \\ \mathbf{w}_{\mathbf{k}} & \text { Deslocamento transversal } \\ W_{e} & \text { Energia elétrica } \\ \boldsymbol{x}_{a} & \text { Vetor de coordenadas aerodinâmicas }\end{array}$

\section{Símbolos gregos}

$\begin{array}{ll}\alpha & \text { Ângulo de ataque } \\ \alpha, \beta & \text { Constantes de proporcionalidade } \\ \rho & \text { Densidade de massa } \\ \theta_{x k} & \text { Rotação de flexão } \\ \varphi_{j} & \text { Escalar do potencial elétrico } \\ \Delta t & \text { Intervalo de tempo } \\ \Delta b & \text { Largura do painel na direção da envergadura } \\ \Gamma & \text { Força da linha de vórtice } \\ \Gamma_{i j} & \text { Circulação local } \\ \Omega & \text { Ohm (unidade de resistência elétrica) } \\ \eta & \text { Vetor de coordenadas modais }\end{array}$



@ Vetor de acoplamento eletromecânico
$\theta \quad$ Vetor de acoplamento eletromecânico
$\Psi \quad$ Vetor de coordenadas mecânicas $\left(\mathrm{n}_{\mathrm{m}} \times 1\right)$
$\Psi_{a} \quad$ Vetor de coordenadas mecânicas dos pontos de controle (malha aerodinâmica)
$\Phi \quad$ Matriz modal
$\Phi_{a} \quad$ Matriz modal em coordenadas aerodinâmicas (extremidades anéis de vórtices)
$\Theta \quad$ Matriz de acoplamento eletromecânico
$\varepsilon \quad$ Matriz de permissividade (constante dielétrica)
$\nabla \phi \quad$ Gradiente do potencial de velocidade

\section{Subscritos}

$u, l \quad$ Refere-se à superfície superior e inferior dos painéis

\section{Sobrescritos}

Transposição 


\section{SUMÁRIO}

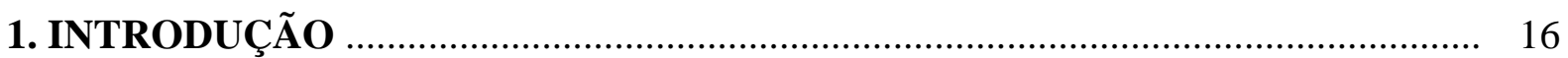

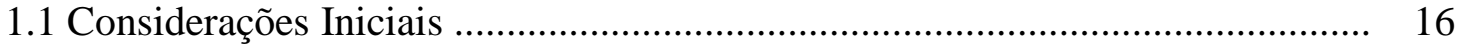

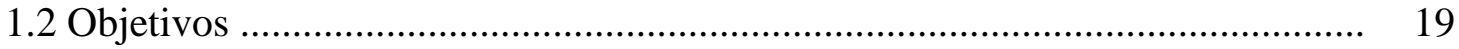

1.3 Organização do trabalho ............................................................................. 19

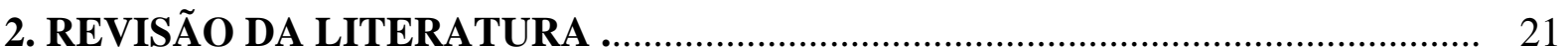

2.1 Aplicações do efeito piezelétrico ................................................................. 21

2.2 Um breve histórico ………………............................................................. 22

2.3 Gerador de energia baseado em vibrações ......................................................... 24

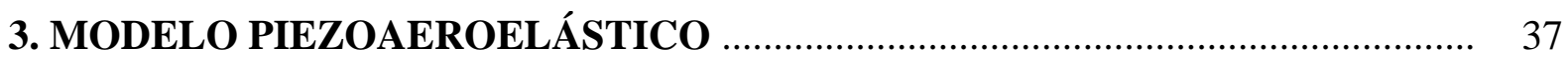

3.1 Modelo por elementos finitos eletromecanicamente acoplado ........................... 37

3.1.1 Princípio de Hamilton ............................................................................... 37

3.1.2 Modelo eletromecanicamente acoplado utilizando elementos finitos............. $\quad 39$

3.2 Modelo Aerodinâmico não-estacionário .......................................................... 45

3.3 Acoplamento entre modelos aerodinâmico e estrutural ..................................... 49

3.4 A Turbulência ....................................................................................... 52

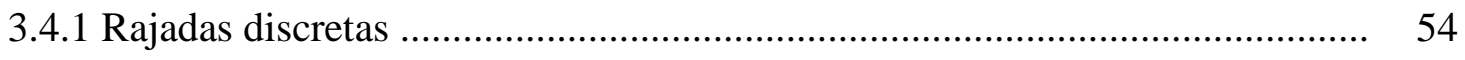

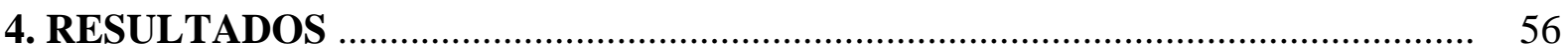

4.1 Estrutura Modelada e Estudos de Caso .......................................................... 56

4.2 Apresentação dos resultados ........................................................................ 60

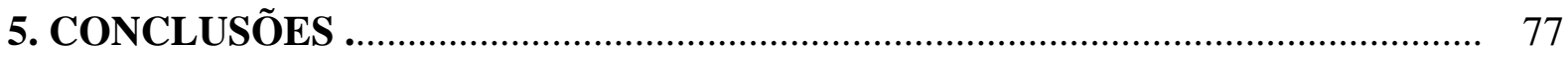

5.1 Sugestões para trabalhos futuros ………………………………………….... 78

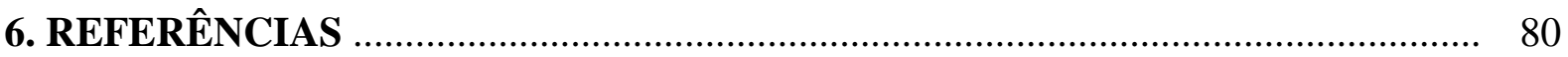




\section{INTRODUÇÃO}

\subsection{Considerações Iniciais}

Nas últimas décadas, tem crescido muito a necessidade de se fornecer energia limpa e renovável para diferentes tipos de sensores e dispositivos wireless e em razão disso, uma quantidade significativa de pesquisas tem sido realizadas para se descobrir diferentes fontes de energia. Os recentes avanços da tecnologia wireless e dos sistemas micro-eletromecânicos (MEMS) têm crescido de forma sustentada, provocando grande diminuição no consumo de energia destes equipamentos (SODANO; INMAN, 2004); enquanto o desenvolvimento de novas tecnologias para baterias permaneceu relativamente estagnado durante a última década (ANTON; SODANO, 2007).

Em razão da autonomia das baterias estar diretamente relacionada ao seu tamanho e peso, a necessidade de fontes de energia adicionais e renováveis tem se tornado muito importante nos diversos segmentos da indústria. Somando-se a isso o fato de que as baterias disponibilizam uma quantidade finita de energia, têm vida útil limitada e contém produtos químicos geralmente perigosos; além do inconveniente da substituição periódica, tarefa que pode ter alto custo e grande complexidade, tornando-se até mesmo impossível em razão do local onde a bateria está instalada (SODANO; INMAN, 2004; NG; LIAO, 2005).

No segmento aeronáutico, o projeto e desenvolvimento de pequenos veículos aéreos não-tripulados (UAVs) e micro veículos aéreos (MAVs) aumentou drasticamente nas últimas três décadas (ANTON; SODANO, 2007) e cada vez torna-se mais necessária a obtenção de fontes de energia adicionais para aumentar a autonomia destes veículos (MUELLER; DELAURIER, 2003). Estas aeronaves podem realizar vôos de longa duração e são utilizadas para substituir o homem em muitas missões e tarefas, incluindo vigilância; links de comunicação; equipar navios: funcionando como alvos para desviar possíveis ataques de 
mísseis; detecção de materiais biológicos, químicos ou nucleares. Além disso, podem ser utilizadas na agricultura de precisão, monitoramento de tráfego, silvicultura, inspeções de linhas de transmissão de energia ou gasodutos em locais remotos, entre várias outras missões. Podem também transmitir imagens durante o dia e a noite para um operador remoto que pode disparar uma ação específica se julgar necessário (MUELLER; DELAURIER, 2003), (DE MARQUI et al., 2010), (JAMES, 2000).

Pesquisas têm sido feitas para se descobrir maneiras eficientes de extrair energia disponível no ambiente e armazená-la em baterias, com isso, o total de trabalhos dedicados ao "power harvesting" tem aumentado rapidamente; nestes trabalhos incluem-se também a geração de energia a partir de vibrações mecânicas ("vibration energy harvesting") e os efeitos deste processo no comportamento dinâmico de uma estrutura, além dos circuitos elétricos de processamento e armazenamento da energia elétrica. (SODANO; INMAN, 2004; MUELLER; DELAURIER, 2003; JUNHUI et al., 2010; ERTURK, 2009d).

Diferentes tipos de transdutores: piezelétricos, eletromagnéticos e eletrostáticos que convertem vibrações mecânicas em eletricidade têm sido pesquisados, porém, os piezelétricos têm recebido maior atenção. Como afirmado por ANTON e SODANO (2007) devido à sua capacidade de converter diretamente a energia de deformação aplicada em energia elétrica utilizável, a facilidade com que pode ser integrado em um sistema, além de apresentar baixo custo, é uma alternativa eficiente para os geradores de energia de baixo nível (DE MARQUI et al., 2009b).

O efeito piezelétrico direto (habilidade do material para transformar a tensão mecânica em carga elétrica) foi demonstrado e publicado pela primeira vez em 1880 por Pierre e Jacques Curie, dois físicos franceses, que também eram irmãos. Um ano depois, eles descobriram o efeito piezelétrico inverso (a capacidade de converter um potêncial elétrico aplicado em tensão mecânica) (ARNAU, 2008; HEYWANG et al., 2008). 
Geradores de energia piezelétricos podem produzir energia elétrica através de vibrações mecânicas devido ao efeito piezelétrico direto.

Nos últimos anos, vários estudos foram feitos para investigar a capacidade de geração de energia dos materiais piezelétricos; para um aprofundamento deste assunto, consulte os trabalhos de UMEDA et al. (1996); XU et al. (1998) e GOLDFARB e JONES (1999).

(a)

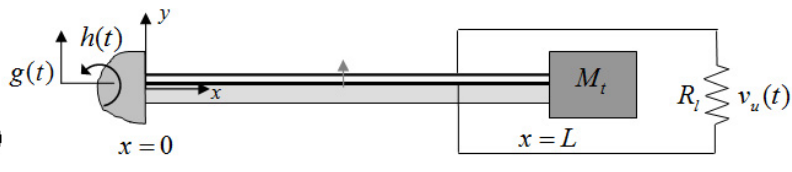

(b)

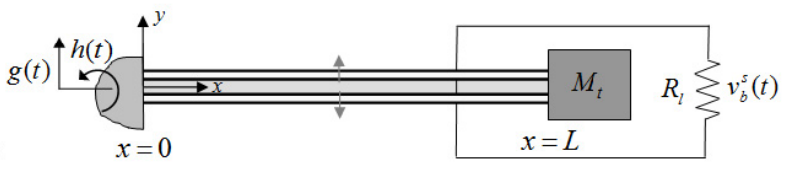

(c)

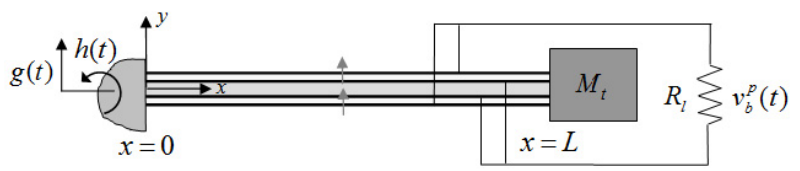

$\square$ Piezoceramic $\square$ Substructure — Electrodes $\uparrow$ Poling direction

Figura 1. Configurações de geradores piezelétricos com excitação da base: (a) unimorph, (b) bimorph (ligação em série) e (c) bimorph (ligação em paralelo)

Uma viga engastada do tipo unimorph é simplesmente uma composição uniforme de uma viga, com uma única camada de PZT perfeitamente fixada à camada da subestrutura e a viga engastada do tipo bimorph, possui duas camadas de PZT perfeitamente fixadas (coladas) na parte de cima e de baixo da camada de subestrutura (DE MARQUI et al., 2009b), (ERTURK; INMAN, 2008a), (ERTURK; INMAN, 2008b).

O gerador piezelétrico de energia ganhou o foco na última década por fornecer energia elétrica para pequenos componentes eletrônicos através da conversão de energia disponível no meio em energia elétrica (ERTURK, 2009d; DE MARQUI et al., 2009b). 


\subsection{Objetivos}

A proposta deste trabalho é realizar simulações computacionais, utilizando um modelo numérico piezoaeroelasticamente acoplado. Este modelo é obtido com a associação de um modelo por elementos finitos eletromecanicamente acoplado e um modelo aerodinâmico nãoestacionário. O modelo por elementos finitos assume as hipóteses de placas de Kirchhoff (De Marqui et al., 2009b). O modelo aerodinâmico é o método de malha de vórtices apresentado por Benini (2002). A estrutura, uma asa tipo placa com piezocerâmicas embutidas, cujos eletrodos estão conectados a um circuito gerador composto por um resistor, é submetida a uma perturbação atmosférica (rajada discreta) representada pela forma '1-cos', para que possam ser analisados os resultados de tensão e potência geradas e também do deslocamento que ocorre na ponta da asa, para diversas velocidades do escoamento e utilizando um conjunto pré-definido de resistências elétricas $\left(R_{l}=10^{2}, 10^{3}, 10^{4}, 10^{5}, 10^{6} \Omega\right)$. As simulações serão divididas em dois grupos principais, onde a principal diferença será a utilização de eletrodos contínuos ou segmentados no circuito elétrico conforme citado no trabalho de DE MARQUI et al. (2010), com o intuito de se obter comparações quanto à eficiência na geração de energia.

\subsection{Organização do trabalho}

Uma abordagem sobre a necessidade de se obter novas fontes de energia renovável e os campos de aplicação em aeronaves, além de informações gerais sobre o objetivo da pesquisa, é tratada no capítulo 1.

O capítulo 2 apresenta um breve relato histórico sobre as origens e a evolução das teorias: piezelétrica, termoelétrica, eletromagnética e do efeito fotovoltaico; também lista 
algumas aplicações do efeito piezelétrico e apresenta os principais trabalhos publicados sobre geradores de energia baseados em vibrações desde 1992 até os dias atuais.

A apresentação de um modelo piezoaeroelástico, o modelo estrutural eletromecanicamente acoplado, o modelo aerodinâmico não-estacionário, o acoplamento entre estes modelos formando o modelo piezoaeroelástico, além da entrada utilizada para o modelo numérico, é o objetivo do capítulo 3.

No capítulo 4 é apresentada a estrutura modelada e os resultados obtidos nas simulações.

Finalizando, as principais conclusões relacionadas com o trabalho e algumas sugestões para trabalhos futuros são abordadas no capítulo 5 . 


\section{REVISÃO DA LITERATURA}

\subsection{Aplicações do efeito piezelétrico}

Durante a última década, a quantidade de literatura sobre o tema "captação de energia" tem aumentado significativamente, devido ao grande interesse em fontes de energia alternativas e renováveis.

Algumas fontes de energia possíveis, são:

- Energia luminosa: proveniente da luminosidade do ambiente (ex. a luz solar).

- Energia térmica: minúsculos geradores termoelétricos produzem eletricidade, quando submetidos a um gradiente de temperatura.

- Volume de vazão (ex. escoamento de líquidos ou gases).

- Energia mecânica: energia liberada por movimento e vibrações.

Podem ser citados quatro métodos principais para a captação de energia (piezelétrico, termelétrico, fotovoltaico, eletromagnético) e três fontes de energia do ambiente (vibração, térmica e solar), a revisão da literatura se restringirá aos trabalhos da área de vibrações, por ser este o escopo do trabalho e somente a literatura que é relevante para a pesquisa realizada nesta dissertação será apresentada em um esforço para limitar o escopo da revisão bibliográfica.

Na Figura 2 são apresentadas algumas aplicações do efeito piezelétrico, presentes na literatura. 


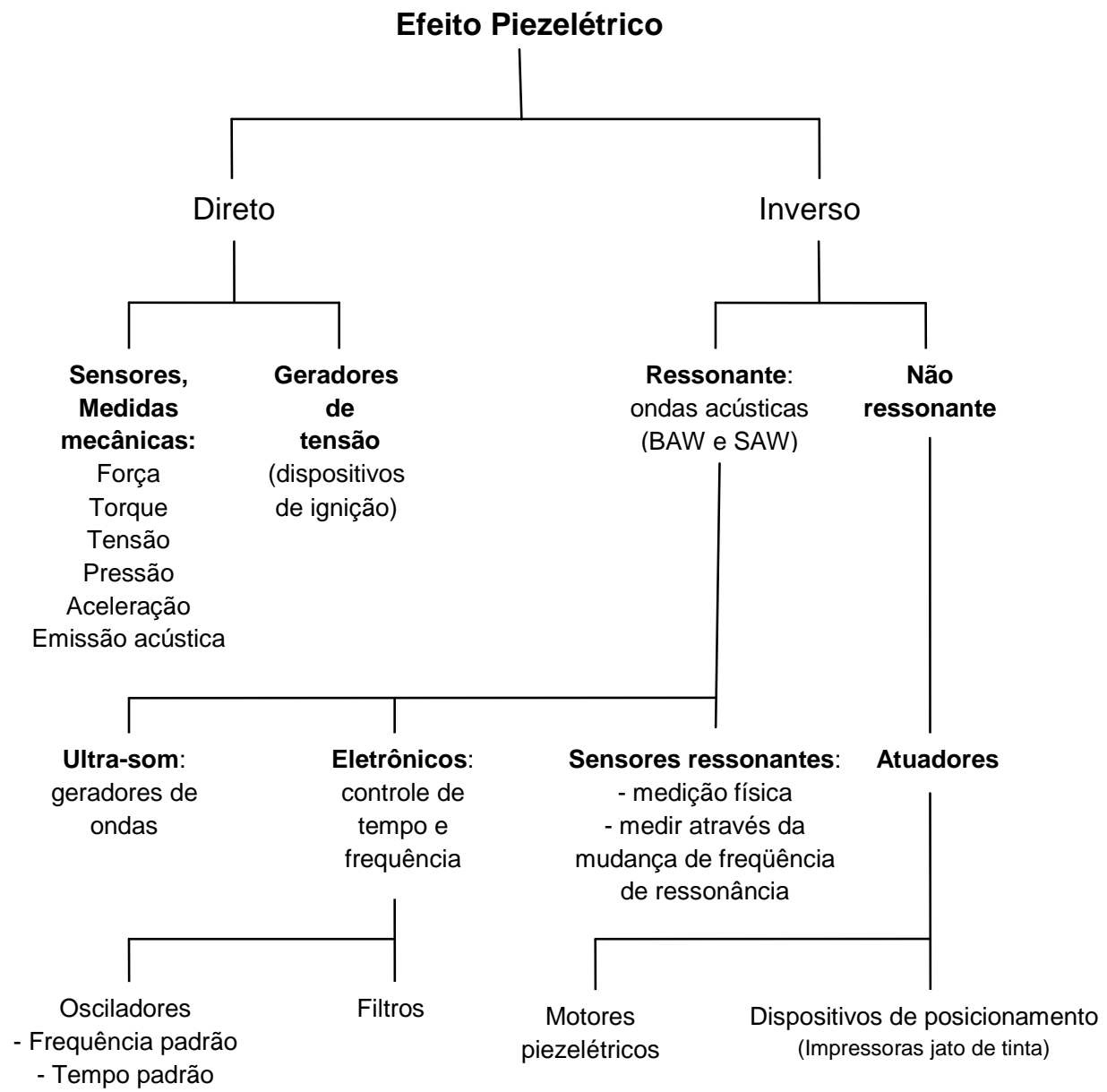

Figura 2. Aplicações do efeito piezelétrico

\subsection{Um breve relato histórico}

Em 1880 o efeito piezelétrico (do grego: piézin - prensar, apertar) direto (efeito piezelétrico direto: habilidade do material para transformar a tensão mecânica em carga elétrica, efeito piezelétrico inverso: capacidade de converter um potencial elétrico aplicado, em tensão mecânica) foi apresentado pelos irmãos Pierre e Jacques Curie, sendo que o termo piezeletricidade surgiu em 1881, proposto por Hankel. Em 1917 durante a Primeira Guerra Mundial, Langevin utilizou um transdutor composto de finos cristais de quartzo colados entre duas chapas de aço no aperfeiçoamento de um sonar. Após a Primeira Guerra, descobriu-se 
que o efeito piezelétrico poderia ser utilizado como elemento de transdução em sensores para medição de força, pressão e vibração; em 1951 no Japão, várias empresas e universidades criaram uma associação de cooperação chamada Comitê para Pesquisa e Aplicações do Titanato de Bário que em 1965 já colhia os primeiros resultados, o esforço japonês começou a atrair a atenção do segmento industrial de diversos países, entre eles Estados Unidos, Rússia, China e Índia a partir de 1980 (GAUTSCHI, 2002; HISTORY OF PIEZOELECTRICITY, 2009).

No campo da termoeletricidade, foi em 1822 que Seebeck constatou a conversão de diferenças de temperatura em energia elétrica. Peltier descobriu em 1834 que o calor é liberado ou absorvido dependendo do sentido da corrente que atravessa uma junção de dois condutores diferentes. Mas foi Thomson em 1851 que demonstrou este efeito com mais precisão. Até 1990 cientistas ainda estavam descobrindo as propriedades de diversos materiais piezelétricos. A condutividade elétrica, a condutividade térmica e o coeficiente de Seebeck são conhecidos como figura de mérito Z. O tipo mais simples de um gerador termoelétrico é conhecido como termopar; sendo composto por termo elementos, um do tipo $\mathrm{P}$ e um do tipo $\mathrm{N}$, conectados eletricamente em série, mas termicamente em paralelo (POLLOCK, 1985; POLLOCK, 1991; ROWE, 1994; NOLAS, 2001).

Já o efeito fotovoltaico (conversão da radiação solar em energia elétrica) foi relatado em 1839 por Becquerel quando utilizou eletrodos em uma solução eletrolítica e somente em 1877 Adams e Day observaram o efeito em um sólido (selênio). A eficiência (capacidade de converter a radiação solar em energia elétrica) das células fotovoltaicas era de cerca de $1 \%$ em 1914 e somente em 1988 os Laboratórios Bell, atingiram a eficiência de 28\% em uma célula de silício, sendo que em 1958 as primeiras 108 células solares foram utilizadas pelo satélite Vanguard. Nas décadas de 1980 e 90 o desenvolvimento da energia fotovoltaica foi 
subestimado pelos governos de todo o mundo (LASNIER e ANG, 1990; BUBE, 1998; LUQUE e HEGEDUS, 2005; GOETZBERGER e HOFFMANN, 2005).

O campo do eletromagnetismo tem suas principais descobertas a partir de 1777, quando Coulomb formulou a lei que leva seu nome (lei do inverso do quadrado das distâncias para as interações de cargas elétricas). Posteriormente Benjamin Franklin (1706-1790), Galvani (1737-1798) e Volta (1745-1827) realizaram vários experimentos e foi em 1820 que Oersted (1777-1851) descobriu que uma corrente elétrica produz um campo magnético, Ampère (1775-1836) já havia estudado a conexão entre corrente constante e magnetismo. Em 1821, Faraday (1791-1867) mostrou que um campo magnético variável poderia produzir uma corrente elétrica; Maxwell (1831-1879) apresentou uma teoria que forneceu uma explicação completa e unificada para os fenômenos elétricos, magnéticos e ópticos em 1864 e Hertz (1857-1894) demonstrou, inequivocamente, a existência de ondas eletromagnéticas (SHAMOS, 1987; OLBY, 1996; SMITH, 1997; KEITHLEY, 1999).

\subsection{Gerador piezelétrico de energia baseado em vibrações}

Dispositivos de geração de energia por vibração são desenvolvidos para converter a energia mecânica em energia elétrica. A conversão do domínio mecânico para o elétrico é realizada através de dispositivos transdutores, sendo que os métodos mais utilizados são: piezoeletricidade, indução eletromagnética (deslocamento de uma bobina eletromagnética) e eletrostática (ROUNDY; WRIGHT; RABAEY, 2002, ROUNDY; WRIGHT, 2004).

Embora existam vários tipos, a transdução piezelétrica tem sido o objeto principal de estudo nos últimos anos, quando o assunto é obter energia proveniente de vibrações. Quando comparados aos transdutores eletromagnéticos e eletrostáticos, os transdutores piezelétricos têm a capacidade de produzir a maior quantidade de energia elétrica (Tabela 1); tais 
transdutores, utilizam o efeito piezelétrico direto para converter as vibrações mecânicas em energia elétrica (ROUNDY; WRIGHT, 2004, DE MARQUI et al., 2010).

Tabela 1. Resumo das densidades de energia máxima de três tipos de transdutores. (ROUNDY; WRIGHT, 2004)

\begin{tabular}{ccc}
\hline Tipo & Densidade de energia $\left(\mathbf{m J ~ c m}^{-3}\right)$ & Pressuposto \\
\hline Piezelétrico & 35,4 & PZT 5 H \\
Eletromagnético & 24,8 & $0.25 \mathrm{~T}$ \\
Eletrostático & 4 & $3 \times 10^{7} \mathrm{~V} \mathrm{~m}^{-1}$ \\
\hline
\end{tabular}

A captação de energia das vibrações aeroelásticas, utilizando materiais piezelétricos, apresenta até o presente momento (2010) poucos trabalhos publicados e uma literatura bastante restrita, pois poucos pesquisadores se dedicaram a estudar o assunto.

SCHIMIDT (1992) propôs revestir as pás de um gerador eólico com filmes de um polímero piezelétrico $\left(\mathrm{PVF}_{2}\right)$ para aumentar a eficiência na produção de energia elétrica. Tal alternativa poderia descartar a necessidade de grandes rotores, girando em altas velocidades, que seriam necessários nos geradores eólicos convencionais, pois isto apresentaria sérios problemas de segurança para pessoas e pássaros. Um grande gerador eólico com as pás revestidas de material piezelétrico oscilando em alta freqüência com pequena amplitude, não representaria grandes problemas de segurança. Construiu um protótipo para testes e constatou que em freqüências próximas a $1 \mathrm{kHz}$ teoricamente é possível produzir uma potência elétrica de aproximadamente $100 \mathrm{~W}$ por $\mathrm{cm}^{3}$ de material piezelétrico, uma eficiência próxima a $70 \%$. Não chegou a construir o gerador proposto em razão do alto custo do material envolvido e também porque o custo de produção do kW na época era considerado alto demais.

A necessidade de obter novas fontes de energia para aumentar a autonomia dos dispositivos de computação móvel, foi abordada em um trabalho de STARNER (1996), onde analisa os potenciais do corpo humano para a geração de energia que serviria de fonte de 
alimentação para tais dispositivos. Starner pesquisou o montante de energia que poderia ser produzida por diversos sistemas do corpo humano, dentre eles: calor do corpo, respiração, pressão arterial, movimento dos membros superiores, caminhada e movimento dos dedos das mãos durante o processo de digitação. $\mathrm{O}$ autor obteve a conclusão de que a forma mais eficiente e que causaria menos fadiga ao usuário seria a inserção de dispositivos piezelétricos sob a palmilha de um sapato que em razão da flexão natural durante uma caminhada rápida (dois passos por segundo) de um homem de 68 quilogramas poderia produzir entre 5 e 8.3 Watts de potência que poderiam ser acumuladas para utilização posterior.

WILLIANS e YATES (1996) derivaram as equações para a conversão de energia mecânica em energia elétrica. Utilizaram um pequeno gerador eletromagnético $(5 \mathrm{~mm} \times 5$ $\mathrm{mm} \times 1 \mathrm{~mm}$ ) e obtiveram $1 \mu \mathrm{W}$ para uma freqüência de excitação de $70 \mathrm{~Hz}$ e $0.1 \mathrm{~mW}$ para uma freqüência de $330 \mathrm{~Hz}$ (assumindo uma deflexão de $50 \mu \mathrm{W}$ ). Concluíram que a potência gerada é proporcional ao cubo da freqüência de vibração, sendo que o tamanho do gerador é a principal limitação imposta à geração de potência; além disso concluíram que, respeitadas as dimensões e o volume do gerador, quanto maior for a massa utilizada e a distância que ela pode percorrer, maior será a potência gerada.

Foi também em 1996 que UMEDA et al. (1996) estudaram as características de um gerador que transforma o impacto mecânico em energia elétrica utilizando um oscilador piezelétrico e uma esfera de aço. Através da análise numérica de um modelo proposto no mesmo artigo. Para esclarecer a relação entre a entrada da energia mecânica proveniente do impacto e a saída de energia elétrica, estudou a colisão entre a esfera de aço e um oscilador piezelétrico, utilizando um circuito transdutor equivalente. Concluiu que a tensão de saída é alterada quando o valor da resistência $\mathrm{R}_{\mathrm{L}}$ é alterado; que existe um valor ótimo de resistência que gera o máximo de eficiência; que a forma de entrada da energia do impacto mecânico afeta a eficiência da transformação em razão da não-linearidade do oscilador e que grande 
parte da energia mecânica do impacto é transferida para a esfera de aço após o salto como energia cinética.

Com o avanço dos dispositivos wireless, o consumo de energia destes equipamentos fica cada vez menor, tornando possível a conversão de energia mecânica em energia elétrica para alimentá-los. O trabalho de ELVIN et al. (2001) faz a análise teórica e experimental de um sensor com comunicação wireless que é auto-alimentado através da energia mecânica de deformação que é convertida em energia elétrica. Mostra que a resposta do sensor depende da freqüência e da magnitude da carga aplicada. Em laboratório foi possível transmitir um sinal por 2 metros de distância utilizando um receptor AM padrão (1 MHz). O sensor PVDF (material piezelétrico) possui $28 \mu \mathrm{m}$ de espessura e em razão da tensão do diodo cut-off requer um mínimo de força aplicada para permitir a alimentação do circuito de telemetria. Nas simulações teóricas a força mínima medida foi de 4 N, mas experimentalmente foi possível medir forças de cerca de $2 \mathrm{~N}(\mathrm{em} 10 \mathrm{~Hz})$ o que corresponde a tensões de $60 \mu \varepsilon$. Em 2001, o trabalho de MENINGER et al. (2001) propôs um sistema que converte vibrações mecânicas do ambiente em energia elétrica para alimentar sistemas eletrônicos autônomos que possuem baixo consumo de energia, utilizando um capacitor variável que utiliza a tecnologia MEMS como transdutor. O dispositivo foi projetado para vibrações mecânicas de $2520 \mathrm{~Hz}$. Com base nos valores previstos da capacitância do transdutor MEMS, estima-se que uma potência de 8,6 $\mu \mathrm{W}$ esteja disponível para utilização pela carga. Para fornecer uma operação mais robusta, uma nova arquitetura que proporciona uma realimentação de energia foi proposta e estima-se que possa produzir aproximadamente 5,6 $\mu \mathrm{W}$.

ROUNDY et al. (2003) publicaram um estudo sobre a viabilidade de se obter energia em aplicações sujeitas a vibrações, avaliando diferentes fontes e mecanismos de conversão de energia mecânica em energia elétrica (mecanismos piezelétricos, eletromagnéticos e eletrostáticos). Conclui que é viável obter energia do ambiente para alimentação de pequenos 
sensores wireless para certas aplicações e que conversores piezelétricos são capazes de converter mais potência por unidade de volume do que os conversores capacitivos, além do que eles não requerem fonte de tensão para funcionarem.

O trabalho de ROUNDY (2005) desenvolve uma fórmula comparativa da eficácia dos diferentes tipos de geradores de energia baseados em vibrações (eletromagnéticos, piezelétricos, magnetoestritivos e eletrostáticos); porém, resultados experimentais com dois geradores piezelétricos mostraram que a teoria desenvolvida ainda apresentou divergências entre a eficácia esperada e a obtida.

CAVALLIER et al. (2005) através de um experimento qualitativo mostram as vantagens de uma micro-máquina vibratória que funciona como um transformador. Criada para armazenar energia mecânica e convertê-la em energia elétrica utilizando uma placa de material piezelétrico, a estrutura converte baixos níveis de vibrações mecânicas com frequiências muito baixas (tipicamente abaixo de $10 \mathrm{~Hz}$ quando a fonte de excitação utilizada é humana) em vibrações mecânicas com freqüências de ressonância que variam de $1 \mathrm{kHz}$ até $1 \mathrm{MHz}$. O dispositivo utilizado nos testes possui quatro pequenas esferas metálicas (com peso de $40 \mathrm{mg}$ cada uma) armazenadas separadamente em compartimentos distintos dentro de uma peça metálica de formato circular, quando este dispositivo é agitado por meio de um excitador (shaker), o choque causado pelo atrito das esferas com placas que alternam camadas de PZT/Silício/PZT convertem a energia mecânica em energia elétrica e transmitem-na para as conexões elétricas. Neste dispositivo, as placas piezelétricas são responsáveis pela conversão piezelétrica e as barras de silício são os elementos responsáveis pelo armazenamento da energia.

Os sistemas de monitoramento da integridade estrutural (HUMS), utilizados nos componentes rotativos de um helicóptero são considerados extremamente importantes para o plano de manutenção (CBM). No passado, os dispositivos desenvolvidos tinham como maior 
obstáculo a manutenção da bateria que alimentaria o sistema. Em ARMS et al. (2006) é apresentada uma nova geração de sensores wireless que seriam utilizados para medir, gravar e transmitir informações sobre deformações e carregamento dos componentes rotativos. Os sensores obteriam a energia de que necessitam para funcionar através de materiais piezelétricos (PZT) implantados no braço que controla o passo das hélices (pitch link), estes dispositivos convertem deformações mecânicas em energia elétrica. Construído e instalado um protótipo deste dispositivo em um helicóptero modelo AH-1W, foi constatado que em condições normais de operação, a energia coletada pelo sistema piezelétrico é superior ao consumo de energia dos sensores wireless o que dispensaria a substituição da bateria para sempre. Para vibrações da ordem de 4,3 Hz o sistema carrega ininterruptamente um capacitor utilizando deformações mecânicas entre $50 \mu$ in./in. e $175 \mu$ in./in; sendo que a potência gerada na saída fica em torno de 1 a $5,5 \mathrm{~mW}$.

Uma revisão do estado da arte em coletores de energia baseados em vibrações para dispositivos wireless e micro-sistemas auto-alimentados, é o tema abordado em BEEBY et al. (2006).

Para um maior aprofundamento na literatura dos trabalhos publicados entre 1983 e 2004 sobre coletores de energia por vibração, consulte SODANO e INMAN (2004). As pesquisas realizadas entre 2003 e 2006 são relacionadas em ANTON e SODANO (2007).

PRIYA (2007) analisa os avanços recentes da tecnologia de coleta de energia utilizando transdutores piezelétricos, mencionando também os resultados obtidos em alguns protótipos. Afirma que os conversores de energia piezelétricos são a melhor opção quando necessitamos converter energia mecânica em elétrica, pois a densidade de energia é três vezes maior se comparado aos conversores eletrostáticos e eletromagnéticos e que a potência elétrica gerada é inversamente proporcional à razão de amortecimento, a qual deve ser minimizada através da seleção de materiais e design. A potência gerada também é 
proporcional ao quadrado da aceleração e atinge seu valor máximo na freqüência de ressonância; sendo que a frequiência de ressonância em um transdutor piezelétrico é dependente da configuração, tamanho e condições de carga. Além disso, faz algumas análises sobre os principais materiais piezelétricos e também sobre modelos analíticos relatados na literatura objetivando analisar a eficiência dos processos de coleta de energia.

COOK-CHENNAULT et al. (2008) publicaram um trabalho onde propõem uma visão geral sobre fontes de energia não regenerativas e regenerativas para alimentação de dispositivos micro-eletromecânicos (MEMS) - integração de elementos mecânicos, sensores, atuadores, e eletrônica em uma pastilha comum de silício com a tecnologia de microfabricação. Os autores revisam os fundamentos e discutem tendências e aplicações para a coleta de energia através de dispositivos piezelétricos. Sistemas de sensores utilizados em ambientes inteligentes, dispositivos de monitoramento, implantes médicos e roupas inteligentes são citados como aplicações de grande potencial para sistemas de fornecimento de energia baseados em vibrações. Existem inúmeras oportunidades para coleta de energia baseadas em vibrações, sendo que uma das fontes mais promissoras mencionadas neste trabalho é o compartimento do motor de um veículo, cujas vibrações podem apresentar uma aceleração de $12 \mathrm{~m} . \mathrm{s}^{-2}$ e um pico de freqüência de $200 \mathrm{~Hz}$. Apresentam três tipos de tecnologia que podem ser utilizadas nestas aplicações, sendo que a eletromagnética e a piezelétrica apresentam-se como as mais promissoras; pois os dispositivos eletrostáticos produzem uma quantidade reduzida de corrente em razão da alta impedância e tensões de saída. Informam que os dispositivos piezelétricos para captação de energia são os mais simples para se obter energia diretamente de vibrações estruturais, pois requerem poucos componentes adicionais e geometrias relativamente simples, além de existir um grande número de técnicas de fabricação de filme fino para aplicação em dispositivos MEMS. 
O trabalho de ANTON (2008), informa os resultados de experimentos práticos que utilizaram dois métodos de geração de energia: fotovoltaico (utilizando painéis solares) e piezelétrico. Utilizou um UAV rádio controlado para comprovar qual dos dois métodos apresenta os melhores resultados práticos e concluiu que após um vôo de 13 minutos os resultados foram promissores, sendo que os painéis solares conseguiram carregar uma bateria de Lítio de 3.7V, 170 mAh em 14\% da sua capacidade; já o sistema piezelétrico (viga apoiada PFC) conseguiu carregar o capacitor interno (capacidade 4,6 mJ) do EH300 (dispositivo piezelétrico) em $70 \%$ de sua capacidade.

ERTURK et al. (2008) propõem a utilização de pares de eletrodos segmentados para evitar o cancelamento de cargas elétricas em um gerador piezelétrico. Os modos de vibração de vigas engastadas (com exceção do primeiro modo) apresentam nós de tensão, onde a distribuição de tensão dinâmica altera o sinal da carga na direção do comprimento da viga.

LEE et al. (2009) apresentam um novo tipo de coletor de energia piezelétrico, chamado de coletor de energia do tipo segmentado que utiliza múltiplas freqüências de ressonância para proporcionar uma maior faixa de captação de energia do ambiente utilizando frequiências de ressonância mais altas. Nesta época, o estado da arte dos coletores de energia piezelétricos utiliza uma única freqüência natural, diminuindo a eficiência destes sistemas quando utilizados em ambientes que apresentam freqüências multimodais. Para prevenir o efeito do cancelamento de cargas, as duas placas piezelétricas são separadas próximo ao ponto de inflexão da deformação mecânica. O coletor alimentou com sucesso um sensor analógico de temperatura, que requer 5,3 V para inicialização; $2,7 \mathrm{~V}$ para transmissão de dados via wireless e cerca de $20 \mu \mathrm{W}$ para monitoramento contínuo da temperatura. Este sensor foi acoplado a um sistema HVAC (aquecimento, ventilação, ar condicionado) de um edifício para efetuar o monitoramento em tempo real da temperatura. 
No trabalho de ELVIN e ELVIN (2009) foi investigado o efeito do amortecimento piezelétrico (amortecimento passivo) para a condição de flutter, utilizando diferentes resistências elétricas, para um tubo engastado (envolto por duas camadas de material piezelétrico, ligadas a um circuito elétrico) e utilizado no transporte de fluidos. Mostram uma grande variedade de respostas mecânicas, incluindo incremento do sistema de amortecimento para fluxo em baixas velocidades, divergência (flambagem) e uma transição para a condição de instabilidade (flutter) para altas velocidades. Demonstrou que um maior coeficiente de acoplamento eletromecânico tende a aumentar a velocidade crítica de flutter devido ao aumento da rigidez do acoplamento eletromecânico; conclui que o efeito de rigidez mecânica para a condição de circuito aberto provoca um aumento da velocidade de flutter, situação que não ocorre na condição de curto-circuito, entretanto, em ambos os circuitos (circuito aberto e curto-circuito) a potência dissipada através do resistor de carga é nula (a potência $P=v i$ onde 'v' é a tensão gerada e 'i' é a corrente. Para circuito aberto $i=0$; para curto circuito $v=0$ ) e que o posicionamento das camadas de material piezelétrico tem grande influência sobre o desempenho geral do sistema. Quando combinado a determinados valores de resistência elétrica, pode incrementar ou decrementar a velocidade de flutter, permitindo uma maior geração de energia ou então, mantendo a estabilidade do sistema.

ERTURK et al. (2009a) apresenta um novo modelo de gerador de energia piezelétrico que utiliza uma viga engastada em forma de L, que pode ser configurado para ter as duas primeiras freqüências naturais relativamente próximas entre si; o que resulta em uma faixa mais ampla para coleta de energia pelo sistema. Sugere a utilização deste novo modelo de gerador no trem de pouso de um UAV, onde a vibração produzida pelo contato das rodas do UAV com uma fonte de vibrações geraria energia elétrica. Os autores demonstram teoricamente que existe uma vantagem significativa da utilização deste modelo de gerador, 
quando comparado com um gerador que utiliza uma viga arqueada utilizado para a mesma finalidade.

O trabalho de ERTURK et al. (2009b) compara os resultados obtidos por um gerador piezomagnetoelástico e outro piezoelástico (a mesma estrutura, porém com os ímãs removidos) e conclui que o gerador piezoelástico apresenta uma maior tensão na saída somente quando a freqüência de excitação está próxima da freqüência de ressonância $(7,4$ $\mathrm{Hz}$ ), ao passo que o gerador piezomagnetoelástico fornece uma tensão até 3 vezes superior para uma faixa de freqüências bem maior, alterando a freqüência de ressonância da estrutura para 10,6 Hz. O gerador piezomagnetoelástico incrementa em 200\% a amplitude da tensão na condição de circuito aberto e permite até $800 \%$ de acréscimo na amplitude da potência.

O trabalho de ERTURK et al. (2009c) apresentou um gerador piezelétrico multicamada (multimorph) com diferentes combinações elétricas e das camadas de piezocerâmica. Utilizando uma longarina modificada, simulações foram feitas para verificar até que ponto a estrutura poderia resistir a vibrações para gerar energia, sem apresentar riscos a segurança; pois a adição de piezocerâmicas na longarina original, em substituição ao alumínio aeronáutico (A17075-T6) reduz o carregamento que pode ser suportado pela estrutura, em razão da natureza frágil deste material. O desempenho eletromecânico de um gerador com 9 camadas (alumínio, PZT-5A, Kapton e epoxy) é investigado experimentalmente e os resultados obtidos ficaram dentro do previsto por um modelo analítico.

Em ANTON et al. (2009) foi proposta uma estrutura multicamadas que acumula as funções de gerador piezelétrico de energia e de bateria (utilizando a nova tecnologia de filmes finos). Experimentos foram realizados para determinar a eficiência de um circuito regulador linear utilizado para ensaios dinâmicos e proposto um circuito de comutação de impedância. O gerador piezelétrico (camadas de piezocerâmica em série, conectadas a uma resistência elétrica de $85 \mathrm{k} \Omega$ ) foi submetido a uma aceleração de 2,0 g na condição de circuito aberto e 
freqüência de ressonância de 211,1 Hz; este caso representa o máximo de energia que pode ser extraído do sistema, tendo sido medida a potência média de 1,6 mW (o gerador piezelétrico produz a potência em corrente alternada que é convertida por um circuito retificador para corrente contínua para permitir o armazenamento na bateria). Um supercapacitor (CapXXGW209F) de 0,12 Farad e 4,5 V inicialmente carregado com 3,0 V foi utilizado para permitir a medição da média de potência gerada pelos dois circuitos a serem avaliados. O primeiro circuito a passar pelos testes, foi o regulador linear. Quando submetido à aceleração de $2,0 \mathrm{~g}$ na freqüência de $210 \mathrm{~Hz}$, a potência média enviada para o supercapacitor foi de $493 \mu \mathrm{W}$, eficiência de $30 \%$ quando comparada ao valor de referência. No novo circuito de chaveamento, em razão do casamento de impedância do circuito de comutação, a frequiência de ressonância para o mesmo valor de resistência foi de $211,1 \mathrm{~Hz}$ e excitando a estrutura a $211,1 \mathrm{~Hz}$ a uma aceleração de 2,0 g; a potência média enviada para o supercapacitor foi de $862 \mu \mathrm{W}$, resultando numa eficiência de $53,8 \%$.

O trabalho de BRYANT e GARCIA (2009) apresenta um sistema aeroelástico simples com dois graus de liberdade, adequado para ser um gerador piezelétrico de energia. A estrutura é composta por um aerofólio ligado a um pino que está conectado a vigas piezelétricas do tipo bimorph e permite extrair energia do escoamento quando este apresenta diferentes velocidades. Quando a velocidade do escoamento atinge o limite crítico de operação, o dispositivo pode ser chaveado para que seja adicionado um amortecimento ao sistema devido à geração de energia, elevando a velocidade de flutter e fazendo com que a amplitude das vibrações seja reduzida. Quando a velocidade do escoamento atingir o limite mínimo de operação, o circuito dos elementos piezelétricos pode ser colocado na condição de curto-circuito para remover o amortecimento elétrico e permitir que as vibrações aumentem, possibilitando que o ciclo possa ser repetido indefinidamente. 
O trabalho de TANG et al. (2009) apresenta o projeto conceitual de um novo gerador de energia, denominado usina de flutter. Lâminas de alumínio engastadas e flexíveis com condutores embutidos e posicionadas entre um par de painéis magnéticos, são submetidas a um escoamento axial até a condição de flutter. A dinâmica do sistema e a transferência de energia entre a lâmina e o escoamento são estudadas com base na teoria do trabalho. Compara o projeto proposto com uma usina eólica convencional, mostrando que por ser uma estrutura simples e ter tamanho compacto. O dispositivo projetado é muito promissor para a geração de energia elétrica. Para os cálculos da potência elétrica gerada, assume-se que somente $10 \%$ da energia capturada pela lâmina é convertida em potência elétrica, os outros $90 \%$ são consumidos pela lâmina para manter a condição de flutter (sob a ação de forças eletromagnéticas induzidas). A lâmina 1 com 0,58 m (comprimento) x 0,2 m (largura) x 0,59 m (altura), pode extrair 10 Watts de potência quando a velocidade do escoamento é de $12 \mathrm{~m} / \mathrm{s}$, se somente $10 \%$ da energia capturada é convertida em energia elétrica, uma saída de 1 Watt é garantida. A lâmina 2 apresenta dimensões menores 0,232 m (comprimento) x 0,2 m (largura) x $0,232 \mathrm{~m}$ (altura), mas trabalha com altas velocidades do escoamento e pode gerar $1 \mathrm{~kW} / \mathrm{m}$ quando a velocidade do escoamento é de $40 \mathrm{~m} / \mathrm{s}$.

Em AKAYDIN et al. (2010) é investigada a geração de energia para altos números de Reynolds (Re>10.000) por uma viga piezelétrica (revestida de fluoreto de polivinilideno PVDF e associada a um circuito elétrico), posicionada atrás de um cilindro. Tendo sido ambos instalados em um túnel de vento que provoca o surgimento de uma esteira de vórtices quando o escoamento passa pelo cilindro, excitando a viga eletromecânica. Obtiveram $4 \mu \mathrm{W}$ como potência máxima (não retificada) utilizando uma resistência de $100 k \Omega$, quando a velocidade do escoamento foi de $7,23 \mathrm{~m} / \mathrm{s}$ e concluíram que o posicionamento do gerador dentro do escoamento influencia o resultado. 
Em Dietl e Garcia (2010), os autores demonstraram que alterando a forma de uma viga geradora piezelétrica bimorph influencia-se significativamente o processo de transdução piezelétrico. Os autores propõem concentrar a tensão em seções específicas da viga, o que contribuiria para uma melhor transdução de energia.

ERTURK et al. (2010) apresentam um modelo piezoaeroelástico que é validado experimentalmente com o foco na potência elétrica gerada e seu efeito na resposta aeroelástica. Embora a análise feita tenha sido linear, conseqüências de não-linearidades em um sistema piezoaeroelástico também são discutidas. Nos experimentos, obteve a potência elétrica máxima de $10,7 \mathrm{~mW}$ quando utilizando uma resistência de $R l=100 \mathrm{k} \Omega$ para a velocidade de flutter linear de $9,30 \mathrm{~m} / \mathrm{s}$. Em condições de curto-circuito e utilizando $R l=100 \Omega$, o modelo matemático prevê a velocidade de flutter linear como sendo $9,06 \mathrm{~m} / \mathrm{s}$, superestimando o resultado experimental de $8,85 \mathrm{~m} / \mathrm{s}$; utilizando $R l=100 \mathrm{k} \Omega$ prevê a velocidade de flutter linear como sendo $9,56 \mathrm{~m} / \mathrm{s}$, sendo que o valor obtido no modelo foi de $9,30 \mathrm{~m} / \mathrm{s}$. Já as freqüências de flutter obtidas através do modelo, considerando $R l=100 \Omega \mathrm{e}$ $R l=100 \mathrm{k} \Omega$ subestimam em $1,7 \%$ e $2,3 \%$ os resultados obtidos experimentalmente.

DE MARQUI et al. (2010) combinam um modelo aerodinâmico não estacionário de malha de vórtices com um modelo de elementos finitos eletromecanicamente acoplado, previamente apresentados, para desenvolver um modelo piezoaeroelástico, investiga a potência elétrica gerada e o deslocamento na ponta da asa para várias velocidades do escoamento, utilizando eletrodos contínuos e segmentados. Conclui que a utilização dos eletrodos segmentados melhora o acoplamento eletromecânico, pois nesta configuração minimiza-se o cancelamento elétrico na saída em razão dos movimentos de torção. Conseqüentemente, ocorre um aumento na velocidade de flutter e obtém-se uma maior potência elétrica na saída. 


\section{MODELO PIEZOAEROELÁSTICO}

Um modelo piezoaeroelástico é obtido através da combinação de um modelo em elementos finitos eletromecanicamente acoplado com um modelo aerodinâmico nãoestacionário (DE MARQUI et al., 2009a). A seguir serão descritas, a formulação dos elementos finitos, o modelo aerodinâmico não-estacionário, o acoplamento destes modelos e a solução numérica para as equações de movimento para uma asa geradora.

\subsection{Modelo por elementos finitos eletromecanicamente acoplado}

\subsubsection{Princípio de Hamilton}

Na ausência de efeitos magnéticos, a generalização do princípio de Hamilton para um corpo eletro-elástico é dado por (CRANDALL et al., 1968):

$$
\int_{t 1}^{t 2}\left[\delta\left(T-U+W_{e}\right)+\delta W\right] d t=0
$$

Onde a energia cinética total $(T)$, a energia potencial total $(U)$ e a energia elétrica $\left(W_{e}\right)$ são definidas como:

$$
\begin{gathered}
T=\int_{V_{s}} \frac{1}{2} \rho_{s} \dot{\boldsymbol{u}}^{t} \dot{\boldsymbol{u}} d V_{s}+\int_{V_{p}} \frac{1}{2} \rho_{p} \dot{\boldsymbol{u}}^{t} \dot{\boldsymbol{u}} d V_{p} \\
U=\int_{V_{s}} \frac{1}{2} \boldsymbol{S}^{t} \boldsymbol{T} d V_{s}+\int_{V_{p}} \frac{1}{2} \boldsymbol{S}^{t} \boldsymbol{T} d V_{p} \\
W_{e}=\int_{V_{p}} \frac{1}{2} \boldsymbol{E}^{t} \boldsymbol{D} d V_{p}
\end{gathered}
$$

Sendo que u é o vetor de deslocamentos mecânicos, $\mathbf{S}$ é o vetor de deformações mecânicas, $\mathbf{T}$ é o vetor de tensões mecânicas, $\mathbf{D}$ é o vetor de deslocamentos elétricos, $\mathbf{E}$ é o 
vetor do campo elétrico, $\rho$ é a densidade de massa, $\mathbf{V}$ é o volume, $\boldsymbol{t}$ denota transposição, um ponto sobre o vetor de deslocamentos mecânicos representa diferenciação com relação ao tempo; os subscritos $\boldsymbol{s}$ e $\boldsymbol{p}$ representam respectivamente, a camada metálica (aqui chamada de subestrutura) e as camadas piezocerâmicas.

Para um conjunto de forças mecânicas discretas $\mathbf{f}$ aplicado na localização $\left(x_{i}, y_{i}\right)$ e por um conjunto discreto de saídas de cargas elétricas q extraídos na localização $\left(x_{j}, y_{j}\right)$, a equação abaixo, expressa a variação do trabalho mecanicamente aplicado e eletricamente extraído:

$$
\delta W=\sum_{i=1}^{n f} \delta \boldsymbol{u}\left(x_{i}, y_{i}, t\right) . \boldsymbol{f}\left(x_{i}, y_{i}, t\right)+\sum_{j=1}^{n q} \delta \varphi\left(x_{j}, y_{j}, t\right) . q\left(x_{j}, y_{j}, t\right)
$$

Onde $n f$ é o número de forças mecânicas discretas, $\varphi_{j}$ é o escalar do potencial elétrico e $n q$ é o número de pares de eletrodos.

Em um problema de acionamento estrutural a carga elétrica é a entrada, portanto, o segundo termo da Eq. (3) tem um sinal negativo (HAGOOD et al.,1990). Neste trabalho é feita a modelagem de um gerador de energia e como existe a captação de energia, um sinal positivo deve ser utilizado (DUTOIT et al.,2005; DUTOIT; WARDLE, 2007). O amortecimento mecânico é excluído neste ponto e será introduzido posteriormente.

A relação linear-elástica pode ser escrita como:

$$
T=c_{s} S
$$

sendo $\mathbf{c}_{\mathrm{s}}$ é a matriz de rigidez elástica (2-D).

A relação constitutiva eletro-elástica para um material piezocerâmico é dada por (OTTMAN et al.,2002): 


$$
\left\{\begin{array}{l}
\boldsymbol{T} \\
\boldsymbol{D}
\end{array}\right\}=\left[\begin{array}{cc}
\boldsymbol{c}_{p}^{E} & -\boldsymbol{e}^{t} \\
\boldsymbol{e} & \boldsymbol{\varepsilon}^{S}
\end{array}\right]\left\{\begin{array}{l}
\boldsymbol{S} \\
\boldsymbol{E}
\end{array}\right\}
$$

Onde c é a matriz de rigidez elástica, e é a matriz de constantes piezelétricas, é a matriz de permissividade (constante dielétrica), os índices $\mathbf{E}$ e $\mathbf{S}$ denotam que os parâmetros são medidos com campo elétrico e tensão constante, respectivamente.

Usando as relações constitutivas dadas pelas equações (4) e (5) na equação (1), tem-se que o princípio de Hamilton generalizado para um gerador de energia piezelétrico é dado por:

$$
\int_{t_{1}}^{t_{2}}\left[\begin{array}{l}
\int_{V_{s}} \rho_{s} \delta \dot{\boldsymbol{u}}^{t} \dot{\boldsymbol{u}} d V_{s}+\int_{V_{p}} \rho_{p} \delta \dot{\boldsymbol{u}}^{t} \dot{\boldsymbol{u}} d V_{p}-\int_{V_{s}} \delta \boldsymbol{S}^{t} \boldsymbol{c}_{s} \boldsymbol{S} d V_{s}-\int_{V_{p}} \delta \boldsymbol{S}^{t} \boldsymbol{c}_{p} \boldsymbol{S} d V_{p}+\int_{V_{p}} \delta \boldsymbol{S}^{t} \boldsymbol{e}^{t} \boldsymbol{E} d V_{p}+\int_{V_{p}} \delta \boldsymbol{E}^{t} \boldsymbol{e} \boldsymbol{S} d V_{p}+\int_{V_{p}} \delta \boldsymbol{E}^{t} \boldsymbol{\varepsilon}^{s} \boldsymbol{E} d V_{p} \\
+\sum_{i=1}^{n f} \delta\left(x_{i}, y_{i}, t\right) \cdot \boldsymbol{f}\left(x_{i}, y_{i}, t\right)+\sum_{j=1}^{n q} \delta \varphi\left(x_{j}, y_{j}, t\right) \cdot q\left(x_{j}, y_{j}, t\right)
\end{array}\right] d t=0
$$

\subsubsection{Modelo eletromecanicamente acoplado utilizando elementos finitos}

O modelo apresentado a seguir é para a configuração de um gerador de energia piezelétrico do tipo unimorph, a placa geradora de energia possui uma camada de estrutura e uma camada de piezocerâmica, como mostrado na figura 3. Assume-se que as camadas de estrutura e a camada piezocerâmica estão perfeitamente unidas entre si.

Em De Marqui et al. (2009a) pode ser encontrada uma descrição detalhada do modelo utilizado neste trabalho.

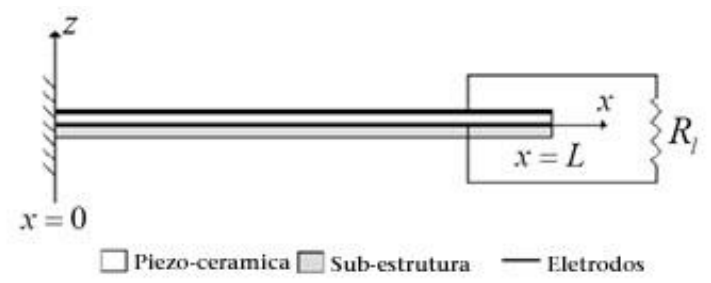

Figura 3. Gerador de energia piezelétrico unimorph 
Um elemento finito retangular com três graus de liberdade mecânicos por nó (chamados de deslocamentos $\mathrm{u}_{\mathrm{x}}, \mathrm{u}_{\mathrm{y}}$ e $\mathrm{u}_{\mathrm{z}}$ nas direções $\mathrm{x}, \mathrm{y}$ e $\mathrm{z}$ ) mostrado na figura 4 é usado para modelar as camadas de estrutura e piezocerâmica. Com base no pressuposto de que cada elemento finito da camada piezocerâmica é totalmente coberto por eletrodos condutivos (na superfície superior e inferior), um grau de liberdade elétrico (tensão $\mathrm{v}_{\mathrm{p}}$ através dos eletrodos) é adicionado para modelar a resposta elétrica destes elementos. Assim, o elemento finito retangular tem 12 graus de liberdade na modelagem da estrutura e 13 graus de liberdade no total, quando modelando a camada de piezocerâmica.

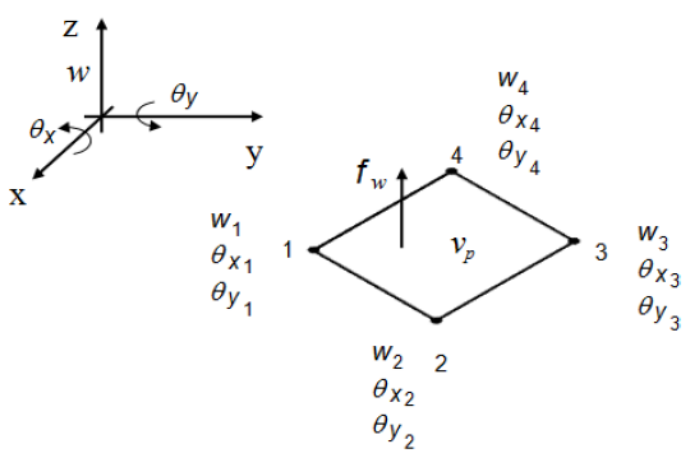

Figura 4. Elemento finito de um piezo-elétrico com 12 graus de liberdade mecânicos e 1 grau de liberdade elétrico.

Com base na teoria das placas de Kirchhoff, as deformações de cisalhamento e as inércias de rotação do elemento finito são desprezadas e deslocamentos no plano $\left(\mathrm{u}_{\mathrm{x}}\right.$ e $\left.\mathrm{u}_{\mathrm{y}}\right)$ são assumidos serem devidos à flexão (rotação da seção transversal) da placa somente. O deslocamento do campo é então:

$$
\boldsymbol{u}=\left\{\begin{array}{l}
u_{x} \\
u_{y} \\
u_{z}
\end{array}\right\}=\left\{\begin{array}{lll}
-z \frac{\partial w}{\partial x} & -z \frac{\partial w}{\partial y} & w
\end{array}\right\}^{t}
$$


Onde as componentes de deslocamento $\mathrm{u}_{\mathrm{x}}, \mathrm{u}_{\mathrm{y}}$ e $\mathrm{u}_{\mathrm{z}}$ para uma espessura nível $\mathrm{z}$ a partir da superfície de referência (neutro), são dadas em termos de deformação transversal (w) da superfície de referência.

As componentes de esforços mecânicos podem ser escritas em função das componentes de deslocamento, como:

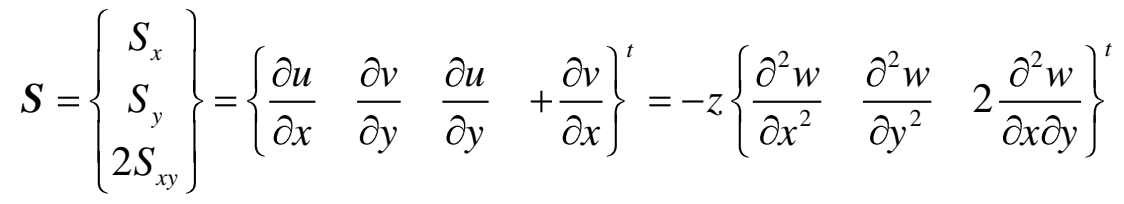

Considerando 4 nós por elemento e 3 graus de liberdade por nó, pode-se definir um vetor $12 \times 1$ de variáveis nodais:

$$
\Psi=\left\{\begin{array}{llllllllllll}
w_{1} & \theta_{x 1} & \theta_{y 1} & w_{2} & \theta_{x 2} & \theta_{y 2} & w_{3} & \theta_{x 3} & \theta_{y 3} & w_{4} & \theta_{x 4} & \theta_{y 4}
\end{array}\right\}^{t}
$$

onde $\mathbf{w}_{\mathbf{k}}$ é o deslocamento transversal para o nó $\mathrm{k}, \theta_{x k}=\partial w /\left.\partial y\right|_{x y . y k} \mathrm{e}$ $\theta_{y k}=-\partial w /\left.\partial y\right|_{x k . y k}$ são rotações de flexão.

Para obter as matrizes elementares (matrizes para cada elemento), o deslocamento do campo u e conseqüentemente as componentes de tensão $\mathbf{S}$ descritas pela Eq. (8) precisam ser expressas como funções de variáveis nodais. Isto é feito expressando o deslocamento transversal e o vetor de curvaturas nos termos da variável nodal,

$$
\begin{gathered}
\left\{\begin{array}{ccc}
\frac{\partial w}{\partial x} & \frac{\partial w}{\partial y} & w
\end{array}\right\}^{t}=\boldsymbol{B}_{\boldsymbol{\eta}} \boldsymbol{\Psi} \\
\left\{\begin{array}{lll}
\frac{\partial^{2} w}{\partial x^{2}} & \frac{\partial^{2} w}{\partial y^{2}} & 2 \frac{\partial^{2} w}{\partial x \partial y}
\end{array}\right\}^{t}=\boldsymbol{B}_{\boldsymbol{\kappa}} \boldsymbol{\Psi}
\end{gathered}
$$


onde $\boldsymbol{B}_{\eta}$ e $\boldsymbol{B}_{\boldsymbol{\kappa}}$ são funções de interpolação. Neste ponto são matrizes 3 x12.

A componente do campo elétrico pode ser expressa como:

$$
E_{z}=-\frac{\partial \varphi}{\partial z}=-\frac{v_{p}}{h_{p}}
$$

Assim, o vetor de componentes do campo elétrico, é dado por:

$$
\boldsymbol{E}=-\boldsymbol{B}_{\boldsymbol{E}} v_{p}
$$

onde:

$$
\boldsymbol{B}_{E}=\left\{\begin{array}{lll}
0 & 0 & \frac{1}{h_{p}}
\end{array}\right\}^{t}
$$

Baseado no princípio de Hamilton dado pela Eq. (6), a matriz elementar de massa $\mathbf{m}$, a matriz de rigidez $\mathbf{k}$, o vetor de acoplamento eletromecânico $\boldsymbol{\theta}$, a capacitância $\mathbf{c}_{\mathbf{p}} \mathrm{e} \mathbf{o}$ vetor de forças mecânicas f podem ser expressos como:

$$
\begin{gathered}
\boldsymbol{m}=\int_{V_{s}} \boldsymbol{B}_{\eta}^{t} \boldsymbol{Z}^{t} \rho_{s} \boldsymbol{Z} \boldsymbol{B}_{\eta} d V_{s}+\int_{V_{p}} \boldsymbol{B}_{\eta}^{t} \boldsymbol{Z}^{t} \rho_{p} \boldsymbol{Z} \boldsymbol{B}_{\eta} d V_{p} \\
\boldsymbol{k}=\int_{V_{s}} z^{2} \boldsymbol{B}_{\kappa}^{t} \overline{\boldsymbol{c}}_{s} \boldsymbol{B}_{\kappa} d V_{s}+\int_{V_{p}} z^{2} \boldsymbol{B}_{\kappa}^{t} \overline{\boldsymbol{c}}_{p}^{E} \boldsymbol{B}_{\kappa} d V_{p} \\
\boldsymbol{\theta}=\int_{V_{p}} z \boldsymbol{B}_{\kappa}^{t} \overline{\boldsymbol{e}}^{t} \boldsymbol{B}_{\mathrm{E}} d V_{p} \\
c_{p}=\int_{V_{p}} \boldsymbol{B}_{\mathrm{E}}^{t} \overline{\boldsymbol{\varepsilon}}^{-s} \boldsymbol{B}_{\mathrm{E}} d V_{p} \\
\boldsymbol{f}=\int_{S} \Gamma^{t} f_{w} d S
\end{gathered}
$$


onde:

$$
\boldsymbol{Z}=\left[\begin{array}{ccc}
-z & 0 & 0 \\
0 & -z & 0 \\
0 & 0 & 1
\end{array}\right]
$$

As equações de movimento global são obtidas pela junção das matrizes elementares dadas pelas Eqs. (15a)-(15e).

$$
\begin{gathered}
\boldsymbol{M} \ddot{\boldsymbol{\Psi}}+\boldsymbol{C} \dot{\boldsymbol{\Psi}}+\boldsymbol{K} \boldsymbol{\Psi}-\boldsymbol{\Theta v}=\boldsymbol{F} \\
\boldsymbol{C}_{p} v_{p}+\boldsymbol{Q}+\Theta^{t} \boldsymbol{\Psi}=0
\end{gathered}
$$

onde $\mathbf{M}$ é a matriz global de massa $\left(\mathrm{n}_{\mathrm{m}} \times \mathrm{n}_{\mathrm{m}}\right), \mathbf{K}$ é a matriz global de rigidez $\left(\mathrm{n}_{\mathrm{m}} \times \mathrm{n}_{\mathrm{m}}\right)$ e $\Theta$ é a matriz de acoplamento eletromecânico, $\mathbf{F}$ é o vetor global de forças mecânicas $\left(n_{m} \times 1\right), \mathbf{Q}$ é o vetor global de cargas elétricas $\left(n_{e} \times 1\right), \Psi$ é o vetor de coordenadas mecânicas $\left(n_{m} \times 1\right)$ e $\mathbf{v}_{\mathbf{p}}$ é o vetor global de tensões de saída $\left(n_{e} \times 1\right)$. Sendo $\mathbf{n}_{\mathbf{m}}$ e $\mathbf{n}_{\mathbf{e}}$ respectivamente o número de graus de liberdade mecânicos e elétricos da chapa geradora. Na Eq. (17a), a matriz global de amortecimento mecânico $\left(\mathrm{n}_{\mathrm{m}} \times \mathrm{n}_{\mathrm{m}}\right)$ é assumida como sendo proporcional às matrizes de massa e rigidez:

$$
\boldsymbol{C}=\alpha \boldsymbol{M}+\beta \boldsymbol{K}
$$

onde $\alpha$ e $\beta$ são constantes de proporcionalidade.

É fácil verificar que a dimensão global do vetor de tensão na saída, Eqs. (17a) e (17b), é igual ao número de elementos finitos usados na malha da camada de piezocerâmica $\left(\mathrm{n}_{\mathrm{e}}\right)$.

$\mathrm{Na}$ prática, porém, as piezocerâmicas são envolvidas por camadas contínuas de eletrodos e a diferença de potencial entre elas, pode ser assumida simplesmente como $v_{p}$. A 
transformação da Eq. (19) considera que as superfícies (superior e inferior) das camadas de piezocerâmicas são inteiramente cobertas por eletrodos (figura 1).

$$
\boldsymbol{v}=\left\{\begin{array}{llll}
v_{1} & v_{2} & \ldots & v_{n_{e}}
\end{array}\right\}^{t}=\left\{\begin{array}{llll}
1 & 1 & \ldots & 1
\end{array}\right\}^{t} v_{p}
$$

Fazendo a derivada no tempo da Eq. (17b), aplicando a transformação da Eq. (19) e pré-multiplicando por $1 \times \mathrm{n}_{\mathrm{e}}$ (vetor $\left.\left\{\begin{array}{llll}1 & 1 & \ldots & 1\end{array}\right\}\right)$, obtém-se a seguinte equação escalar:

$$
C_{p} \dot{v}_{p}+\dot{Q}+\tilde{\Theta}^{t} \dot{\Psi}=0
$$

O termo de acoplamento eletromecânico é o vetor: $\tilde{\Theta}=\left\{\begin{array}{llll}1 & 1 & \ldots & 1\end{array}\right\}^{t} \Theta\left(n_{m} \times 1\right)$

Sendo que a condição de contorno elétrica para uma carga resistiva $\left(R_{l}\right)$ é $\dot{Q}=v_{p} / R_{l}$, Eqs. (17a) e (20), tem-se:

$$
\begin{gathered}
\boldsymbol{M} \ddot{\boldsymbol{\Psi}}+\boldsymbol{C} \dot{\boldsymbol{\Psi}}+\boldsymbol{K} \boldsymbol{\Psi}-\tilde{\Theta} v_{p}=\boldsymbol{F} \\
C_{p} \dot{v}_{p}+\frac{v_{p}}{R_{l}}+\tilde{\Theta}^{t} \dot{\boldsymbol{\Psi}}=0
\end{gathered}
$$

As quais descrevem as equações eletromecânicas para uma placa geradora piezelétrica do tipo unimorph (figura 3).

O modelo de elementos finitos utilizado para representar um gerador piezelétrico unimorph pode ser facilmente modificado para representar um gerador bimorph (uma camada de subestrutura envolta por duas camadas idênticas de piezocerâmica). A camada adicional de piezocerâmica deve fazer parte também das matrizes de massa, rigidez e amortecimento.

Os pares de eletrodos dispostos nas camadas de piezocerâmica podem estar conectados em série ou em paralelo a uma resistência externa. Para uma conexão em série em um gerador bimorph as camadas de piezocerâmica devem estar polarizadas em direções opostas, o vetor de acoplamento eletromecânico é igual ao mesmo utilizado para uma única camada de 
piezocerâmica e a capacitância é metade da capacitância de uma única camada de piezocerâmica (ERTURK; INMAN, 2008a; WANG; CROSS, 1999).

\subsection{Modelo aerodinâmico não-estacionário}

Um modelo aerodinâmico não estacionário de malha de vórtices (VLM) é usado para obter o carregamento sobre uma placa engastada que simula uma asa (BENINI; BELO; MARQUES, 2004; KATZ; PLOTKIN, 2001). A asa é representada por uma fina superfície de sustentação dividida em inúmeros elementos quadriláteros, denominados de painéis. Um anel de vórtice planar é associado a cada painel retangular da estrutura e também da esteira. A singularidade do vórtice é uma solução para a equação de Laplace e o carregamento aerodinâmico da asa pode ser obtido pela combinação destas singularidades com o escoamento incompressível ao redor da estrutura.

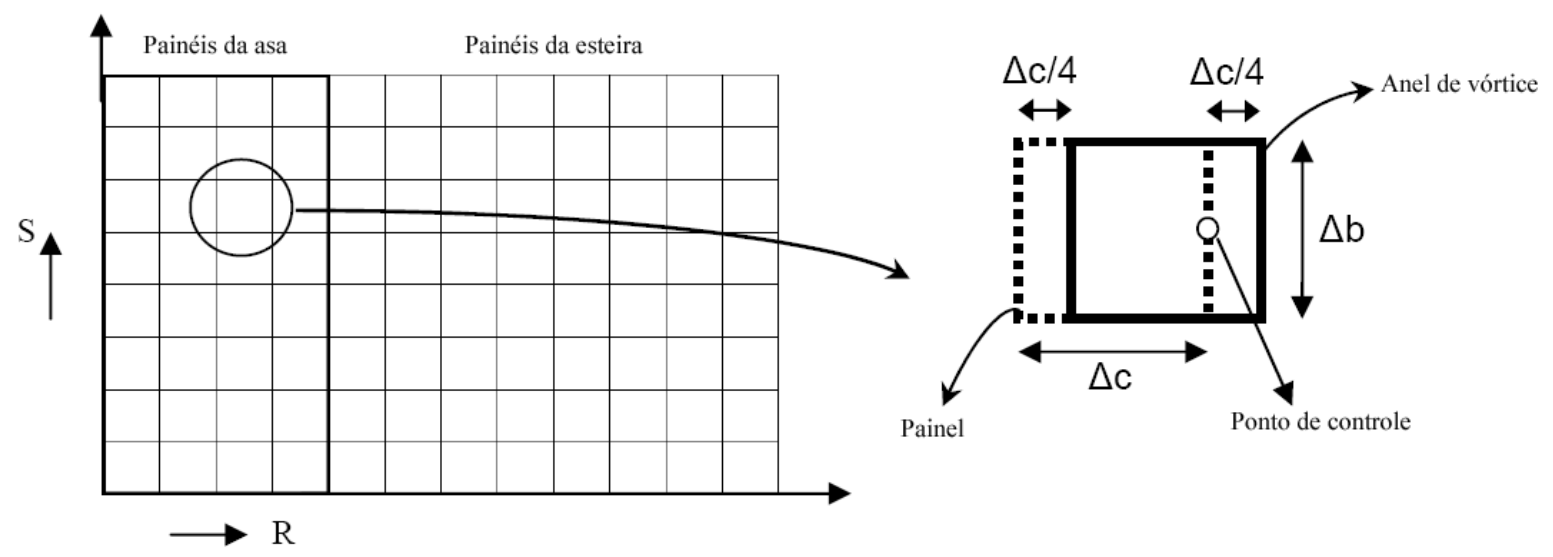

Figura 5. Método de malha de vórtices para uma asa engastada

Uma malha de vórtices típica para um problema de escoamento tridimensional é mostrada na figura 5. O segmento frontal de cada anel de vórtice é localizado a um quarto da linha de corda e o ponto de controle, onde se aplica a condição de contorno (a componente 
normal da velocidade do escoamento é zero através do contorno sólido da asa), a três quartos, correspondendo ao centro de cada anel de vórtice.

$$
\left(\nabla \phi+\boldsymbol{v}_{\text {movimento }}+\boldsymbol{v}_{\text {esteira }}\right) \cdot \boldsymbol{n}=0
$$

onde $\nabla \phi$ é o gradiente do potencial de velocidade que corresponde a perturbação da velocidade induzida pelas singularidades dos vórtices na asa onde $\boldsymbol{v}_{\text {movimento }}$ é a velocidade em razão do movimento da asa (componente da velocidade do escoamento livre adicionado às velocidades dos pontos de controle em razão da deformação estrutural da asa) e $\boldsymbol{v}_{\text {esteira }}$ é a velocidade induzida pela esteira nos pontos de controle e $\boldsymbol{n}$ representa a direção da normal da superfície da asa para os pontos de controle. A condição de controle deve ser satisfeita para cada passo de tempo da solução não estacionária e desta forma corrigir os valores para a circulação das singularidades de vórtices obtidas. A velocidade induzida para um ponto arbitrário $P$ por um segmento de reta de um anel de vórtice apontando do ponto 1 ao ponto 2 é dada pela lei de Biot-Savart.

$$
\boldsymbol{V}=\frac{\Gamma}{4 \pi} \frac{\boldsymbol{r}_{1} \times \boldsymbol{r}_{2}}{\left|\boldsymbol{r}_{1} \times \boldsymbol{r}_{2}\right|^{2}}\left(\frac{\boldsymbol{r}_{1}}{\left|\boldsymbol{r}_{1}\right|}-\frac{\boldsymbol{r}_{2}}{\left|\boldsymbol{r}_{2}\right|}\right) \cdot \boldsymbol{r}_{1}-\boldsymbol{r}_{2}
$$

onde as bordas do vórtice segmentado para um ponto arbitrário $P$ são localizadas pelos vetores $\boldsymbol{r}_{1}$ e $\boldsymbol{r}_{2}$ e $\Gamma$ é a intensidade do vórtice (circulação ao redor do segmento de vórtice). De acordo com a Eq. (23), a perturbação da velocidade induzida pelas singularidades dos vórtices na asa (primeiro termo da condição de contorno, Eq. (23)) depende das características geométricas da grade aerodinâmica (posição das extremidades dos anéis de vórtices e pontos de controle) e dos valores da circulação. É importante notar que a circulação na asa deve ser determinada para cada passo de tempo do esquema da solução numérica. $\mathrm{O}$ 
procedimento básico é assumir a circulação igual à unidade $(\Gamma=1)$ na Eq. (23). Os vetores $\boldsymbol{r}_{1}$ e $\boldsymbol{r}_{2}$ são conhecidos (da solução das equações de movimento (Eqs. (21a) e 21b)) e a quantidade relativa à velocidade induzida em um ponto de controle por um vórtice reto de circulação unitária é conhecida como coeficiente de influência e é simplesmente obtida através da relação geométrica dada pela Eq. (23).

Se a superfície da asa tem $m$ painéis ( $m=R \times S$, onde $R$ e $S$ representam o número de painéis ao longo da corda e envergadura respectivamente) e conseqüentemente $m$ anéis de vórtices e pontos de controle, a condição de contorno em termos dos coeficientes de influência pode ser expressa como:

$$
\left[\begin{array}{cccc}
a_{11} & a_{12} & \cdots & a_{1 m} \\
a_{21} & a_{22} & \cdots & a_{2 m} \\
\vdots & \vdots & \ddots & \vdots \\
a_{m 1} & a_{m 2} & \cdots & a_{m m}
\end{array}\right]\left\{\begin{array}{c}
\Gamma_{1} \\
\Gamma_{2} \\
\vdots \\
\Gamma_{m}
\end{array}\right\}=-\left\{\begin{array}{c}
\boldsymbol{v}_{\text {movimento }_{1}}+\boldsymbol{v}_{\text {esteira }_{1}} \\
\boldsymbol{v}_{\text {movimento }_{2}}+\boldsymbol{v}_{\text {esteira }_{2}} \\
\vdots \\
\boldsymbol{v}_{\text {movimento }_{m}}+\boldsymbol{v}_{\text {esteira }_{m}}
\end{array}\right\} \cdot\left\{\begin{array}{c}
\boldsymbol{n}_{1} \\
\boldsymbol{n}_{2} \\
\vdots \\
\boldsymbol{n}_{m}
\end{array}\right\}
$$

onde $a_{K L}$ é o coeficiente de influência que relaciona a circulação para o anel de vórtice $K$ para o produto interno da velocidade perturbada para o ponto $L$. Ambos contadores $K$ e $L$ podem ter valores de 1 até $R \times S$. Por exemplo, para encontrar todos os anéis de vórtice que estão influenciando o ponto $K$, um laço de busca interno é necessário com o contador $L=1 \rightarrow S \times R$. As incógnitas deste conjunto de equações lineares são as circulações $\Gamma_{m}$ para cada anel de vórtice. Utilizando-se a regra da mão direita, os termos da Eq. (24) são facilmente obtidos como descritos a seguir.

O termo $v_{\text {movimento }}$ é dado pela velocidade de fluxo livre somado às velocidades dos pontos de controle em razão das deformações estruturais da asa. O fluxo livre é sempre conhecido; as velocidades dos pontos de controle são determinadas através da solução do modelo por elementos finitos (EF) eletromecanicamente acoplado no domínio do tempo. As 
velocidades induzidas pela esteira $v_{\text {esteira }}$ são obtidas através da Eq. (23). A cada passo de tempo, novos anéis de vórtice são formados e adicionados à esteira através do bordo de fuga. A condição de Kutta é satisfeita impondo os valores de circulação dos anéis de vórtice gerados mais recentemente para cada passo de tempo, como os mesmos no bordo de fuga no passo anterior.

A circulação dos anéis de vórtice na esteira permanece inalterada e a esteira não carrega cargas aerodinâmicas. Os valores de circulação para os anéis de vórtice colocados na asa são obtidos da solução do sistema de equações lineares dado pela Eq. (24). Portanto, o carregamento aerodinâmico pode ser calculado a partir da equação não-estacionária de Bernoulli.

$$
p_{l}-p_{u}=\frac{1}{2} \rho\left(V_{u}^{2}-V_{l}^{2}\right)+\left(\frac{\partial \phi_{u}}{\partial t}-\frac{\partial \phi_{l}}{\partial t}\right)
$$

onde $p$ é a pressão estática e os subscritos $u$ e $l$ referem-se à superfície superior e inferior dos painéis. O último termo no lado direito da Eq. (25) representa o carregamento não-estacionário no painel (BENINI; BELO; MARQUES, 2004) e pode ser expresso em termos da circulação como:

$$
\frac{\partial \phi_{u}}{\partial t}-\frac{\partial \phi_{l}}{\partial t}=\frac{\Gamma(t)-\Gamma(t-1)}{\Delta t}
$$

onde $t$ é o tempo e $\Delta t$ é o passo de tempo.

O primeiro termo da Eq. (25) é obtido através do teorema de Kutta-Joukowsky e é relacionado à parte estacionária da solução,

$$
\frac{1}{2}\left(V_{u}^{2}-V_{l}^{2}\right)=\frac{V_{\infty} \Gamma \Delta b \cos \alpha}{A}
$$


onde $V_{\infty}$ é a velocidade do fluxo livre, $\Delta b$ é a largura do painel (na direção da envergadura), $\alpha$ é o angulo de ataque local e $A$ é a área de um painel. $\mathrm{O}$ carregamento normal de cada painel é dado pela soma das cargas estacionária (Eq. 27) e não-estacionária (Eq. 26). Vale à pena mencionar que a circulação local é necessária na equação acima e é igual a $\Gamma_{i j}$ para os painéis do bordo de ataque, sendo igual a $\Gamma_{i j}-\Gamma_{i-1, j}$ para todos os outros elementos. $\mathrm{O}$ contador $i$ procura pela corda $(i=1 \rightarrow R)$ e $j$ procura pela envergadura $(j=1 \rightarrow S)$. O procedimento do painel de malha leva a primeira linha da corda $(i=1)$ e procura pela envergadura com $j=1 \rightarrow S$ e assim por diante.

\subsection{Acoplamento entre modelos aerodinâmico e estrutural.}

As equações de movimento obtidas através da formulação dos elementos finitos podem ser representadas no domínio modal como:

$$
\begin{gathered}
\overline{\boldsymbol{M}} \ddot{\boldsymbol{\eta}}+\overline{\boldsymbol{C}} \dot{\boldsymbol{\eta}}+\overline{\boldsymbol{K}} \boldsymbol{\eta}-\boldsymbol{\Phi}^{t} \tilde{\boldsymbol{\Theta}} v_{p}=\Phi_{a}^{t} \boldsymbol{F}_{a} \\
C_{p} \dot{v}_{p}+\frac{v_{p}}{R_{l}}+\tilde{\boldsymbol{\Theta}}^{t} \boldsymbol{\Phi}^{t} \dot{\boldsymbol{\eta}}=0
\end{gathered}
$$

onde $\eta$ é o vetor de coordenadas modais, $\Phi$ é a matriz modal (massa normalizada de modo que a matriz de massa modal $\overline{\boldsymbol{M}}$ é a matriz identidade), $\overline{\boldsymbol{C}}$ é a matriz diagonal de amortecimento modal, $\overline{\boldsymbol{K}}$ é a matriz diagonal de rigidez e $\boldsymbol{F}$ é o vetor do carregamento aerodinâmico e $\Phi_{a}$ é a matriz modal em coordenadas aerodinâmicas. Esta é a forma de desacoplamento das equações de movimento (no sentido modal), portanto, a solução pode ser obtida considerando-se os modos mais significantes do problema aeroelástico. 
A solução do modelo piezoaeroelástico no domínio do tempo tem uma complicação particular: a dependência entre a solução eletromecânica e a solução aerodinâmica que originalmente são resolvidas para malhas distintas (nós da malha de EF e pontos de controle da malha de vórtices). Esta dependência é explicada a seguir: para obter o carregamento aerodinâmico é necessário saber a resposta estrutural (e consequientemente a resposta elétrica), que é diretamente dependente na previsão do carregamento aerodinâmico. Um método iterativo que leva em conta a interação entre o domínio aerodinâmico e eletromecânico é utilizado para solucionar as equações de movimento. Porém, o carregamento aerodinâmico e o movimento estrutural são obtidos utilizando-se métodos numéricos distintos com malhas distintas. Portanto, os nós do EF estrutural e os pontos de controle aerodinâmicos podem ser relacionados como:

$$
\Psi_{a}=\boldsymbol{G} \Psi
$$

Onde $\Psi$ é o vetor global de coordenadas mecânicas (do modelo de EF) e $\Psi_{a}$ é o vetor de coordenadas mecânicas dos pontos de controle da malha aerodinâmica, e $\boldsymbol{G}$ é a matriz de transformação. A mesma matriz de transformação pode ser utilizada para escrever a forma dos modos estruturais em termos de coordenadas aerodinâmicas:

$$
\Phi_{a}=\boldsymbol{G} \Phi
$$

Onde $\Phi_{a}$ é a matriz modal em coordenadas aerodinâmicas (extremidades dos anéis de vórtices).

Considerando que o trabalho virtual feito pelas forças aerodinâmicas é o mesmo para as representações em ambos os domínios, este pode ser expresso por:

$$
\delta \Psi_{a}^{t} \boldsymbol{F}_{a}=\delta \Psi^{t} \boldsymbol{F}
$$


Onde $\boldsymbol{F}_{a}$ são as cargas aerodinâmicas dos pontos de controle e $\boldsymbol{F}$ são as cargas aerodinâmicas na malha estrutural (nós). Utilizando as Eqs. (30) e (31), as equações de movimento (28a e $28 \mathrm{~b})$, podem ser escritas como,

$$
\begin{gathered}
\overline{\boldsymbol{M}} \ddot{\boldsymbol{\eta}}+\overline{\boldsymbol{C}} \dot{\boldsymbol{\eta}}+\overline{\boldsymbol{K}} \boldsymbol{\eta}-\boldsymbol{\Phi}^{t} \tilde{\boldsymbol{\Theta}} v_{p}=\boldsymbol{\Phi}_{a}^{t} \boldsymbol{F}_{a} \\
C_{p} \dot{v}_{p}+\frac{v_{p}}{R_{l}}+\tilde{\boldsymbol{\Theta}}^{t} \boldsymbol{\Phi}^{t} \dot{\boldsymbol{\eta}}=0
\end{gathered}
$$

E as cargas aerodinâmicas são transformadas para os nós da malha estrutural. Em adição, os deslocamentos estruturais obtidos para os nós da malha de EF para cada passo de tempo devem ser obtidos nas extremidades dos anéis de vórtices (malha aerodinâmica) para o cálculo das cargas aerodinâmicas. Desta forma, outra matriz de transformação é apresentada para converter as coordenadas modais para as extremidades dos anéis de vórtices.

$$
\boldsymbol{x}_{a}=\Phi_{a}^{*} \boldsymbol{\eta}
$$

Onde $\boldsymbol{x}_{a}$ é o vetor de coordenadas aerodinâmicas e as matrizes $\boldsymbol{\Phi}_{a}$ e $\boldsymbol{\Phi}_{a}^{*}$ são interpoladas neste trabalho utilizando o método de splines de superfícies. As equações de movimento, podem ser escritas como um sistema de equações diferenciais ordinárias de primeira ordem $(2 n+1)$, onde $n$ é o número de modos considerados na solução.

Assumindo o vetor $\boldsymbol{y}$ como sendo,

$$
\boldsymbol{y}=\left\{\begin{array}{lll}
\boldsymbol{y}_{1} & \boldsymbol{y}_{2} & y_{3}
\end{array}\right\}^{t}
$$

Onde $\boldsymbol{y}_{1}=\boldsymbol{\eta}, \boldsymbol{y}_{2}=\dot{\boldsymbol{\eta}}$ e $y_{3}=v_{p}$. Tendo a derivada de $\boldsymbol{y}$ e utilizando as equações de movimento: mecânica e elétrica (Eqs. 32a e 32b), podem-se ter equações diferenciais ordinárias de primeira ordem $(2 n+1)$,

$$
\dot{\boldsymbol{y}}=\left\{\begin{array}{lll}
\dot{\boldsymbol{y}}_{1} & \dot{\boldsymbol{y}}_{2} & \dot{y}_{3}
\end{array}\right\}^{t}
$$

$\mathrm{E}$, 


$$
\begin{gathered}
\dot{\boldsymbol{y}}_{1}=\boldsymbol{y}_{2} \\
\dot{\boldsymbol{y}}_{2}=\boldsymbol{\Phi}_{a}^{t} \boldsymbol{F}_{a}-\overline{\boldsymbol{C}} \boldsymbol{y}_{2}-\overline{\boldsymbol{K}} \boldsymbol{y}_{1}-\boldsymbol{\Phi}^{t} \tilde{\boldsymbol{\Theta}} \boldsymbol{y}_{3} \\
\dot{y}_{3}=\frac{1}{C_{p}}\left(-\tilde{\Theta}^{t} \boldsymbol{\Phi}^{t} \boldsymbol{y}_{2}-\frac{y_{3}}{R_{l}}\right)
\end{gathered}
$$

As equações diferenciais ordinárias $(2 n+1)$ com o carregamento aerodinâmico aplicado para os nós do EF são resolvidas utilizando-se um método preditor-corretor que acumula para as interações entre o domínio aerodinâmico e elétrico (BENINI; BELO; MARQUES, 2004; KATZ; PLOTKIN, 2001). O método preditor-corretor de AdamsBashforth-Moulton é usado neste trabalho e uma descrição detalhada do método pode ser encontrada na literatura (LAMBERT, 1991). As equações do preditor utilizam a família de métodos Adams-Bashforth e as equações do corretor utiliza a família de métodos AdamsMoulton. O erro de truncamento local (ETL) é dado pela estimativa de Milne e o termo de correção pode ser incluso, o que melhora a precisão do resultado em cada passo.

\subsection{A turbulência}

A turbulência pode ser considerada como um movimento do ar através do qual a aeronave passa (WRIGHT; COOPER, 2007). Movimentos de turbulência no ar geralmente são conhecidos como rajadas (WAH, 2009).

Qualquer componente da velocidade do ar (também chamada "velocidade de rajada") perpendicular (vetor normal) ao trajeto de vôo (Figura 6) para o caso de uma rajada vertical, alterará a incidência efetiva das superfícies aerodinâmicas, causando mudanças repentinas nas forças de sustentação e conseqüentemente uma resposta dinâmica da aeronave envolvendo uma deformação flexível (WRIGHT; COOPER, 2007). 


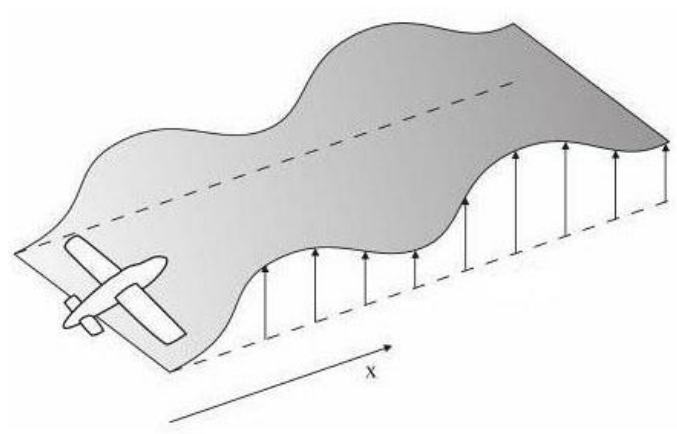

Figura 6. Aeronave encontrando uma área de turbulência Fonte: (WRIGHT; COOPER, 2007).

Embora a turbulência seja um fenômeno bastante complexo, para fins de representação e estudos, foram idealizadas duas categorias (WRIGHT; COOPER, 2007):

a) rajadas discretas: a velocidade da rajada varia de forma determinística, idealiza-se um evento discreto que a aeronave encontra no seu trajeto de vôo; freqüentemente, adota-se a representação dada pela função ' 1 -cos'

b) turbulência contínua: a velocidade da rajada varia randomicamente, ou seja, de forma aleatória.

A resposta a uma rajada discreta é resolvida no domínio do tempo enquanto que a resposta de uma turbulência contínua é resolvida no domínio da freqüência, utilizando-se um método de densidade espectral de potência (WRIGHT; COOPER, 2007).

Rajadas e turbulência podem ser verticais, laterais ou ter qualquer outra orientação relativa ao trajeto de vôo, normalmente os casos: lateral e vertical são tratados separadamente. Em uma aeronave simétrica, uma rajada vertical provocará elevação (ou mergulho) / arfagem, enquanto uma rajada lateral provocará movimentos de derrapagem/guinada/rolamento, todos estes movimentos estarão acoplados em uma aeronave assimétrica. Para fins de cálculos, normalmente é assumido que não existe variação da velocidade da rajada em toda a extensão da aeronave (ou com a altura, no caso de rajadas laterais) (WRIGHT; COOPER, 2007). 
A maneira pela qual a turbulência tem sido modelada tem alterado significantemente durante os anos, particularmente pela dificuldade da definição da entrada do carregamento externo e da realização de cálculos. Apesar de não estar dentro do escopo deste trabalho, uma revisão histórica pode ser encontrada em FUNG (1993), HOBLIT (1988), FLOMENHOFT (1997) e BISPLINGHOF et al. (1996).

Evidências consideradas mostram que rajadas severas ocorrem mais ou menos como rajadas individuais (Figura 7). Na FAR (Federal Aviation Regulation) Parte 25, Seção 341 e também na CS-25 (certificação atual da Agência Européia para a Segurança da Aviação); estão descritos os padrões para avaliação dos efeitos de rajadas e turbulências na estrutura de uma aeronave.

\subsubsection{Rajadas discretas}

Neste trabalho, uma rajada discreta é modelada utilizando a aproximação 1-cos (CHUDÝ, 2004; IHS ESDU - 04024, 2004; FAA, 1996; CS-25, 2007; WAH, 2009). Nesta situação, o campo de ação da turbulência é reduzido para a forma de uma rajada discreta dominante. A forma da rajada é dada por:

$$
\begin{gathered}
U=\frac{U_{d s}}{2}\left[1-\cos \left(\frac{\pi s}{H}\right)\right] \\
U_{d s}=U_{r e f} F_{g}\left(\frac{H}{350}\right)^{\frac{1}{6}}
\end{gathered}
$$

onde $s$ é a distância penetrada na rajada (em pés), $U_{d s}$ é a velocidade da rajada e $H$ é o gradiente da rajada, que é a distância (em pés) paralela à trajetória da aeronave. $U_{\text {ref }}$ é a 
velocidade de referência da rajada (56 pés no nível do mar) e $F_{g}$ é usado para considerar que diferentes configurações de aeronave reagirão de formas diferentes ao passar pela mesma rajada. As expressões são válidas para $0 \leq s \leq 2 H$.

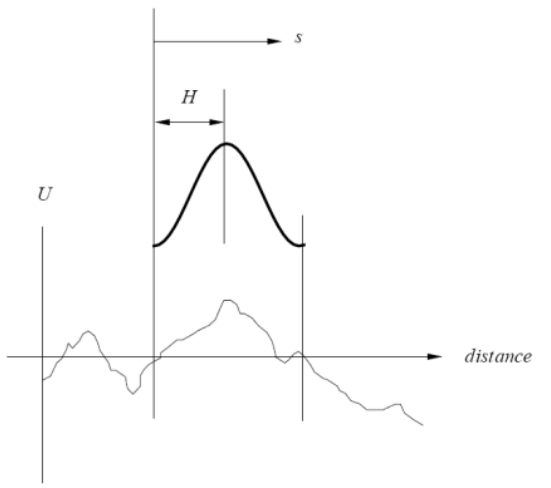

Figura 7. Uma rajada discreta modelada utilizando a forma (1-cos) dentro de uma grande região de turbulência contínua. 


\section{Resultados}

\subsection{Estrutura Modelada e Estudos de Caso}

Neste item são apresentados os resultados das simulações realizadas com o modelo piezoaeroelástico apresentado no Capítulo 3 como a combinação de um modelo por elementos finitos eletromecanicamente acoplado e um modelo aerodinâmico não-estacionário. A asa elástica é aqui representada por uma placa plana engastada e com duas camadas de piezocerâmica (PZT-5A) embutidas em sua superfície superior e inferior (intra e extradorso). Uma resistência elétrica conectada em série aos eletrodos das camadas piezocerâmicas é considerada no domínio elétrico do problema com o intuito de se avaliar a potência elétrica gerada e a influência da geração de energia sobre o comportamento aeroelástico da asa. Vale ressaltar que as implicações de conexões em série ou em paralelo dos eletrodos de geradores piezelétricos de energia foi discutida no Capítulo 3.

A resposta piezoaeroelástica da asa geradora é apresentada no domínio do tempo, onde a potência elétrica, a voltagem e o deslocamento na extremidade livre da asa são analisados para várias velocidades do escoamento e também para um conjunto de resistências elétricas $\left(10^{2}, 10^{3}, 10^{4}, 10^{5}, 10^{6} \Omega\right)$. As condições iniciais são fixadas em zero, a densidade do ar utilizada é $1,225 \mathrm{~kg} / \mathrm{m}^{3}$ e a entrada assumida para as simulações é uma perturbação causada por uma rajada discreta do tipo 1-cos, detalhada ao longo do Capítulo 3.

Dentre as diversas simulações realizadas, apresentam-se resultados para três faixas de velocidades de escoamento escolhidas em função do amortecimento aerodinâmico, ou seja, baixa velocidade (pequena influência aerodinâmica), faixa de velocidades em torno da região de máximo amortecimento aerodinâmico e por último na velocidade de flutter em curto circuito (carga resistiva tendendo a zero) da asa. Duas configurações de eletrodos foram investigadas para estas velocidades. A primeira considera eletrodos contínuos cobrindo as 
camadas piezocerâmicas e a segunda, eletrodos segmentados na metade da corda (Figuras 8a e 8b). As características das respostas piezoaeroelásticas dos casos com eletrodos contínuos e segmentados são comparadas para as velocidades e resistências aqui consideradas.

Para a configuração de eletrodos contínuos as camadas piezocerâmicas (A e B) são polarizadas em sentidos opostos, como apresentado na Figura 8a. O eletrodo inferior de A é conectado com o eletrodo superior de B e os outros dois eletrodos restantes conectados a carga resistiva, ou seja, conexão em série. Para um modo de vibrar de torção com linha nodal correspondente a linha central da largura da placa (ou metade da corda da asa), o cancelamento da saída elétrica ocorre em ambas as camadas de piezocerâmicas.

A configuração segmentada de eletrodos visa se evitar o cancelamento da saída elétrica dos modos de torção. Assim, quando os quatro eletrodos das camadas piezocerâmicas são segmentados na metade da corda originam-se oito eletrodos, como apresentado na Figura 8b. Para evitar o cancelamento da saída elétrica do modo fundamental de torção, a alternativa escolhida foi combinar as saídas elétricas das camadas superiores (A1 e A2) e das camadas inferiores (B1 e B2) em série. A conexão em paralelo de A1 e A2 pode ser combinada com a conexão em paralelo de B1 e B2 da seguinte forma: o eletrodo inferior de A1, o eletrodo superior de A2, o eletrodo superior de B1 e o inferior de B2 são conectados. O eletrodo superior de A1 e o inferior de A2 são conectados a um terminal do resistor externo enquanto o eletrodo inferior de B1 e o superior de B2 conectados ao terminal oposto do resistor. É importante destacar que a configuração apresentada vai resultar no cancelamento da saída elétrica de modos de flexão. Na prática é necessário o uso de diodos para evitar este problema. Nas simulações aqui realizadas com eletrodos segmentados é assumida a combinação conveniente para cada modo de vibrar, ou seja, o cancelamento de saída elétrica é evitado para modos de flexão e de torção. Para isso, o sinal da constante piezelétrica se torna dependente do modo de vibrar, ou seja, sempre o mesmo sinal para modos de flexão e sinal 
invertido a partir da região de segmentação de eletrodos. Desta forma, o vetor de acoplamento eletromecânico é modificado com o modo de vibrar. Na solução modal aqui apresentada através das Equações 28, a inversão de sinal resulta na simples troca do termo no vetor de acoplamento eletromecânico pelo obtido para o caso segmentado quando este for relacionado a um modo de torção. Um ponto importante é que a capacitância efetiva e o vetor de acoplamento eletromecânico são os mesmos no caso de eletrodos contínuos e segmentados (exceto pela troca de sinais).

As dimensões da asa utilizada neste trabalho são $1200 \times 240 \times 3 \mathrm{~mm}^{3}$. As camadas de piezocerâmica incorporadas são idênticas e tem a mesma largura da corda da asa, cobrem $30 \%$ da envergadura (do engastamento para a ponta da asa) e cada camada tem a espessura de $0,5 \mathrm{~mm}$
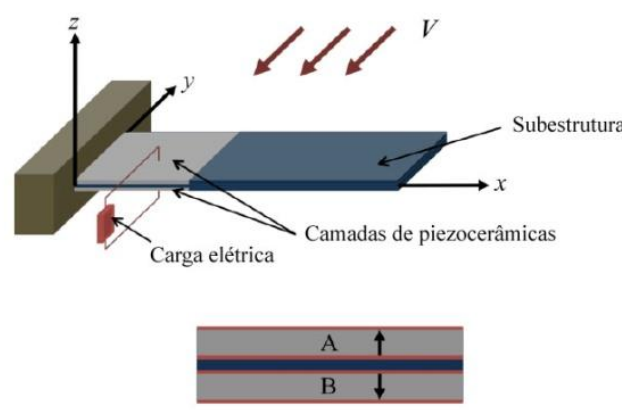

a)
- Piezocerâmica $\uparrow$ Polarização

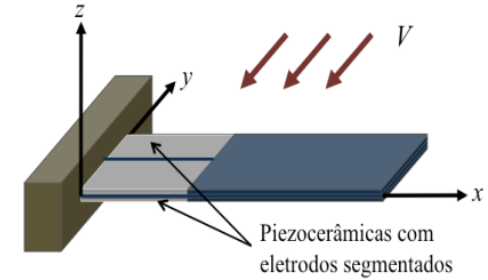

$\mathrm{A} 1 \uparrow \mid \uparrow \mathrm{A} 2$ $\mathrm{B} 1 \downarrow \downarrow \mathrm{B} 2$

b) \ubestrutura $\square$ Piezocerâmica $\uparrow$ Polarização $\quad$ Eletrodos

Figura 8. Asa geradora de energia sob excitação do escoamento em corte da região com piezocerâmicas para e eletrodos contínuos (a) e segmentados (b).

A geometria e as propriedades do material utilizado na asa (liga de alumínio aeronáutico Al 2024-T3) estão apresentadas na Tabela 2. 
Tabela 2. Geometria e propriedades materiais da asa de alumínio com piezocerâmicas incorporadas

\begin{tabular}{lc}
\hline Comprimento da asa $(\mathrm{mm})$ & 1200 \\
Largura da asa $(\mathrm{mm})$ & 240 \\
Espessura da asa $(\mathrm{mm})$ & 3 \\
Módulo de Young da asa $(\mathrm{GPa})$ & 70.0 \\
Densidade de massa (subestrutura) $\left(\mathrm{kg} / \mathrm{m}^{3}\right)$ & 2750 \\
Constante proporcional $-\alpha(\mathrm{rad} / \mathrm{s})$ & 0.1635 \\
Constante proporcional $-\beta(\mathrm{s} / \mathrm{rad})$ & $4.17 \times 10^{-4}$ \\
\hline
\end{tabular}

As propriedades típicas da piezocerâmica PZT-5A, são mencionadas na Tabela 3.

Tabela 3. Propriedades materiais e eletromecânicas do PZT-5A

\begin{tabular}{lc}
\hline Densidade de massa $\left(\mathrm{kg} / \mathrm{m}^{3}\right)$ & 7800 \\
Permissividade $\varepsilon_{33}^{T}(\mathrm{nF} / \mathrm{m})$ & $1800 \times \varepsilon_{0}$ \\
$c_{11}^{E}, c_{22}^{E}(\mathrm{GPa})$ & 120.3 \\
$c_{12}^{E}(\mathrm{GPa})$ & 75.2 \\
$c_{13}^{E}, c_{23}^{E}(\mathrm{GPa})$ & 75.1 \\
$c_{33}^{E}(\mathrm{GPa})$ & 110.9 \\
$c_{66}^{E}(\mathrm{GPa})$ & 22.7 \\
$e_{31}, e_{32}\left(\mathrm{C} / \mathrm{m}^{2}\right)$ & -5.2 \\
$e_{33}\left(\mathrm{C} / \mathrm{m}^{2}\right)$ & 15.9 \\
\hline
\end{tabular}

A sequiência dos modos de vibrar da estrutura e as freqüências naturais foram inicialmente obtidas a partir do modelo por elementos finitos eletromecanicamente acoplado (De Marqui et al., 2009) para a condição de curto-circuito. Verifica-se o primeiro modo de flexão a 1,68 Hz, o segundo de flexão a 10,46 Hz, o primeiro de torção a $16,66 \mathrm{~Hz}$ e terceiro de flexão a $27,74 \mathrm{~Hz}$ e o segundo de torção a $48,65 \mathrm{~Hz}$. Os modos são apresentados na Figura 9. 

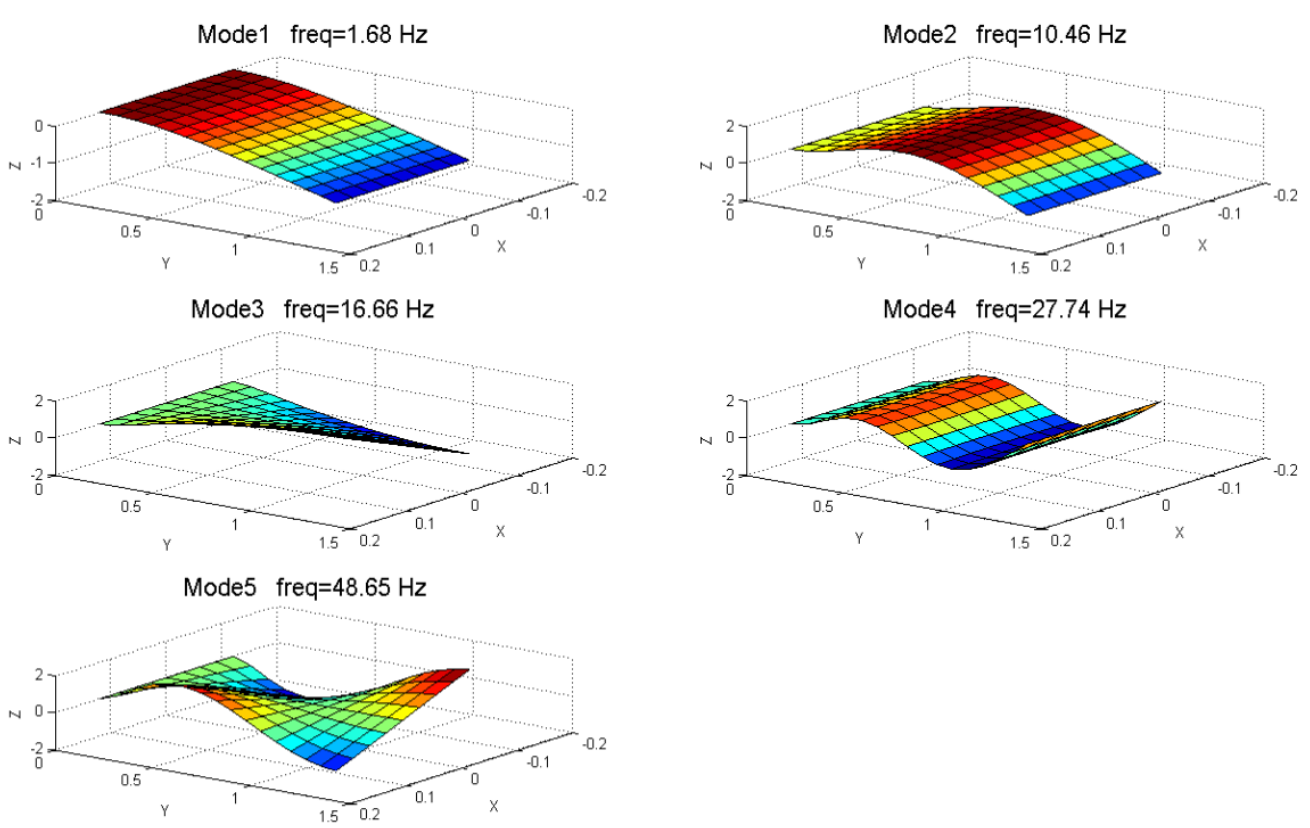

Figura 9. Modos de vibrar e freqüências naturais da asa obtidas com o modelo por EF para a condição de curto-circuito.

\subsection{Apresentação dos resultados}

O primeiro caso abordado nas simulações envolve eletrodos contínuos cobrindo as camadas de piezocerâmica (polarizadas em direções opostas) que estão conectadas em série com uma resistência elétrica (Figura 8a).

Segundo a fórmula estática de Pratt-Walker o valor de $H$ deve ser equivalente a 12,5 vezes o comprimento da corda, considerando que na asa utilizada nas simulações, a corda mede 0,24 metros, então o valor de $H$ deve ser 12,5 x 0,24= 3 metros, aproximadamente 9,84 pés. Mas nas simulações o valor de $H$ para a estrutura utilizada foi de 5 pés e o valor de $U_{d s}$ considerado foi de 3,0 pés/s. As simulações consideraram quatro passos de tempo para cada velocidade e resistência.

A história no tempo da voltagem para os cinco valores de resistências considerados neste trabalho e para a velocidade de $10 \mathrm{~m} / \mathrm{s}$ é apresentada na figura 10 . Nesta faixa de velocidades o amortecimento aerodinâmico é muito baixo, se comparado com o 
amortecimento estrutural, e o sistema piezoaeroelástico apresenta comportamento estável. Verifica-se o aumento da amplitude de voltagem com o aumento da resistência considerada no domínio elétrico do problema.

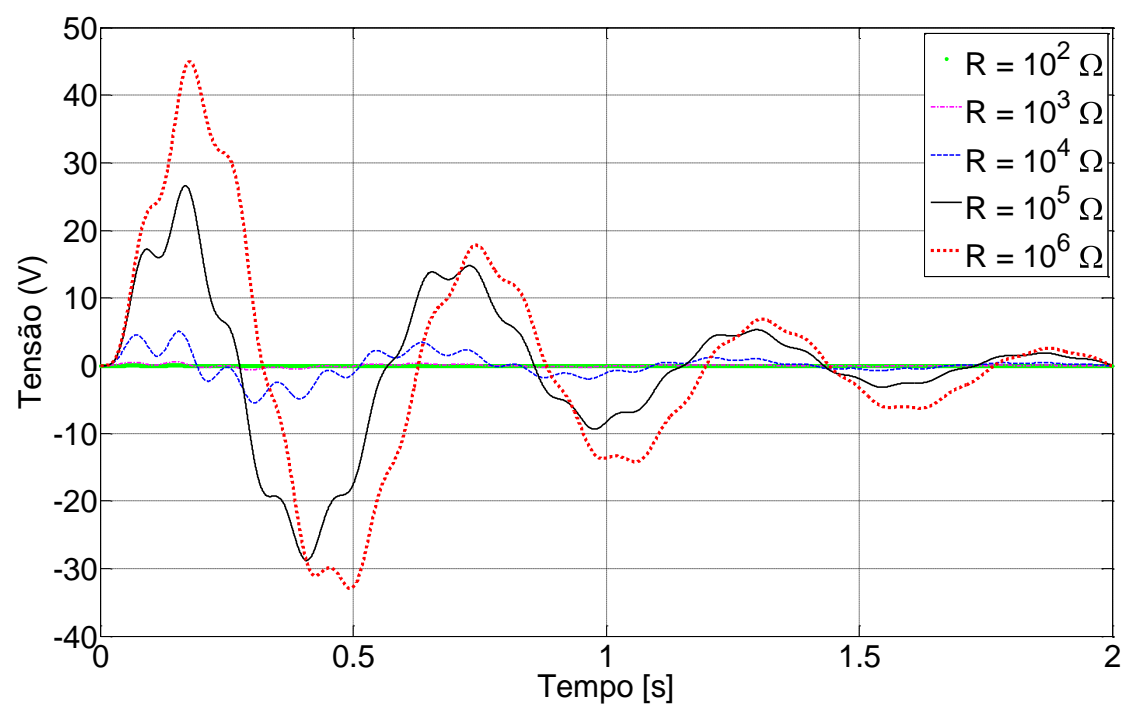

Figura 10. Voltagem para 5 diferentes valores de resistência elétrica utilizando eletrodos contínuos e velocidade do escoamento $10 \mathrm{~m} / \mathrm{s}$.

A potência elétrica extraída das oscilações aeroelásticas para a velocidade de $10 \mathrm{~m} / \mathrm{s}$ é apresentada na figura 11. Nesta faixa de velocidades as cargas aerodinâmicas não são elevadas e o valor máximo de potência está na ordem de $8 \mathrm{~mW}$. Observa-se que a potência elétrica aumenta com o aumento da resistência externa desde a condição próxima ao curto circuito até $R_{l}=10^{5} \Omega$. Quando a resistência é aumentada para a condição próxima de circuito aberto $\left(R_{l}=10^{6} \Omega\right)$ pode se obervar que a potência gerada é reduzida. Assim, a resistência de $R_{l}=10^{5} \Omega$ é a resistência ótima entre as testadas para este caso. 


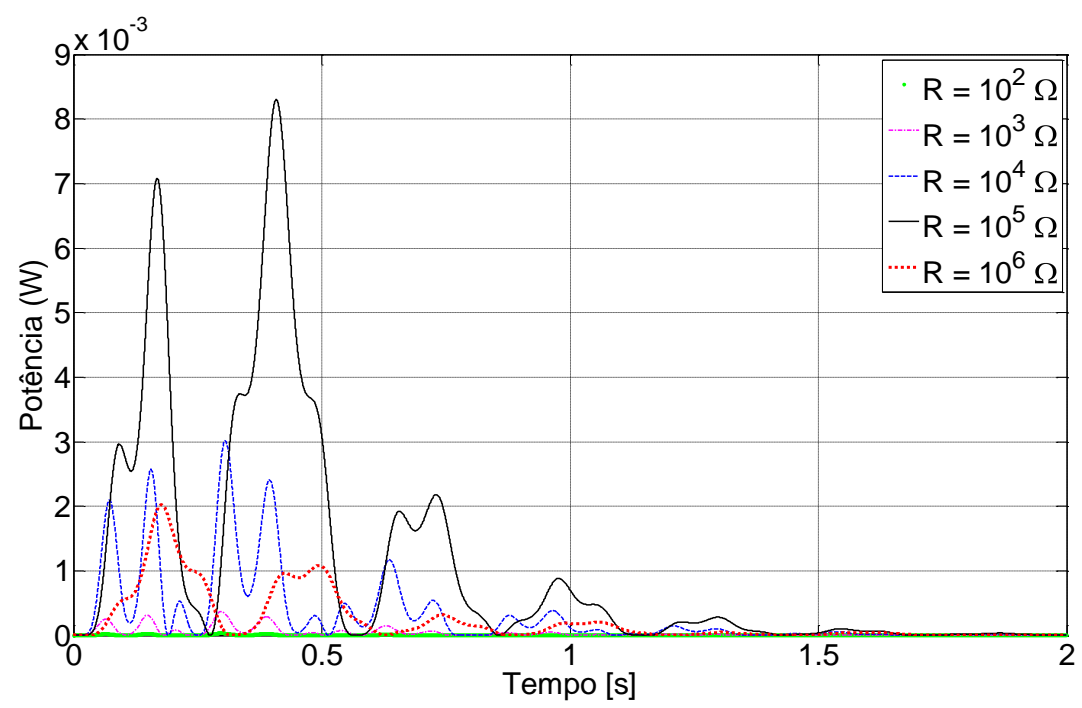

Figura 11. Potência gerada para 5 diferentes valores de resistência elétrica utilizando eletrodos contínuos e velocidade do escoamento $10 \mathrm{~m} / \mathrm{s}$.

Ainda com a velocidade do escoamento de $10 \mathrm{~m} / \mathrm{s}$, para o caso de eletrodos contínuos, o deslocamento na ponta da asa (medido na metade da corda) é apresentado na figura 12. Dois pontos interessantes devem ser destacados na análise dos deslocamentos mecânicos. Primeiro é a variação da frequência das respostas entre as condições de curto circuito $\left(R_{l}=10^{2} \Omega\right)$ e circuito aberto $\left(R_{l}=10^{6} \Omega\right)$ (Figura 13). Tal comportamento pode ser explicado devido a dependência das propriedades mecânicas do piezelétrico em relação as condições de contorno elétricas do problema. Assim o sistema oscila na frequência de ressonância de curto circuito para um caso e circuito aberto para o outro caso. O segundo ponto é o efeito shunt damping resistivo da geração piezelétrica de energia. A amplitude do movimento não é significativamente modificada a medida que a resistência externa é aumentada de $R_{l}=10^{2} \Omega$ até $R_{l}=10^{4} \Omega$. O máximo efeito shunt damping é observado para $R_{l}=10^{5} \Omega$, a resistência ótima entre as testadas. Quando a resistência é aumentada para a condição de circuito aberto $\left(R_{l}=10^{6} \Omega\right)$ a amplitude volta a aumentar. 


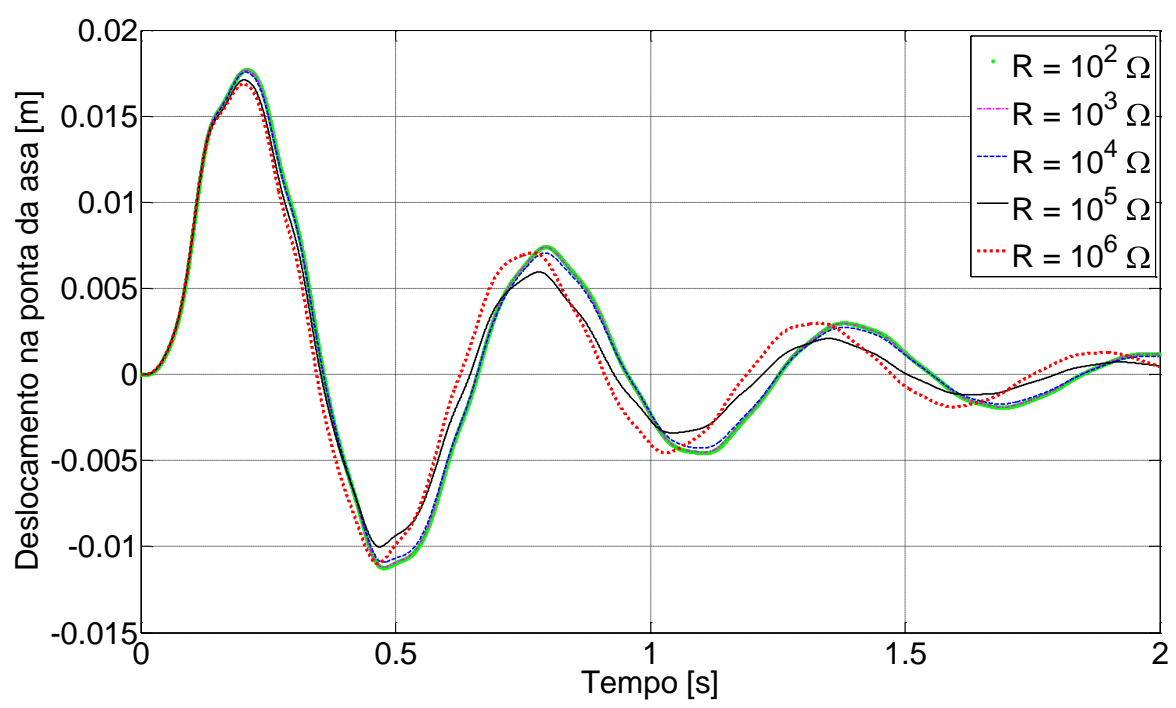

Figura 12. Deslocamento na ponta da asa para 5 diferentes valores de resistência elétrica utilizando eletrodos contínuos e velocidade do escoamento $10 \mathrm{~m} / \mathrm{s}$.

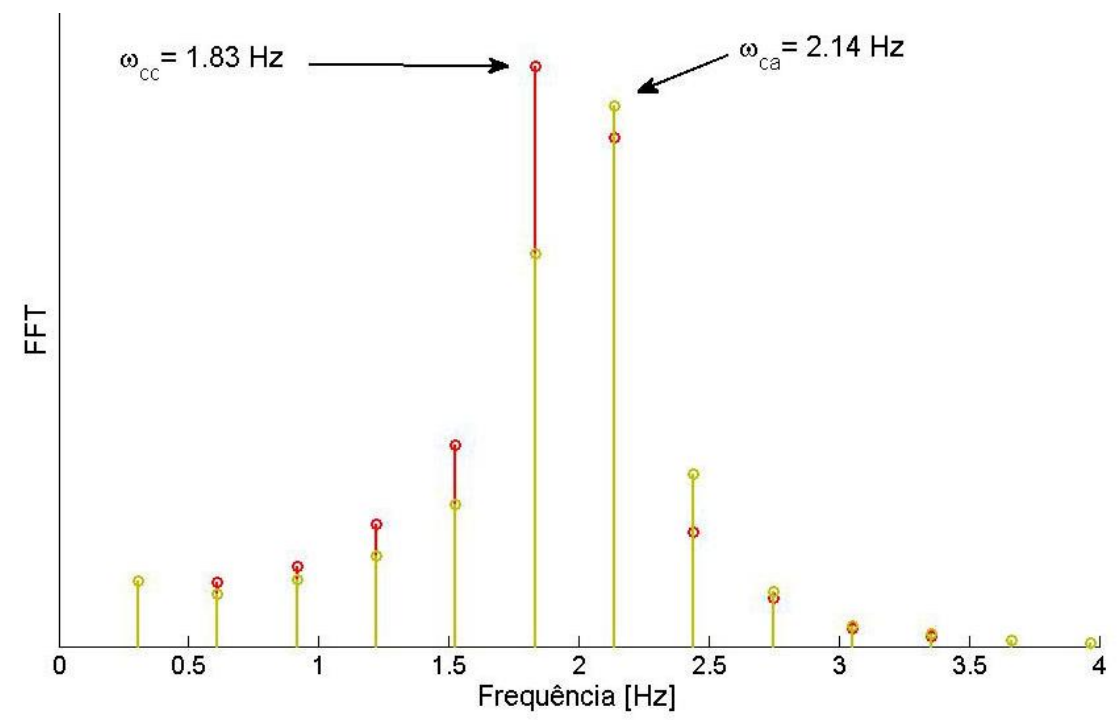

Figura 13. Deslocamento na ponta da asa - variação da frequência das respostas entre as condições de curto circuito $\left(R_{l}=10^{2} \Omega\right)$ e circuito aberto $\left(R_{l}=10^{6} \Omega\right)$

No segundo caso estudado a velocidade do escoamento foi aumentada para $20 \mathrm{~m} / \mathrm{s}$. Observa-se um aumento na voltagem, se comparado com o caso anterior de $10 \mathrm{~m} / \mathrm{s}$. Entretanto, observa-se também o aumento do amortecimento aerodinâmico com o aumento da velocidade do escoamento. Assim, as respostas são mais rapidamente amortecidas com o tempo (Figura 14). 


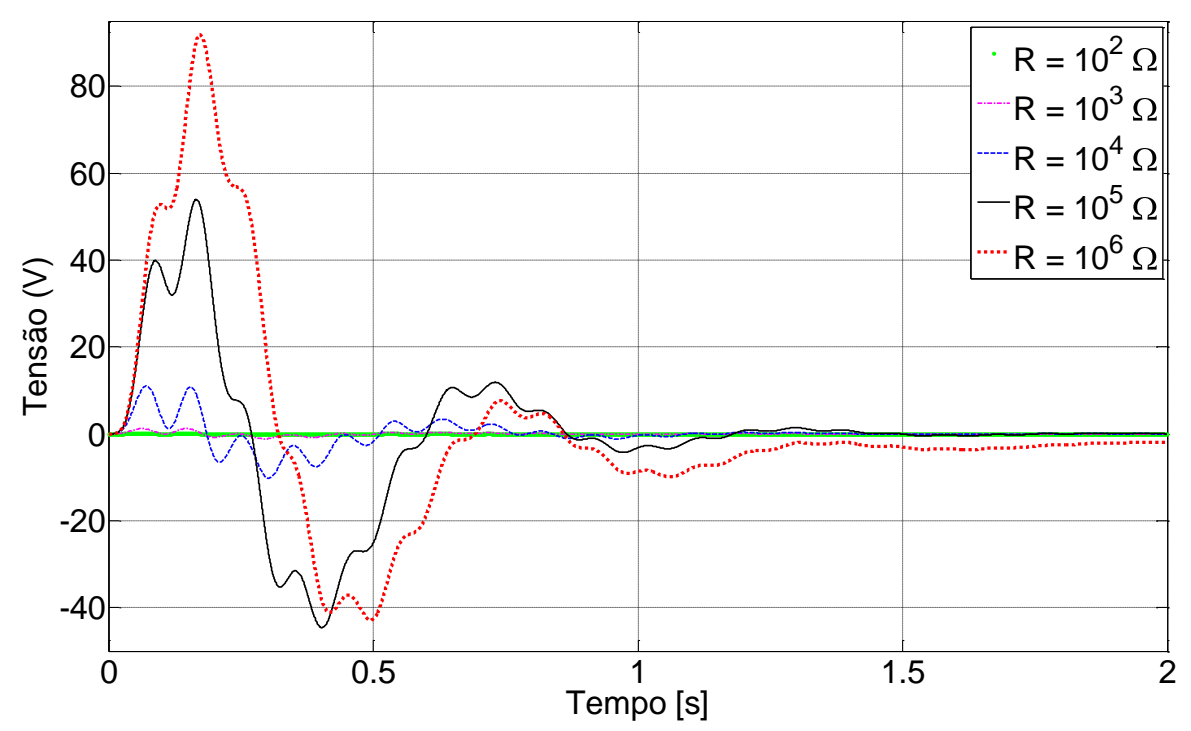

Figura 14. Voltagem para 5 diferentes valores de resistência elétrica utilizando eletrodos contínuos e velocidade do escoamento $20 \mathrm{~m} / \mathrm{s}$.

A potência gerada para a velocidade de $20 \mathrm{~m} / \mathrm{s}$ é observada na figura 15 . Apesar do pico ser maior que o pico gerado para a velocidade de escoamento de $10 \mathrm{~m} / \mathrm{s}$ nenhuma potência é gerada após 0,5 segundos já que as oscilações são mais rapidamente amortecidas neste caso. Ainda assim, o pico gerado é uma ordem de magnitude maior do que o caso de velocidade $10 \mathrm{~m} / \mathrm{s}$. Assim, maior carregamento aerodinâmico implica em maior pico, apesar do aumento do amortecimento.

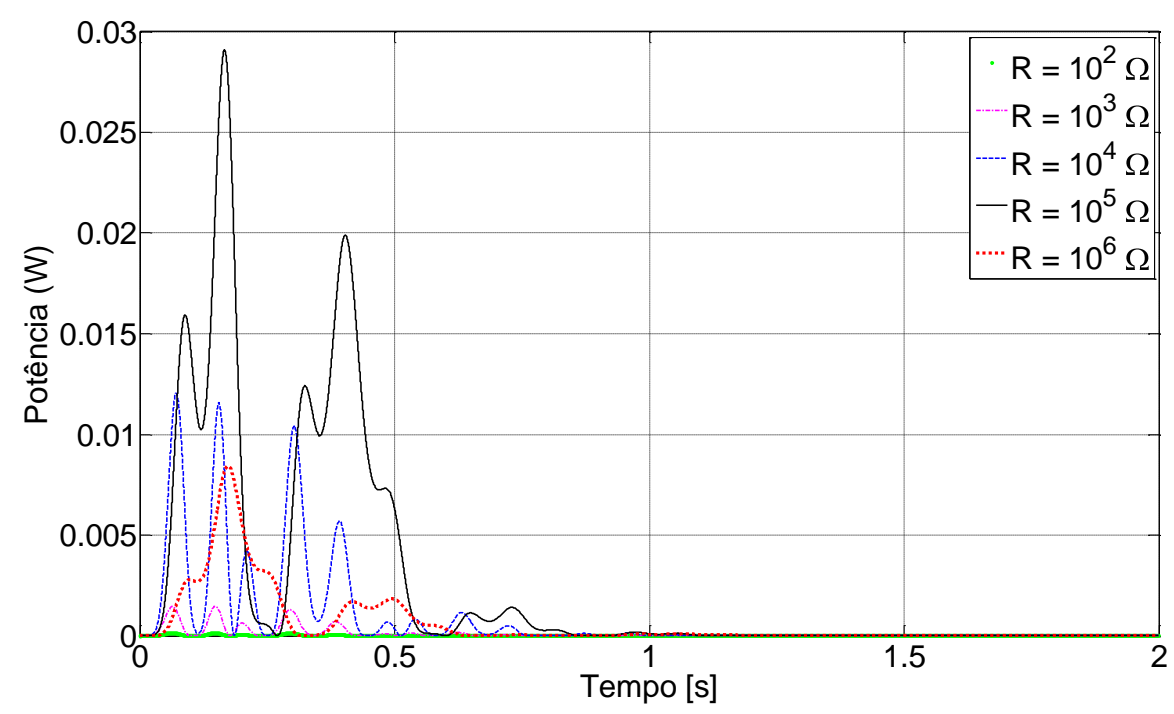

Figura 15. Potência gerada para 5 diferentes valores de resistência elétrica utilizando eletrodos contínuos e velocidade do escoamento $20 \mathrm{~m} / \mathrm{s}$. 
Ainda nas mesmas condições, o deslocamento na ponta da asa é apresentado na figura 16. Mesmo com o aumento do amortecimento aerodinâmico ainda é possível observar o efeito shunt damping resistivo da geração piezelétrica de energia.

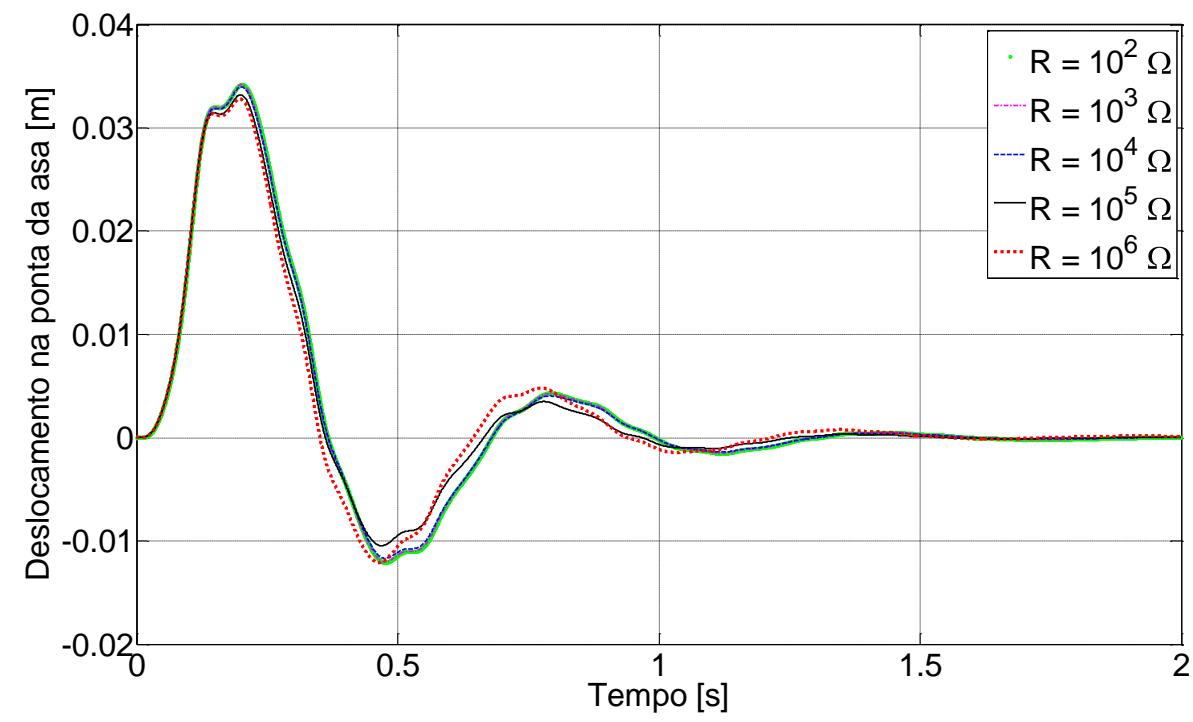

Figura 16. Deslocamento na ponta da asa para 5 diferentes valores de resistência elétrica utilizando eletrodos contínuos e velocidade do escoamento $20 \mathrm{~m} / \mathrm{s}$.

No terceiro caso estudado a velocidade do escoamento foi alterada para $35 \mathrm{~m} / \mathrm{s}$ e mantendo-se os eletrodos contínuos. Nesta situação, o amortecimento aerodinâmico encontra-se próximo ao seu valor máximo e as respostas elétricas e mecânicas são rapidamente amortecidas como pode se obervar nas figuras 17 até 19 . Apesar do aumento do carregamento aerodinâmico e aumento da amplitude das saídas elétricas, este caso (assim como anterior) não é interessante para a geração piezelétrica de energia devido ao amortecimento. 


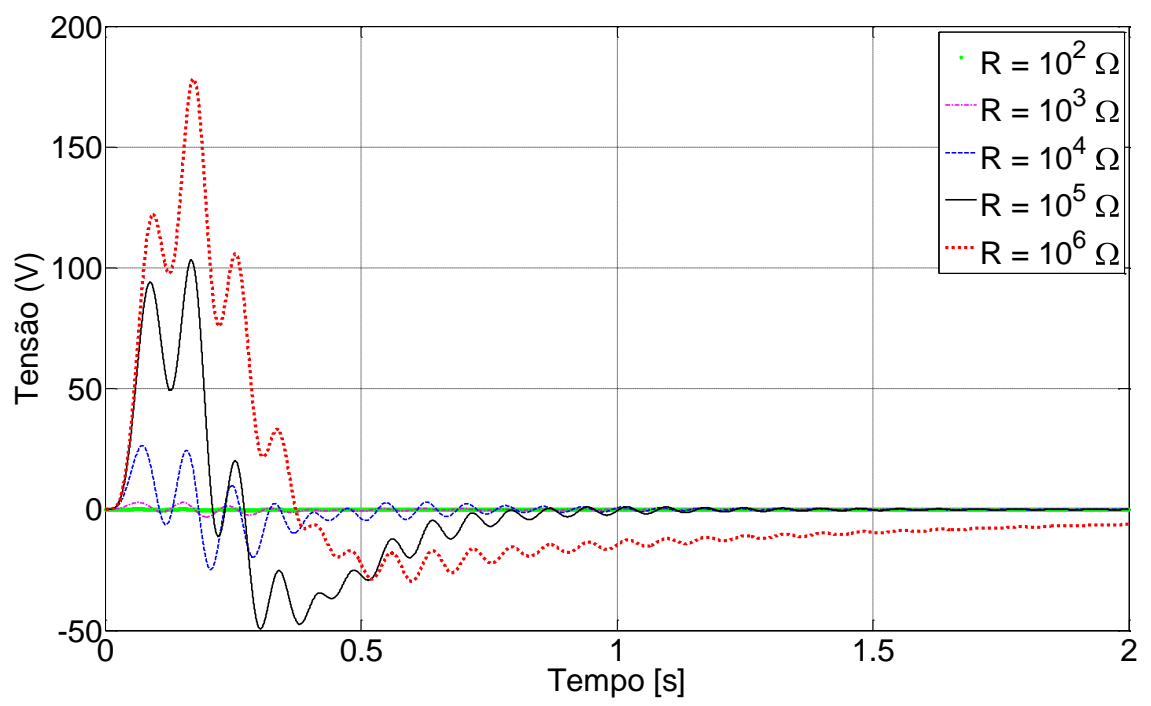

Figura 17. Voltagem para 5 diferentes valores de resistência elétrica utilizando eletrodos contínuos e velocidade do escoamento $35 \mathrm{~m} / \mathrm{s}$.

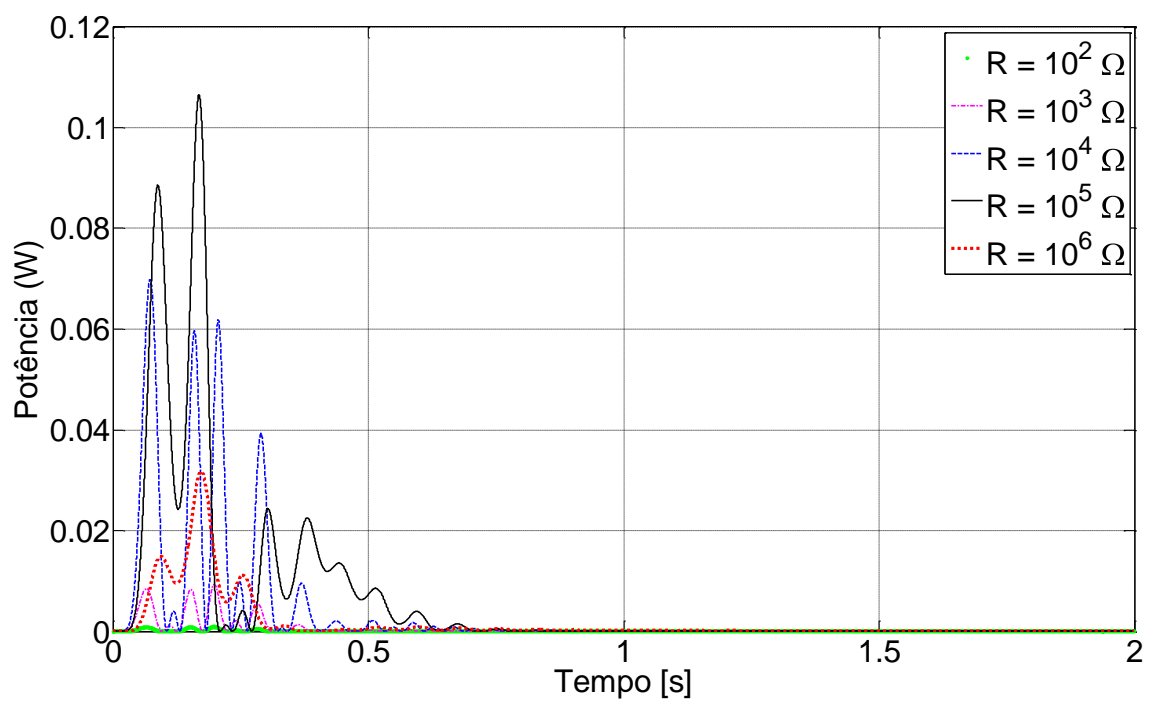

Figura 18. Potência gerada para 5 diferentes valores de resistência elétrica utilizando eletrodos contínuos e velocidade do escoamento $35 \mathrm{~m} / \mathrm{s}$. 


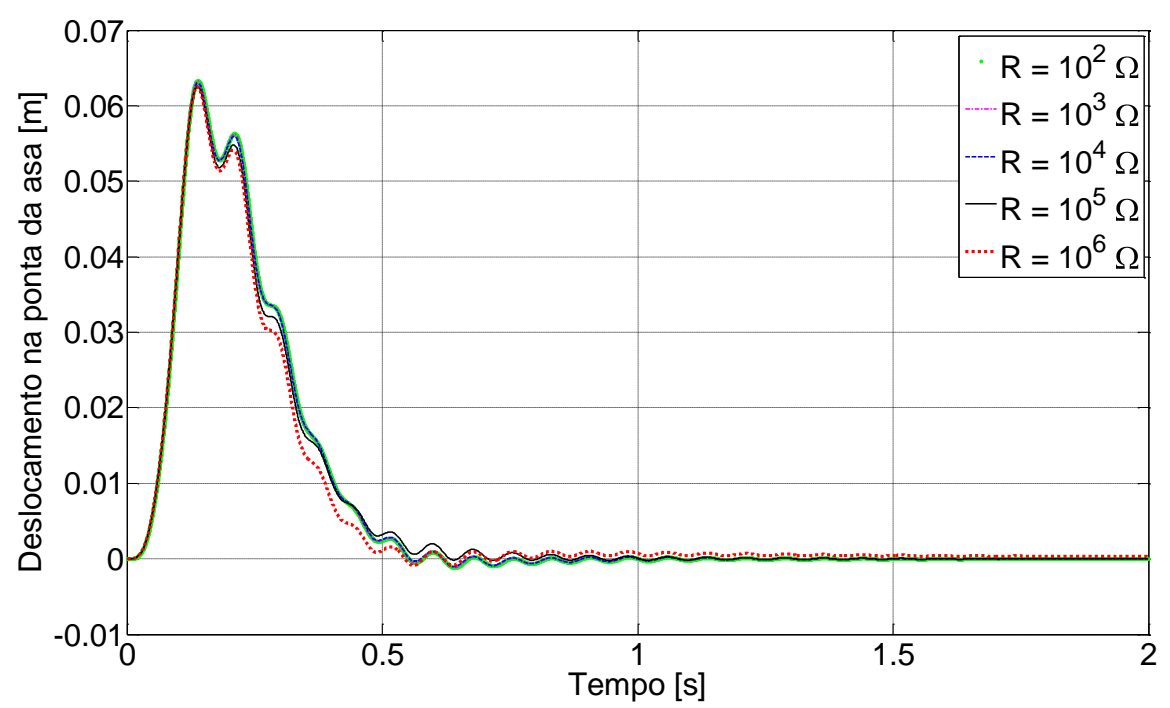

Figura 19. Deslocamento na ponta da asa para 5 diferentes valores de resistência elétrica utilizando eletrodos contínuos e velocidade do escoamento $35 \mathrm{~m} / \mathrm{s}$.

No quarto caso estudado a velocidade de escoamento foi de $40 \mathrm{~m} / \mathrm{s}$. Observa-se que nesta condição o sistema piezoaeroelástico apresenta oscilações persistentes típicas da condição de flutter. O comportamento da voltagem para as resistências utilizadas neste trabalho é apresentado na figura 20.

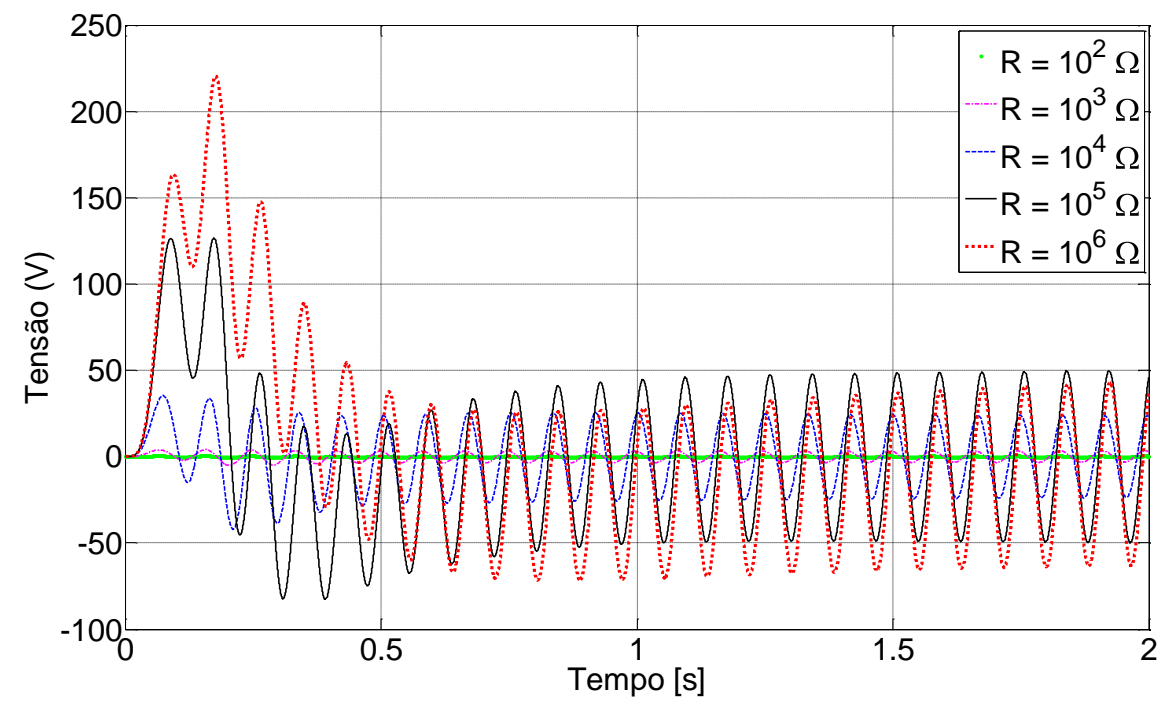

Figura 20. Voltagem para 5 diferentes valores de resistência elétrica utilizando eletrodos contínuos e velocidade do escoamento $40 \mathrm{~m} / \mathrm{s}$. 
A potência elétrica gerada para a velocidade de $40 \mathrm{~m} / \mathrm{s}$ é mostrada na figura 21 , onde pode-se notar que a potência elétrica gerada aumenta com o aumento da resistência elétrica desde $R_{l}=10^{2} \Omega$ até $R_{l}=10^{4} \Omega$. Claramente o valor de resistência $R_{l}=10^{4} \Omega$ proporciona a potência máxima entre os valores de resistência aqui considerados. Note também que o caso de potência máxima também apresenta o maior decaimento devido ao efeito shunt damping resistivo da geração piezelétrica de energia. Quando a carga resistiva é aumentada para a condição próxima de circuito aberto, a potência é significantemente reduzida, com valores próximos a condição de curto circuito. Apesar da condição de fluter ser uma situação crítica que deve ser evitada em casos reais, é a que permite a coleta de energia por mais tempo, considerando-se que a estrutura oscila persistentemente, pois neste caso, o amortecimento aerodinâmico tende a zero.

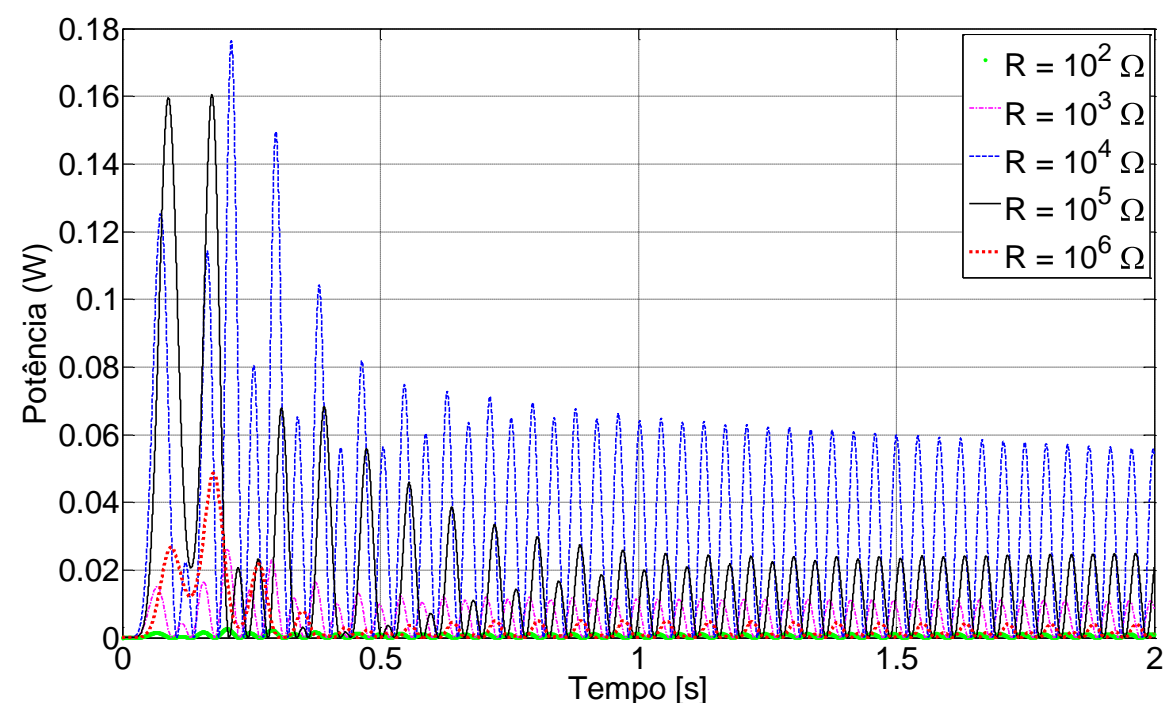

Figura 21. Potência gerada para 5 diferentes valores de resistência elétrica utilizando eletrodos contínuos e velocidade do escoamento $40 \mathrm{~m} / \mathrm{s}$. 
A resposta mecânica do sistema na condição de flutter é observada na figura 22. Observa-se que a amplitude do movimento é reduzida com o aumento da resistência até $R_{l}=10^{4} \Omega$ (ver quadro interno - zoom - na figura 22 ). Claramente esta é a resistência que fornece a máxima saída elétrica (potência) e máximo efeito shunt damping. Quando a resistência é novamente aumentada para condições próximas ao circuito aberto observa-se o aumento das amplitudes de vibração. A variação do efeito shunt damping é mais evidente nas respostas de potência elétrica. Entretanto, é interessante observar que a resistência ótima torna o sistema novamente estável. Apesar disso, com um pequeno aumento na velocidade das simulações o sistema torna-se instável novamente. Mesmo assim, é interessante observar que a velocidade de $40 \mathrm{~m} / \mathrm{s}$ pode ser definida como a velocidade de flutter em curto circuito do sistema piezoaeroelástico em estudo.

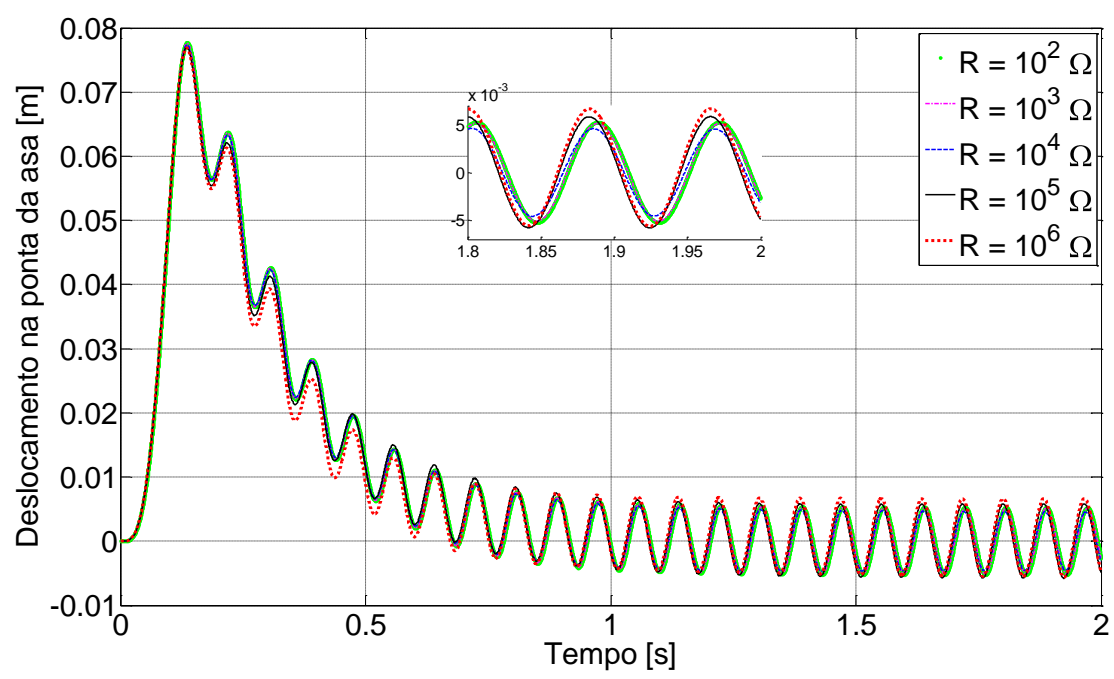

Figura 22. Deslocamento na ponta da asa para 5 diferentes valores de resistência elétrica utilizando eletrodos contínuos e velocidade do escoamento $40 \mathrm{~m} / \mathrm{s}$.

Constatou-se que na condição de flutter a asa piezoaeroelástica oscila com a combinação de um modo de flexão e outro de torção. A figura 23 apresenta a estrutura deformada em um instante de tempo da simulação realizada com o modelo piezoaeroelástico, 
eletrodos em curto circuito e velocidade de $40 \mathrm{~m} / \mathrm{s}$ (velocidade de flutter em curto circuito). Como discutido anteriormente, o uso de eletrodos contínuos envolvendo cada camada de piezocerâmica implica no cancelamento da saída elétrica a partir de modos de torção. Assim, o uso de eletrodos segmentados, conforme descrito no início deste capítulo, deve evitar tal cancelamento. Na prática, a idéia é segmentar os eletrodos na posição relativa a metade da corda da asa. Para as simulações, aqui realizadas no domínio modal, o vetor de acoplamento eletromecânico é modificado. Ou seja, os termos relativos aos modos de flexão são mantidos como nas simulações com eletrodos contínuos, e os termos relativos aos modos de torção são substituídos pelos valores obtidos a partir do modelo por elementos finitos com a segmentação dos eletrodos. Desta forma, evita-se tanto o cancelamento a partir de modos de flexão quanto de torção.

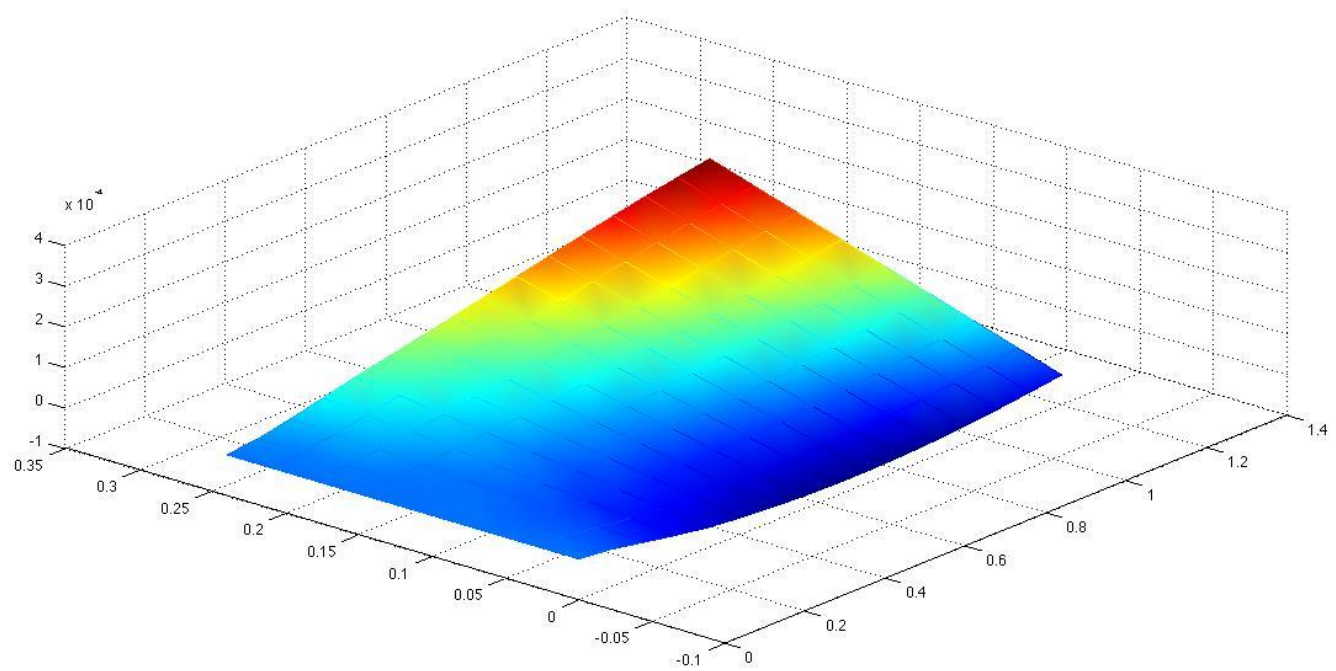

Figura 23. Condição de flutter: acoplamento do segundo modo de flexão e primeiro modo de torção.

A segmentação de eletrodos e a combinação dos mesmos resulta em um melhor acoplamento eletromecânico, consequentemente espera-se que alguns efeitos sejam mais evidentes na resposta piezoaeroelástica no domínio do tempo, como o efeito shunt damping e a potência elétrica gerada. 
Os resultados das simulações para as velocidades de $10 \mathrm{~m} / \mathrm{s}$ e $35 \mathrm{~m} / \mathrm{s}$ utilizando-se eletrodos segmentados não serão apresentados. A análise destes resultados seria bastante semelhante ao caso de eletrodos contínuos e, portanto, acrescentaria pouca informação ao leitor. Vale destacar também que os resultados para $10 \mathrm{~m} / \mathrm{s}$ com eletrodos contínuos ou segmentados são bastante semelhantes. Este fato é esperado já que em baixas velocidades o acoplamento entre os modos ainda não é significativo. Assim, conforme comentado para o caso de eletrodos contínuos, o sistema responde basicamente com movimentos de flexão para a velocidade de $10 \mathrm{~m} / \mathrm{s}$ (independentemente do tipo de eletrodo), o que torna o efeito de eletrodos segmentados pouco evidente. Apenas para elucidar esta discussão apresenta-se na figura 24 a resposta de voltagem para o caso de eletrodos segmentados na velocidade de 20 $\mathrm{m} / \mathrm{s}$. O leitor pode verificar que as curvas são muito semelhantes ao caso de eletrodos contínuos da Figura 20. Mesmo nesta velocidade o acoplamento ainda é pouco significativo. Já para a velocidade de $35 \mathrm{~m} / \mathrm{s}$ o sistema é bastante amortecido devido aos efeitos aerodinâmicos e as respostas pouco interessantes..

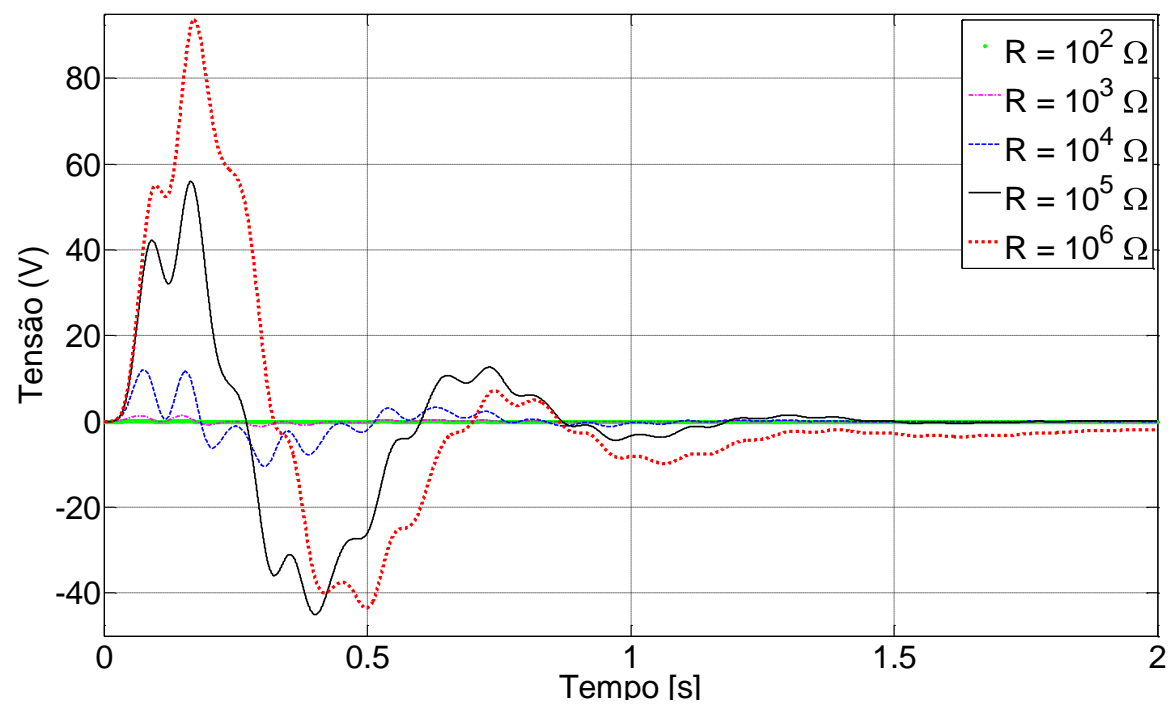

Figura 24. Voltagem para 5 diferentes valores de resistência elétrica utilizando eletrodos segmentados e velocidade do escoamento $20 \mathrm{~m} / \mathrm{s}$. 
Um caso interessante pode ser observado na velocidade de flutter em curto circuito para o caso de eletrodos contínuos, ou seja, $40 \mathrm{~m} / \mathrm{s}$. A variação da voltagem é apresentada na Figura 25. Como anteriormente, a amplitude aumenta com o aumento do valor da resistência. Um fato interessante a ser destacado para a velocidade do escoamento de $40 \mathrm{~m} / \mathrm{s}$ é que o sistema piezoaeroelástico ainda não se encontra na condição de flutter, ou seja, as oscilações persistentes que caracterizam este fenômeno ainda não são notadas e a amplitude das oscilações está decaindo (mesmo que lentamente) (Figura 25).

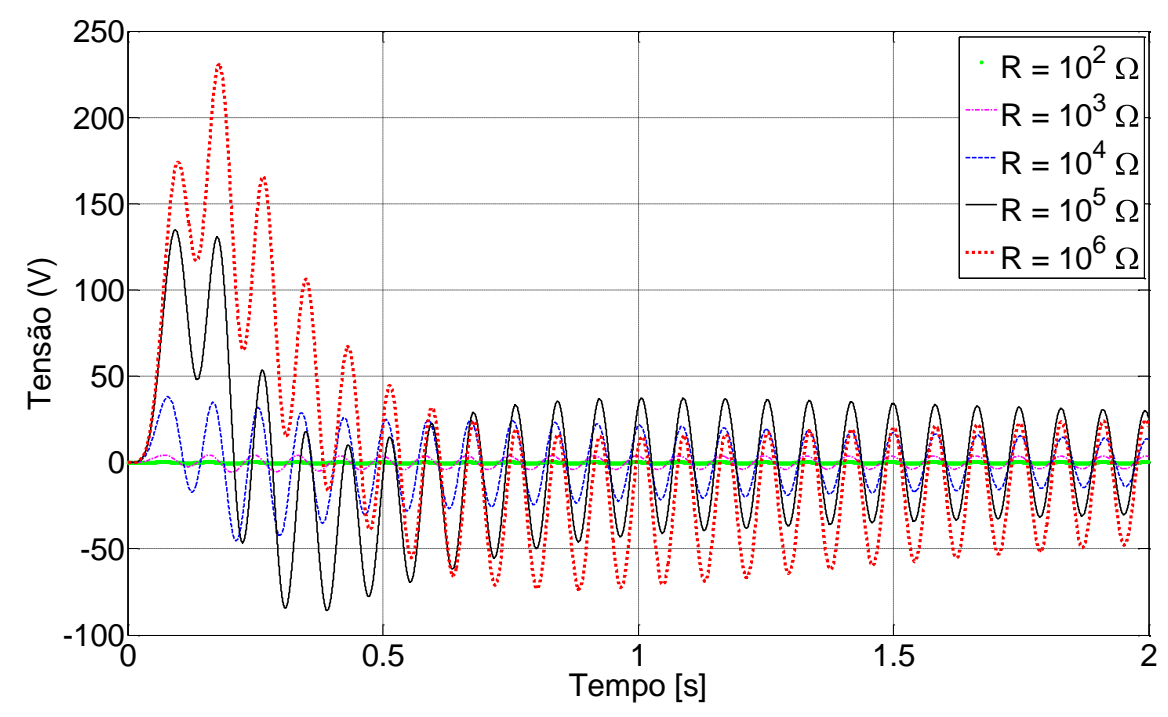

Figura 25. Voltagem para 5 diferentes valores de resistência elétrica utilizando eletrodos segmentados e velocidade do escoamento $40 \mathrm{~m} / \mathrm{s}$.

Para a mesma situação, a potência elétrica é apresentada na Figura 26. O pico de potência gerada fica em torno de $200 \mathrm{~mW}$ para $R_{l}=10^{4} \Omega$ (aumento de $19 \%$ quando comparado ao pico obtido com eletrodos contínuos) no primeiro 0,5 segundo. A estabilidade da resposta é ainda mais evidente no caso da potência elétrica para a mesma resistência elétrica, confirmando que a estrutura ainda não encontra-se em condição de flutter. Com a utilização dos eletrodos segmentados, temos um maior amortecimento passivo (shunt 
damping), fazendo com que ocorra um aumento na velocidade em que a estrutura entra na condição de flutter (Figura 26).

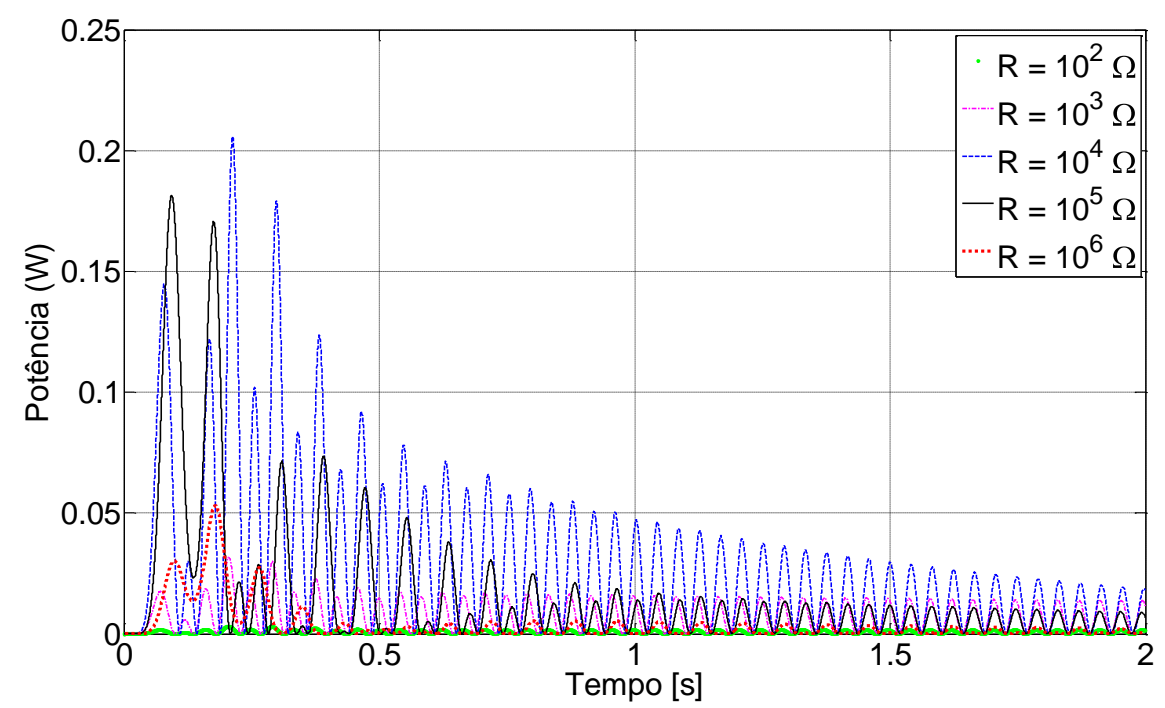

Figura 26. Potência gerada para 5 diferentes valores de resistência elétrica utilizando eletrodos segmentados e velocidade do escoamento $40 \mathrm{~m} / \mathrm{s}$.

O deslocamento na ponta da asa para a velocidade de $40 \mathrm{~m} / \mathrm{s}$ é apresentado na Figura 27. Para resistências próximas a condição de curto circuito verifica-se um comportamento semelhante ao observado na condição de eletrodos contínuos para esta mesma velocidade do escoamento. Entretanto, fica evidente para o caso de resistência ótima, $R_{l}=10^{4} \Omega$, que o maior efeito shunt damping resistivo da geração piezelétria de energia para o caso de eletrodos segmentados. 


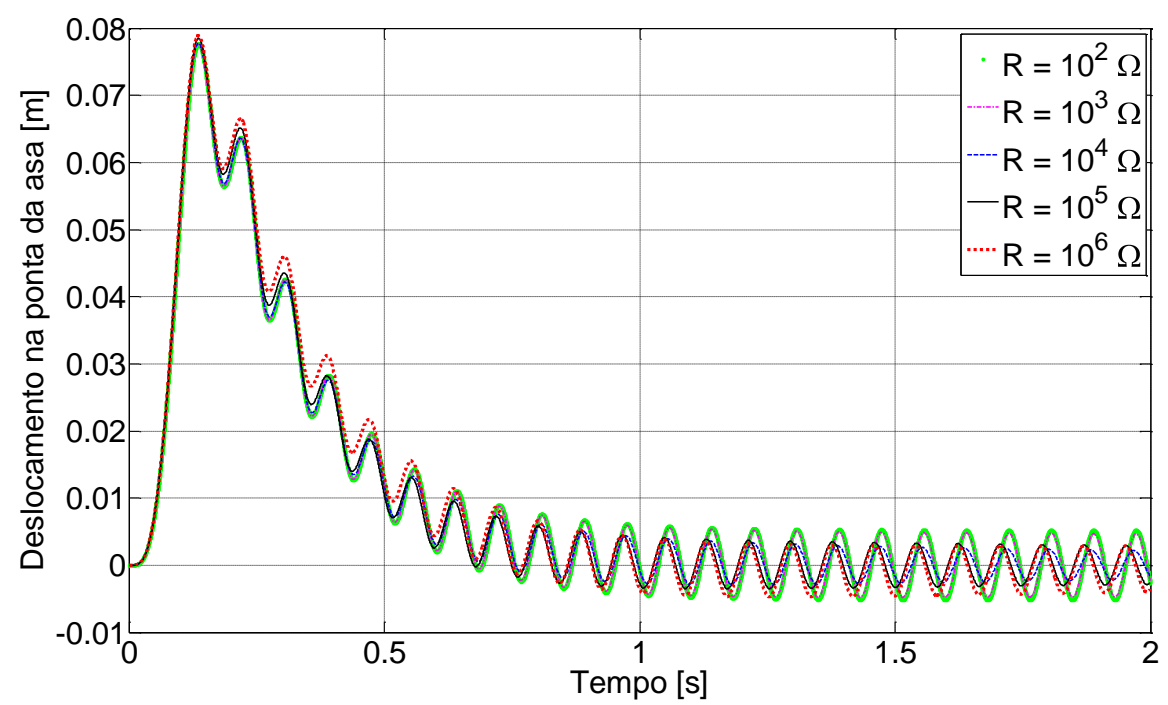

Figura 27. Deslocamento na ponta da asa para 5 diferentes valores de resistência elétrica utilizando eletrodos segmentados e velocidade do escoamento $40 \mathrm{~m} / \mathrm{s}$.

Ainda utilizando eletrodos segmentados, nota-se que a estrutura entra na condição de flutter quando a velocidade do escoamento atinge $41 \mathrm{~m} / \mathrm{s}(1 \mathrm{~m} / \mathrm{s}$ superior à velocidade de flutter em curto circuito obtida com a utilização dos eletrodos contínuos). A saída de voltagem para a nova velocidade de flutter é apresentada na Figura 28.

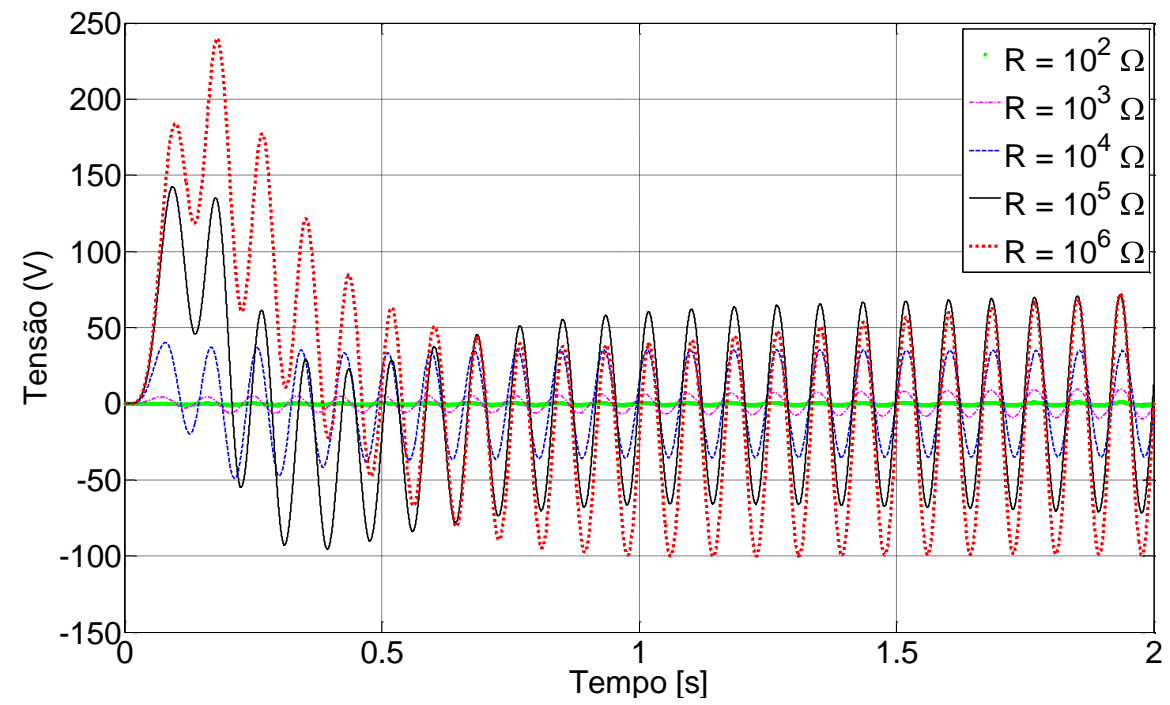

Figura 28. Voltagem para 5 diferentes valores de resistência elétrica utilizando eletrodos segmentados e velocidade do escoamento $41 \mathrm{~m} / \mathrm{s}$. (velocidade de flutter) 
A potência gerada, apresentada na Figura 29, fica em torno de $120 \mathrm{~mW}$ para $R_{l}=10^{4} \Omega$, resistência ótima para este caso. Esta potência praticamente o dobro da potência obtida na condição de flutter com a utilização de eletrodos contínuos. A potência máxima gerada ainda apresenta um certo decaimento devido ao efeito shunt damping resistivo da geração piezelétrica de energia, porém, este decaimento é menor se comparado ao caso que utiliza eletrodos contínuos para a mesma velocidade do escoamento.

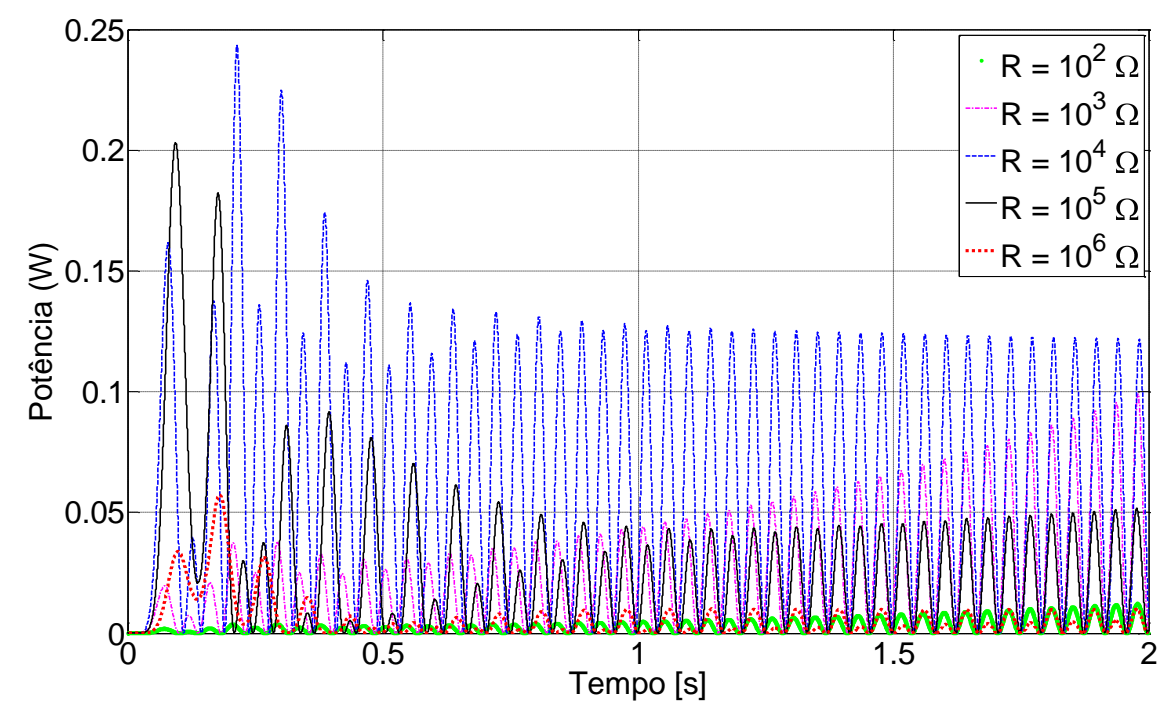

Figura 29. Potência gerada para 5 diferentes valores de resistência elétrica utilizando eletrodos segmentados e velocidade do escoamento $41 \mathrm{~m} / \mathrm{s}$. (velocidade de flutter)

A figura 30 mostra a resposta mecânica do sistema na condição de flutter, utilizando eletrodos segmentados. Fica bastante evidente que o sistema piezoaeroelástico é instável para a maioria das condições de contorno elétricas utilizadas neste trabalho, exceto para o caso do resistor ótimo que induz o maior efeito shunt damping e torna o sistema estável. 


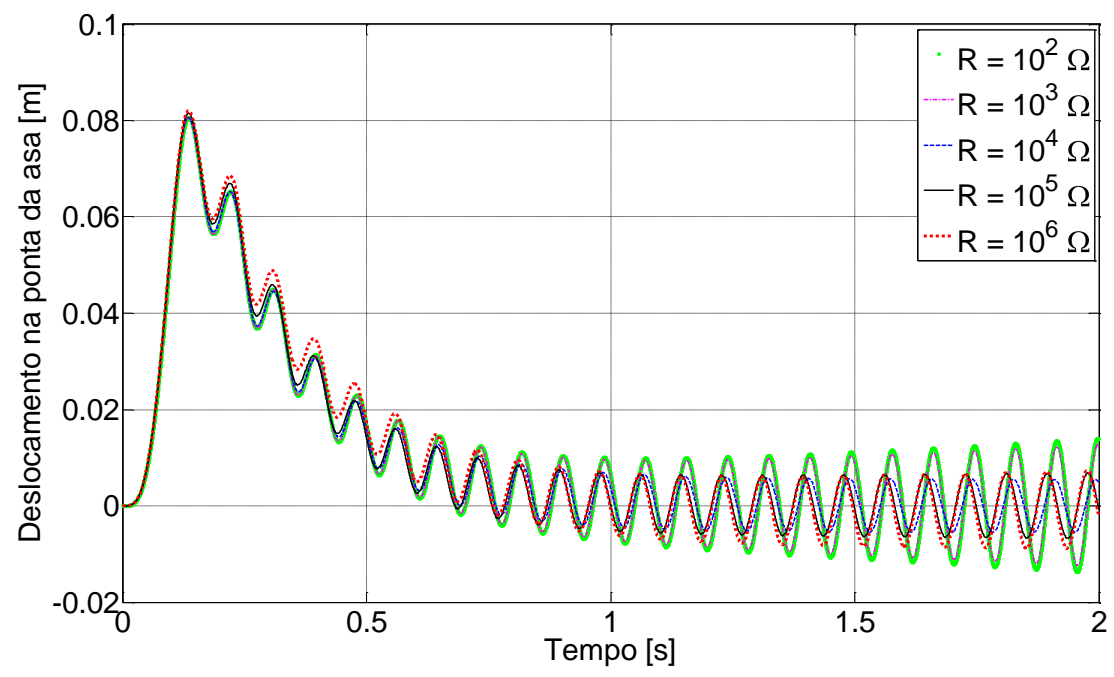

Figura 30. Deslocamento na ponta da asa para 5 diferentes valores de resistência elétrica utilizando eletrodos segmentados e velocidade do escoamento $41 \mathrm{~m} / \mathrm{s}$. (velocidade de flutter) 


\section{CONCLUSÕES}

A conversão de oscilações aeroelásticas em energia elétrica foi investigada neste trabalho. Simulações foram realizadas em diversas velocidades de escoamento e diferentes condições de contorno elétricas. Um modelo piezoaeroelástico no domínio do tempo foi apresentado como a associação de um modelo por elementos finitos eletromecanicamente acoplado com um modelo aerodinâmico não-estacionário. Fica evidente que, para os casos lineares aqui investigados, a melhor condição para geração piezelétrica de energia é próxima a velocidade de flutter. Nesta condição, o amortecimento do sistema tende a zero e oscilações persistentes são verificadas, possibilitando a extração contínua de energia.

O efeito da geração piezelétrica de energia sobre o comportamento aeroelástico leva a discussões interessantes. Nos casos aqui estudados um elemento resistivo foi considerado no circuito externo. Como a condição de estabilidade do sistema piezoaeroelástico é dependente do resistor utilizado, verifica-se que é possível determinar uma velocidade de flutter para cada condição de contorno elétrica. A velocidade de referência para as análises dos resultados é a velocidade do sistema na condição de curto-circuito. Um ponto que deve ser ressaltado é que se assume neste trabalho o caso em que $R_{l}=100 \Omega$ é um caso próximo a condição de curto circuito que se convencionou chamar de curto circuito. Verifica-se na literatura (Erturk e Inman, 2008a; De Marqui, Erturk e Inman, 2009b) que a resposta para este resistor tende a resposta em curto circuito.

A condição de flutter em curto circuito é modificada quando o resistor que fornece a máxima potência elétrica é utilizado. Entre os analisados neste trabalho, este resistor é também o que induz ao máximo efeito shunt damping. Por consequiência, o sistema passa a apresentar oscilações decrescentes, ou seja, estáveis quando o resistor ótimo é utilizado. Assim, além do benefício de gerar energia elétrica o efeito shunt damping resultante é um fato positivo para o sistema aeroelástico. 
O efeito de segmentação de eletrodos também foi investigado. A potência elétrica gerada a partir do caso de eletrodos segmentados é sempre maior que a potência gerada para o caso de eletrodos contínuos. O cancelamento de saídas elétricas a partir de movimentos de torção é evitado com a segmentação de eletrodos aqui apresentada. Conseqüentemente, além de aumentar a potência gerada, o efeito shunt damping resistivo também é melhorado utilizando-se eletrodos segmentados. Nas simulações realizadas na velocidade de $40 \mathrm{~m} / \mathrm{s}$ (velocidade de flutter em curto circuito para eletrodos contínuos) fica claro que as oscilações são estáveis para qualquer resistor utilizado. Entretanto, para a mesma velocidade e eletrodos contínuos, a estabilidade é observada somente para o caso em que o resistor ótimo foi usado. Vale ressaltar que tanto as dimensões assumidas para as camadas piezelétricas quando a posição para a segmentação dos eletrodos não foram otimizadas. O desempenho do sistema pode ser melhorado avaliando-se a forma do modo de vibrar na condição de flutter e determinando-se uma melhor distribuição de piezelétricos ou uma melhor segmentação dos eletrodos.

O modelo piezoaeroelástico deste trabalho foi utilizado em um trabalho publicado por DE MARQUI et al. (2010), onde a mesma estrutura foi submetida a uma rajada do tipo degrau. Comparando os resultados obtidos entre os dois trabalhos, conclui-se que os melhores resultados são obtidos quando a estrutura é submetida a uma rajada discreta do tipo '1-cos'.

\subsection{Sugestões para trabalhos futuros}

Alguns trabalhos podem ser sugeridos para aperfeiçoamento deste ou sua aplicação:

- Utilizar uma entrada que simule uma situação de turbulência contínua e investigar a conversão de energia, 
- Desenvolvimento de modelos piezoaeorelásticos no domínio da frequiência. O menor custo computacional permitirá a otimização do domínio elétrico do problema,

- Desenvolvimento de circuitos geradores mais elaborados que permitam o condicionamento da energia e sua utilização no carregamento de baterias, por exemplo,

- Desenvolvimento de modelos estruturais não-lineares e o estudo do efeito da geração piezelétrica de energia sobre o comportamento aeroelástico não-linear,

- Investigar o efeito do uso de circuitos ressonantes sobre a estabilidade do sistema aeroelástico. 


\section{REFERÊNCIAS}

AKAYDIN, H.D.; ELVIN, N.; ANDREOPOULOS, Y. (2010). Energy Harvesting from Highly Unsteady Fluid Flows using Piezoelectric Materials, Journal of Intelligent Material Systems and Structures, DOI: 10.1177/1045389X10366317 - 2010

ANTON, S.R.; SODANO, H.A. (2007). A review of power harvesting using piezoelectric materials (2003-2006), Smart Material Structure, v.16, R1-R21

ANTON, S.R. (2008). Energy Harvesting for Unmanned Aerial Vehicles, Disponível em: <http://www.vsgc.odu.edu/src/Conf08/Papers08/Anton,\%20Steven\%20Paper.pdf>. Acesso em: 20 jul.2010.

ANTON, S.R. et al. (2009). Self-charging Structures Using Piezoceramics and Thin-film Batteries, Proceedings of the ASME 2009 Conference on Smart Materials, Adaptive Structures and Intelligent Systems - SMASIS2009

ARMS, S.W.; MOON, S.M.; PHAN, N. (2006). Energy Harvesting Wireless Sensors for Helicopter Damage Tracking, Proceedings of AHS International Forum 62, HUMS III session, Phoenix, AZ, 2006

ARNAU, A. (2008). Piezoeletric Transducers and Applications. Springer, Berlin Disponível em:

<http://books.google.com.br/books?id=az1RYaJr5HsC\&dq=Piezoelectric+Transducer $\mathrm{s}+$ and + Applications \& printsec $=$ frontcover\&source $=\mathrm{bn} \& \mathrm{hl}=\mathrm{pt}-$

BR\&ei=OZ5qTIXeNYPGIQfTluH1AQ\&sa=X\&oi=book_result\&ct=result\&resnum=4 $\& v e d=0 C C 8 Q 6 A E w A w \# v=$ onepage \&q\&f=false $>$. Acesso em: 05 jun.2009

BENINI, G.R. (2002). Modelo numérico para simulação aeroelástica de asas fixas. 97f. Dissertação (Mestrado) - Escola de Engenharia de São Carlos, Universidade de São Paulo, São Carlos, 2002.

BENINI, G.R., BELO, E.M.; MARQUES, F.D. (2004). Numerical Model for the Simulation of Fixed Wings Aeroelastic Response, Journal of the Brazilian Society of Mechanical Sciences \& Engineering, v.26, p.129-136

BISPLINGHOFF et al. (1996). Aeroelasticity. New York: Dover.

BRYANT, M.; GARCIA, E. (2009). Development of an Aeroelastic Vibration Power Harvester, Proceedings of SPIE v.7288 728812-1

BUBE, R.H. (1998). Photovoltaic materials. Imperial College Press: London. Disponível em:

$<$ http://books.google.com.br/books?id=fIgTBAIza34C\&printsec $=$ frontcover\&dq=Phot ovoltaic\&hl=pt-BR\&ei=XO4PTP-

WCcOblgfxxNzoBg\&sa=X\&oi=book_result\&ct=result\&resnum $=9 \& v e d=0$ CF0Q6AE

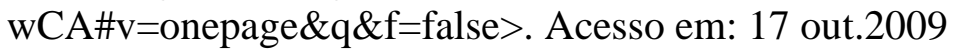


CAVALLIER, B. et al. (2005). Energy harvesting using vibrating structures excited by shock, IEEE Ultrasonics Symposium, 0-7803-9383-X/05, p.943-945

BEEBY, S.P.; TUDOR, M.J.; WHITE, N.M. (2006). Energy harvesting vibration sources for microsystems applications, Meas. Sci. Technol., v.17, R175-R195

CHUDÝ, P. (2004). Response of a Light Aircraft Under Gust Loads, Acta Polytechnica, v.44, No. $2 / 2004$

COOK-CHENNAULT, K.A.; THAMBI, N.; SASTRY, A.M. (2008). Powering MEMS portable devices - a review of non-regenerative and regenerative power supply systems with special emphasis on piezoelectric energy harvesting systems, Smart Materials and Structures, v.17, 043001, (33pp)

CRANDALL, S.H., KARNOPP, D.C., KURTZ JR, E.F.; PRIDMORE-BROWN, D.C. (1968). Dynamics of Mechanical and Electromechanical Systems. New York: McGraw-Hill.

CS-25 - EUROPEAN AVIATION SAFETY AGENCY - Certification specifications (2007). Disponível em: <http://www.easa.europa.eu/agency-measures/certificationspecifications.php>. Acesso em: 07 nov.2009.

DE MARQUI JR, C.; ERTURK, A.; INMAN, D.J. (2009a). Finite element analysis of a UAV wing spar with piezoceramics for vibration energy harvesting; 50th AIAA/ASME/ASCE/AHS/ASC Structures, Structural Dynamics, and Materials Conference

DE MARQUI JR, C.; ERTURK, A.; INMAN, D.J. (2009b). An electromechanical finite element model for piezoelectric energy harvester plates. Journal of Sound and Vibration, v. 327, n.1-2

DE MARQUI JR, C.; ERTURK, A.; INMAN, D.J. (2010). Piezoaeroelastic Modeling and Analysis of a Generator Wing with Continuous and Segmented Electrodes. Journal of Intelligent Material Systems and Structures, v.21 - July 2010

DIETL, J.M.; GARCIA, E. (2010). Beam Shape Optimization for Power Harvesting, Journal of Intelligent Material Systems and Structures,

DOI: $10.1177 / 1045389 X 10365094-2010$

DUTOIT, N.E.; WARDLE, B.L.; KIN, S.G. (2005). Design considerations for MEMSscale piezoelectric mechanical vibration energy harvesters, Integrated Ferroelectrics, v.71, p. 21-160

DUTOIT, N.E.; WARDLE, B.L. (2007). Experimental verification of models for microfabricated piezoelectric vibration energy harvesters, AIAA Journal, v.45, p.1126-1137

ELVIN, N.G.; ELVIN, A.A; SPECTOR, M. (2001). A self-powered mechanical strain energy sensor, Smart Materiais and Structures, v.10, p.293-299 
ELVIN, N.G.; ELVIN, A.A. (2009). The Flutter Response of a Piezoelectrically Damped Cantilever Pipe, Journal of Intelligent Material Systems and Structures 2009; v.20, p.2017

ERTURK, A.; INMAN, D.J., (2008a). A distributed parameter electromechanical model for cantilevered piezoelectric energy harvesters, ASME Journal of Vibration and Acoustics, v. 130, 041002

ERTURK, A.; INMAN, D.J. (2008b). Issues in mathematical modeling of piezoelectric energy harvesters, Smart Mater. Struct. v.17-065016 (14pp)

ERTURK, A. et al. (2008). Effect of Strain Nodes and Electrode Configuration on Piezoelectric Energy Harvesting from Cantilevered Beams, Journal of Vibration and Acoustics, v.130

ERTURK, A.; RENNO, J.M.; INMAN, D.J. (2009a). Modeling of Piezoelectric Energy Harvesting from an L-shaped Beam-mass Structure with an Application to UAVs, Journal of Intelligent Material Systems and Structures, v.20, mar/2009

ERTURK, A.; HOFFMANN, J.; INMAN, D.J. (2009b). A piezomagnetoelastic structure for broadband vibration energy harvesting, Applied Physics Letters v.94, 254102

ERTURK, A.; ANTON, S.R.; INMAN, D.J. (2009c). Piezoelectric energy harvesting from multifunctional wing spars for UAVs - Part 1: coupled modeling and preliminary analysis, Proceedings of SPIE, v.7288, 72880C

ERTURK, A. (2009d). Electromechanical Modeling of Piezoelectric Energy Harvesters, Dissertation, Virginia Polytechnic Institute and State University, Blacksburg, VA

ERTURK, A. et al (2010). On the energy harvesting potential of piezoaeroelastic systems, Applied physics letters, v. 96, 184103

FEDERAL AVIATION ADMINISTRATION (FAA) - Code of Federal Regulations - Part. 25 / Sec. 25.341 (1996). Disponível em:

<http://rgl.faa.gov/Regulatory_and_Guidance_Library/rgFAR.nsf/0/156ccf55583a0ac 985256672004ec0d4!OpenDocument>. Acesso em 14 abr.2010.

FLOMENHOFT, H.I. (1997). The revolution in structural dynamics: the big "shake-up" in airframe design. Palm Beach Gardens, FL: Dynaflo Press.

FUNG, Y.C. (1993). An Introduction to the Theory of Aeroelasticity. New York : Dover.

GAUTSCHI, G. (2002). Piezoelectric Sensorics. Springer-Verlag: Berlin Heidelberg, 2002. Disponível em: <http://books.google.com.br/books?id=-nYFSLcmc$\mathrm{cC} \& \mathrm{dq}=$ Piezoelectric + Sensorics $\&$ printsec $=$ frontcover \&source $=\mathrm{bn} \& \mathrm{hl}=\mathrm{pt}-$ BR\&ei=zehhTMXhL8T38Ab9z7T2CQ\&sa=X\&oi=book_result\&ct=result\&resnum=4 $\& v e d=0 C D A Q 6 A E w A w \# v=$ onepage $\& q \& f=$ false $>$. Acesso em: 20 nov.2009 
GOETZBERGER, A.; HOFFMANN, V.U. (2005). Photovoltaic solar energy generation. Berlin: Springer.

GOLDFARB, M.; JONES, L.D. (1999). On the Efficiency of Electric Power Generation with Piezoelectric Ceramic, ASME Journal of Dynamic Systems, Measurement, and Control, v.121, p.566-571.

HAGOOD, N.W.; CHUNG, W.H.; VON FLOTOW, A. (1990). Modelling of piezoelectric actuator dynamics for active structural control, Journal of Intelligent Material Systems and Structures v.1, p.327-354

HEYWANG, W.; LUBITZ, K.; WERSING, W. (2008). Piezoelectricity: Evolution and Future of a Technology. Springer, Berlin. Disponível em:

$<$ http://books.google.com.br/books?id=8KyawZ92eIEC\&printsec=frontcover\&dq=Pie zoelectricity:+Evolution+and+Future+of+a+Technology\&hl=pt-

BR\&ei=6J9qTOT5DMKclgeXtejNAQ\&sa=X\&oi=book_result\&ct=result\&resnum $=1$ $\& v e d=0 C C g Q 6 A E w A A \# v=$ onepage $\& q \& f=$ false $>$. Acesso em: 14 jun.2009.

HISTORY OF PIEZOELECTRICITY (2009). Disponível em:

<http://www.piezo.com/tech4history.html>. Acesso em: 20 nov.2009

HOBLIT, F.M. (1988). Gust loads on aircraft: concepts and applications. Washington, D.C.: American Institute of Aeronautics and Astronautics.

IHS ESDU (2004). An introduction to rigid aeroplane response to gusts and atmospheric turbulence, 04024. Disponível em:

<http://www.esdu.com/graphics/dataitem/di_04024a.htm>. Acesso em 03 nov.2009

JAMES, G.K. (2000). Unmanned aerial vehicles and special operations: future directions, Master's Thesis, Naval Postgraduate School, Monterey, CA

JUNHUI, H. et al. (2010). Vibration Energy Harvesting Based on Integrated Piezoelectric Components Operating in Different Modes, IEEE Transactions on Ultrasonics, Ferroelectrics, and Frequency Control, v.57, n.2, February 2010

KATZ, J.; PLOTKIN, A. (2001). Low Speed Aerodynamics (Cambridge University Press)

KEITHLEY, J.F. (1999). The story of electrical and magnetic measurements: from 500 B.C. to the 1940s. New York: IEEE Press.

LAMBERT, J.D. (1991). Numerical Methods for Ordinary Differential Systems: The Initial Value Problem (Chichester: Wiley)

LASNIER, F.; ANG, T.G. (1990). Photovoltaic engineering handbook. Bristol, England: A. Hilger.

LEE, S.; YOUN, B.D.; JUNG, B.C. (2009). Robust segment-type energy harvester and its application to a wireless sensor, Smart Mater. Struct., v.18, 095021, (12pp) 
LUQUE, A.; HEGEDUS, S. (2005). Handbook of photovoltaic science and engineering. Chichester [West Sussex]: Wiley.

MENINGER, S. et al. (2001). Vibration-to-Electric Energy Conversion, IEE Transactions on Very Large Scale Integration (VLSI) Systems, v.9, n.1, fev.2001

MUELLER, T.J.; DELAURIER, J. (2003). Aerodynamics of small vehicles, Annual Reviews Fluid Mech. v.35, p.89-111

NG, T.H.; LIAO, W.H. (2005). Sensitivity analysis and energy harvesting for a selfpowered piezoelectric sensor, Journal of Intelligent Material Systems and Structures v.16, p.785-97

NOLAS, G.S.; SHARP, J.; GOLDSMID, H.J. (2001). Thermoelectrics: Basic Principles and New Materials Developments. Springer: New York. Disponível em: $<$ http://books.google.com.br/books? id=0q5mi2XKbFAC\&printsec=frontcover $\& \mathrm{dq}=\mathrm{T}$ hermoelectrics:+Basic+Principles+and+New+Materials+Developments\&hl=pt$\mathrm{BR} \&$ ei=ZrgKTIfNFcaAlAf5muGBDw\&sa $=X \&$ oi $=$ book_result\&ct $=$ result\&resnum $=1$ \&ved=0CC4Q6AEwAA\#v=onepage \&q\&f=false >. Acesso em 14 dez.2009

OLBY, R.C. et al. (1996). Companion to the history of modern science. London: Routledge New York.

POLLOCK, D.D. (1985). Thermoelectricity: theory, thermometry, tool. Philadelphia, PA: ASTM.

POLLOCK, D.D. (1991). Thermocouples: theory and properties. CRC Press

Disponível em: <http://books.google.com.br/books?hl=pt-

$\mathrm{BR} \& \mathrm{lr}=\& \mathrm{id}=\_\mathrm{CK} 8 \mathrm{U} \_\mathrm{bzgKQC} \& \mathrm{oi}=\mathrm{fnd} \& \mathrm{pg}=\mathrm{PA} 1 \& \mathrm{dq}=$ theory + thermoelectric + pheno mena\&ots $=$ SqDNBEeo1f\&sig=t31lQg-

LK4XjomICrFDqWDHvweg\#v=onepage \&q=theory\%20thermoelectric\%20phenomen $\mathrm{a} \& \mathrm{f}=$ false $>$. Acesso em 16 dez.2009

PRIYA, S. (2007). Advances in energy harvesting using low profile piezoelectric transducers, J Electroceram, v.19, p.165-182

ROUNDY, S.; WRIGHT, P.K.; RABAEY, J. (2002). Engaging Nonlinearity for Enhanced Vibratory Energy Harvesting, Computer Communications 26 (2003) 1131-1144

ROUNDY, S. et al (2003). A study of low level vibrations as a power source for wireless sensor nodes, Computer Communications, v.26, p.1131-1144

ROUNDY, S.; WRIGHT, P.K. (2004). A piezoelectric vibration based generator for wireless electronics, Smart Material and Structures, 13 (2004) 1131-1142

ROUNDY, S. (2005). On the Effectiveness of Vibration-based Energy Harvesting, Journal of Intelligent Material Systems and Structures, v.16, p.809

ROWE, D.M. (1994). CRC Handbook of Thermoelectrics. Boca Raton, FL: CRC Press. 
SCHIMIDT, V.H. (1992). Piezoeletric Energy Conversion in Windmills, Ultrasonics Symposium -897

SHAMOS, M.H. (1987). Great experiments in physics: firsthand accounts from Galileo to Einstein. New York: Dover.

SMITH, G.S. (1997). An introduction to classical electromagnetic radiation. Cambridge University Press: United Kingdom. Disponível em:

<http://books.google.com.br/books?id=m8RzbqS772IC\&pg=PA1\&dq=Electromagnet $\mathrm{ic}+$ Classic+Theory\&lr=\&cd=11\#v=onepage\&q=Electromagnetic\%20Classic\%20Theo ry \&f=false>. Acesso em 06 nov.2009

SODANO, H.A.; INMAN, D.J. (2004). A Review of Power Harvesting from Vibration using Piezoelectric Materials, The Shock and Vibration Digest, v.36(3), p.197-205

STARNER, T. (1996). Human-powered wearable computing, IBM Systems Journal, v.35, NOS $3 \& 4$

TANG et al. (2009). Flutter-Mill: a New Energy-Harvesting Device, Disponível em: <http://www.ontario-sea.org/Storage/26/1817_Flutter-Mill-_a_New_EnergyHarvesting_Device.pdf>. Acesso em 24 jul.2010.

UMEDA, M.; NAKAMURA, K.; UEHA, S. (1996). Analysis of the Transformation of Mechanical Impact Energy to Electrical Energy Using a Piezoeletric Vibrator, Jpn. J. Appl. Phys. v.35 (1996), p.3267-3273

WAH, T. NG (2009). MAE3407 Aircraft Structures II / Chapter 4 - Basic Airframe Loads Disponível em: <http://biofuturex.com/mae3407/>. Acesso em 14 abr.2010.

WANG, Q.M.; CROSS, L.E. (1999). Constitutive equations of symmetrical triple layer piezoelectric benders, IEEE Transactions on Ultrasonics, Ferroelectrics, and Frequency Control, v.46, p.1343-51

WILLIANS, C.B.; YATES, R.B. (1996). Analysis of a Micro-Electric Generator for Microsystems, Sensors \& Actuators, v.52, No. 1-3, p.8-11.

WRIGHT, J.R.; COOPER, J.E. (2007). Introduction to aircraft aeroelasticity and loads. Disponível em:

<http://books.google.com.br/books?id=305nZEgRN6IC\&pg=PA293\&lpg=PA293\&dq $=$ discrete+gust + book \&source $=$ bl\&ots $=$ QE2qgsz2I\&sig=yinV1Zfgm1Ytmp9ElNKlaIwmG20\&hl=pt-BR\&ei=Q-

RnTLfqGYO01QehyKWfBQ\&sa $=X \&$ oi $=$ book_result\&ct $=$ result\&resnum $=10 \& v e d=0$ CEMQ6AEwCQ\#v=onepage \&q=discrete\%20gust\%20book\&f=false>. Acesso em: 15 ago.2010.

XU, C.N. et al. (1998). Electrical Power Generation Characteristics of PZT Piezoelectric Ceramics, IEEE Transaction on Ultrasonics, Ferroelectrics and Frequency Control, v.45(4), p.1065-1070. 